\title{
Kapitel 7 \\ Bausteine zur Integration des Natur- und Umweltschutzes in eine zukunftsfähige Agrarpolitik
}

In diesem Kapitel werden zunächst Gestaltungsmöglichkeiten für die verschiedenen agrarpolitischen Instrumente diskutiert. Dabei soll vor dem Hintergrund der SWOT-Analyse diskutiert werden, welche Veränderungen im agrarpolitischen Instrumentenkasten dazu beitragen könnten, dem Leitbild einer multifunktionalen, natur- und umweltverträglichen Landwirtschaft näher zu kommen. Es soll also erörtert werden, wie die verschiedenen agrarpolitischen Komponenten besser naturund umweltschutzfachlich ausgerichtet und ausgestaltet werden können.

Wir diskutieren zunächst die Rolle und Entwicklungsmöglichkeiten des Ordnungsrechts und der gesetzlichen Mindeststandards für die landwirtschaftliche Praxis (Abschn. 7.1). Es folgt eine Erörterung möglicher Varianten zur Entwicklung des Budgets der Agrarpolitik (Abschn. 7.2) sowie der beiden Hauptelemente, mit denen Zahlungen und Anforderungen an die landwirtschaftlichen Betriebe verknüpft werden können - die Direktzahlungen (Abschn. 7.3) sowie die regional und standörtlich ausgerichteten Zahlungen, die derzeit in der Zweiten Säule verankert sind (Abschn. 7.4). Es folgen Überlegungen zu nicht-staatlichen Standards und Ko-Regulierung (Abschn. 7.5), zu den Monitoring- und Sanktionssystemen (Abschn. 7.6) sowie zu unterstützenden Elementen wie Beratung und verbraucherorientierte Maßnahmen (Abschn. 7.7). Ein kurzes Fazit schließt das Kapitel ab. Die Darstellung wird ergänzt durch einen Überblick über eine Auswahl von zielführenden, beispielhaften Management-Maßnahmen zum Schutz der Umweltressourcen, der biologischen Vielfalt und der Ökosystemleistungen, der sich im Anhang findet. 


\subsection{Baustein 1: Ordnungsrecht und gesetzliche Mindeststandards}

Der gesetzliche Mindeststandard legt fest, welche Rahmenbedingungen und Auflagen von den Landwirten einzuhalten und welche Maßnahmen ggf. ergriffen werden müssen. Diese Standards sind damit überall und jederzeit die Grundlage der Bewirtschaftung und für jeden Landwirt verbindlich (BMEL 2014b). Die gesetzlichen Mindeststandards werden durch das Ordnungs- und Fachrecht in Gesetzen und Verordnungen festgelegt, mit denen zumeist Richtlinien der EU in nationales Recht umgesetzt werden. Zum Ordnungsrecht gehören Ge- und Verbote, Anzeigepflichten, Genehmigungsvorbehalte, Kontroll-, Untersuchungs- und Anordnungsbefugnisse der Behörden (Möckel 2013). Es ,zeichnet sich durch seinen direkten Zugriff auf das zu steuernde Verhalten als ausgesprochen ökologisch treffsicher aus" (Rothstein und Schröder 2016).

Der gesetzliche Mindeststandard legt insbesondere die Abgrenzung zwischen Verursacher- und Gemeinlastprinzip fest. Die Kosten der Maßnahmen und Auflagen, die im Rahmen des gesetzlichen Mindeststandards umzusetzen sind, sind von den Verursachern, also den Landwirtinnen und Landwirten, zu tragen. Dem gegenüber steht das Gemeinlastprinzip. Die Kosten von Maßnahmen, die über den gesetzlichen Mindeststandard hinausgehen, werden demnach von der Allgemeinheit übernommen.

Dem gesetzlichen Mindeststandard liegt außerdem das Vorsorgeprinzip zugrunde. Nach dem Vorsorgeprinzip soll die Entstehung von Schäden vermieden werden. Auf Grundlage der Kenntnisse der Umweltwirkungen, der Weiterentwicklung der guten fachlichen Praxis und dem allgemeinen Stand der Technik sowie den gesellschaftlichen Erwartungen werden die gesetzlichen Mindeststandards immer wieder angepasst, wie dies auch Anfang 2017 im Zusammenhang mit der Novellierung der Düngeverordnung geschehen ist. Möckel et al. (2014, S 533) empfehlen eine „Dynamisierung der Anforderungen der guten fachlichen Praxis am besten durch eine regelmäßige (z. B. alle fünf Jahre) und wissenschaftlich fundierte Überprüfung der Standards“.

Die Definition des gesetzlichen Mindeststandards für die Landbewirtschaftung erscheint nicht immer ganz eindeutig. So können die in Tab. 7.1 aufgeführten Ansätze für die Abgrenzung des gesetzlichen Mindeststandards herangezogen werden.

Nach Maßgabe des Verursacherprinzips sind in der heutigen Ausgestaltung die Einhaltung des Stands der Technik und die gute fachliche Praxis als gesetzlicher Mindeststandard anzusehen, bei dem das Verursacherprinzip greift (SchröterSchlaack et al. 2016). Allerdings ist eine Durchsetzung eines neuen Stands der Technik teils mit langen Übergangsfristen verbunden, begründet u. a. mit der langen Abschreibungs- und Nutzungsdauer landwirtschaftlicher Maschinen und Stallanlagen. Eine rasche Anhebung des einzusetzenden Stands der Technik ist auf den Betrieben teils mit hohen Kosten verbunden und wird i. d. R. mit Investitionsförderprogrammen bzw. langen Übergangsfristen abgemildert. 


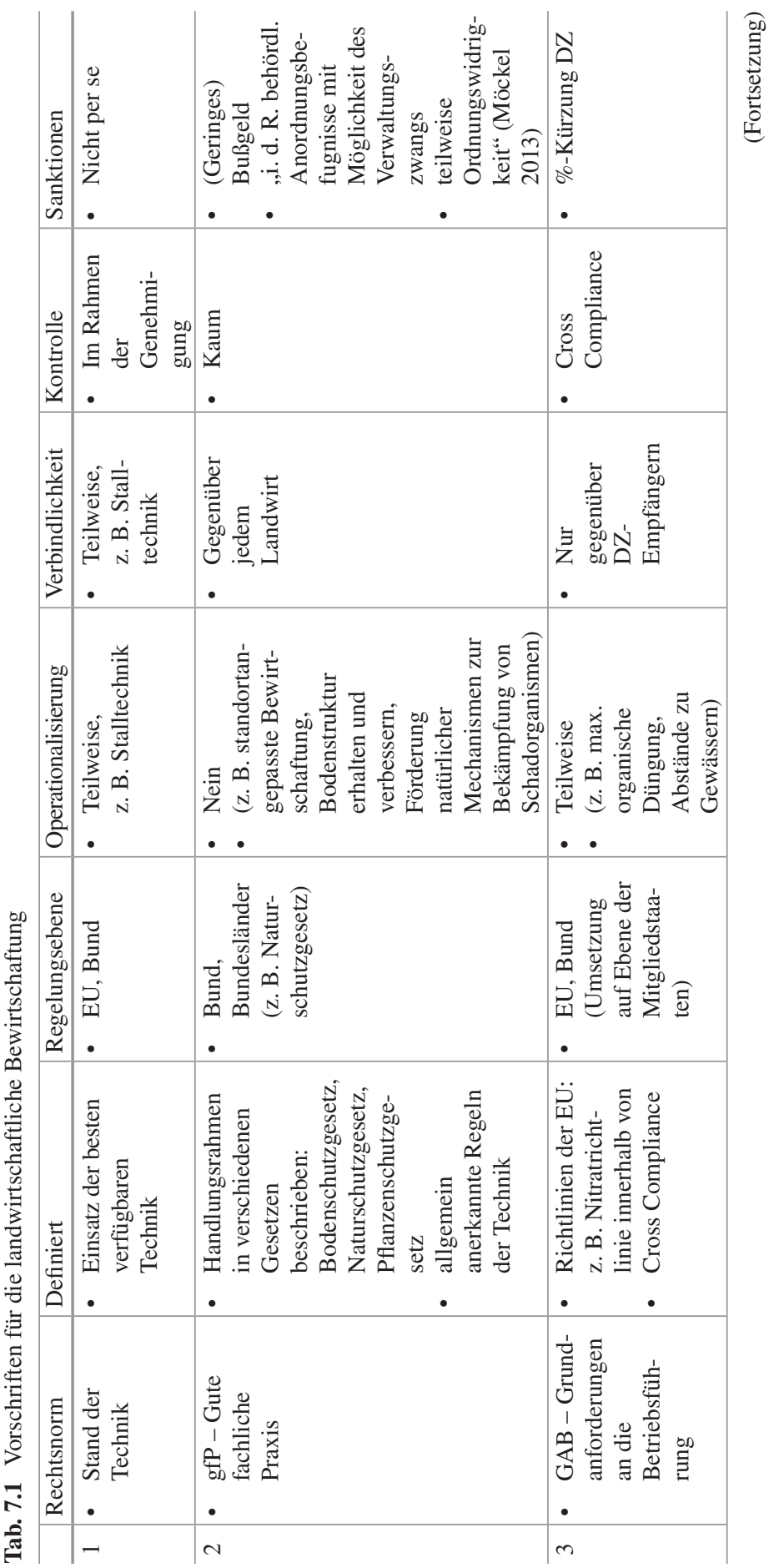


1647 Bausteine zur Integration des Natur- und Umweltschutzes in eine zukunftsfähige ...

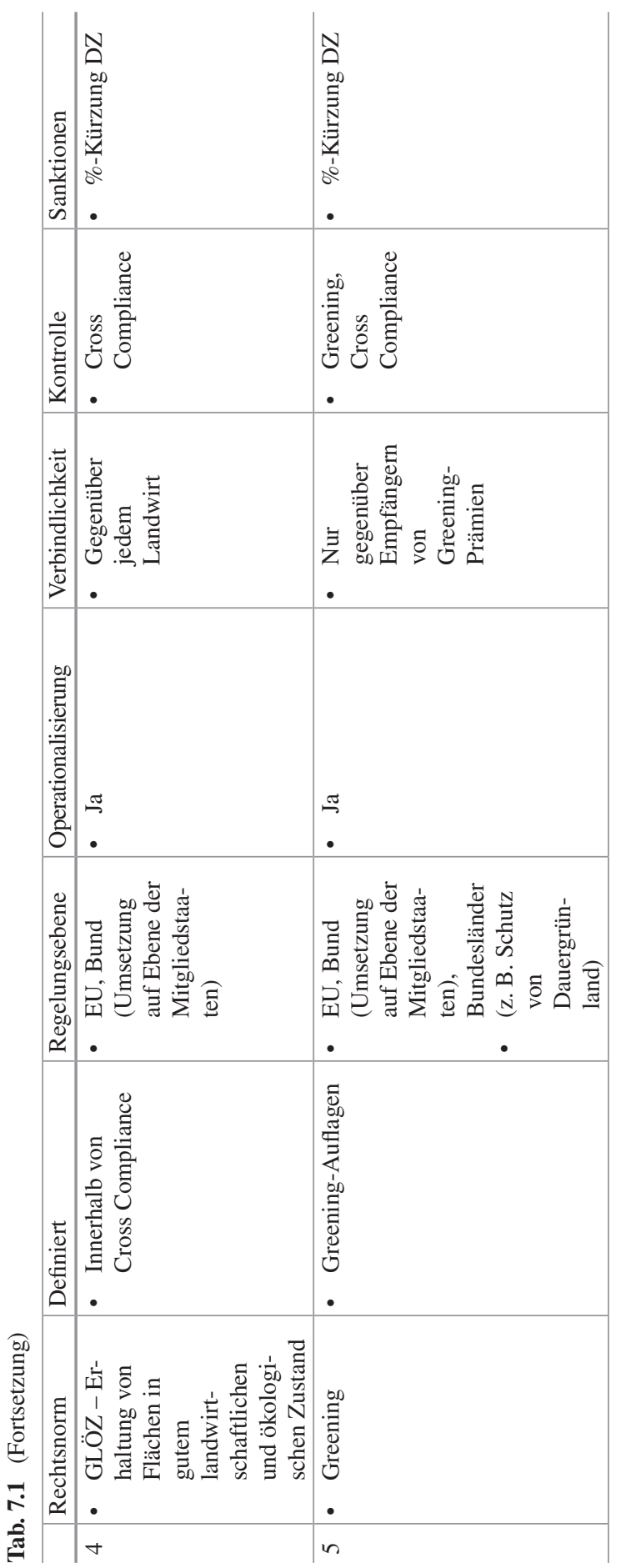




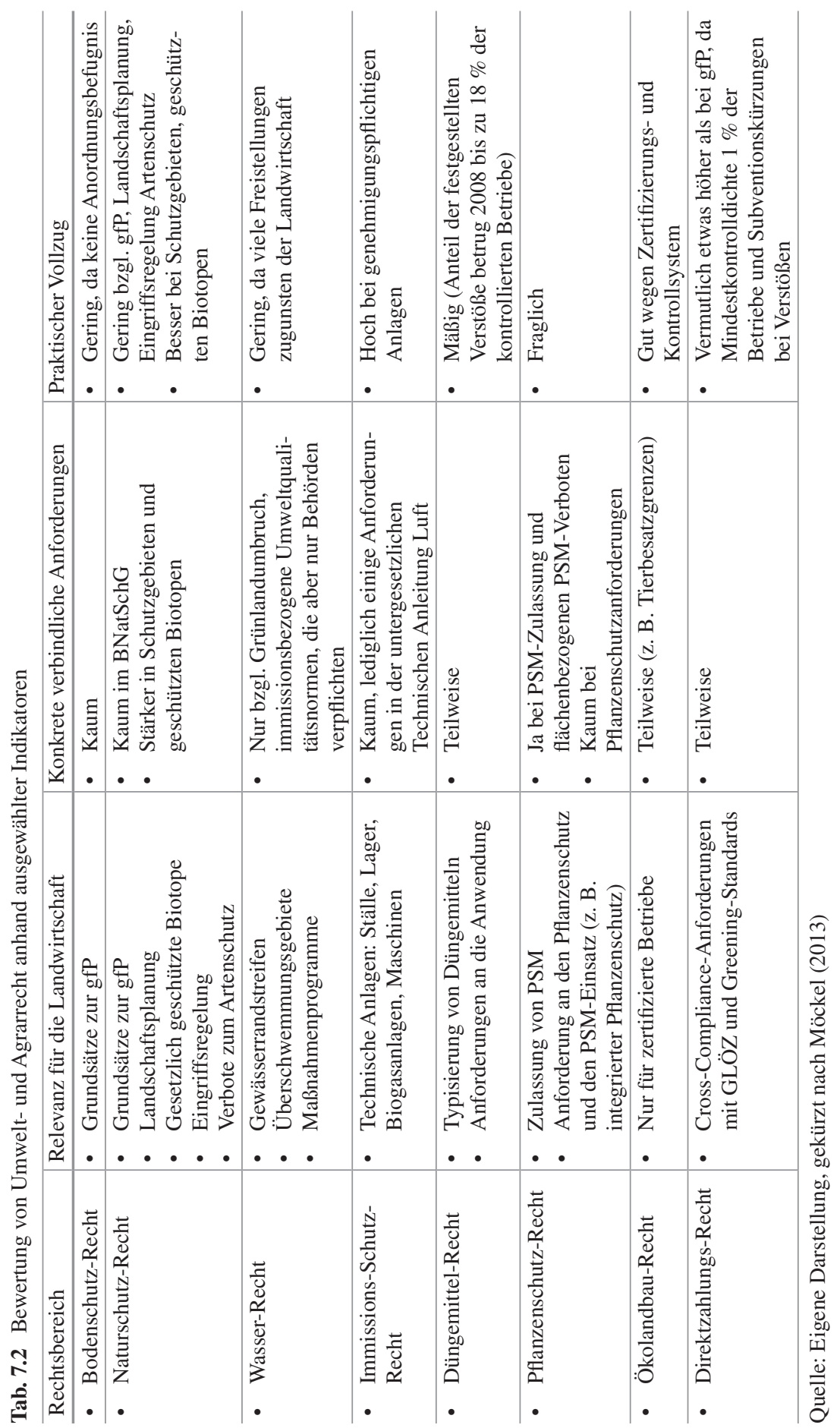


Auch die Einhaltung der GAB kann als verbindlicher Mindeststandard angesehen werden, da auch Betriebe, die keine Direktzahlungen erhalten, diese Auflagen einzuhalten haben. Es wird des Weiteren die Ansicht vertreten, dass auch die GLÖZ-Standards in das Ordnungsrecht integriert werden sollten, ,um eine Harmonisierung auf einem insgesamt höhere $(\mathrm{m})$ Umweltschutzniveau zu erreichen und die Anforderungen als verpflichtende Mindeststandards dauerhaft abzusichern, [...] da es sich bei den Cross-Compliance-Anforderungen um Mindestanforderungen im Sinne der guten fachlichen Praxis und nicht um zu honorierende darüber hinausgehende ökologische Leistungen der Landwirte handelt" (Möckel et al. 2014).

Ausgehend von den dargestellten Überlegungen wird im Folgenden der gesetzliche Mindeststandard als die Einhaltung des Stands der Technik, der guten fachlichen Praxis und der GAB angesehen. Die Durchsetzung der GLÖZ- und Greening-Auflagen ist in Verbindung mit der Gewährung von Direktzahlungen zu sehen.

\begin{tabular}{ll|l}
\hline \multicolumn{2}{l}{ Definition des gesetzlichen Mindeststandards } \\
\hline - Stand der Technik, gfP, GAB: & gesetzlicher Mindeststandard (für alle Betriebe verbindlich) \\
\hline - GLÖZ, Greening-Auflagen: & $\begin{array}{l}\text { bisher kein gesetzlicher Mindeststandard (Ausstiegsoption } \\
\text { gegen Verlust von bis zu } 125 \% \text { der Greening-Zahlungen) }\end{array}$ \\
\hline
\end{tabular}

Die folgende Tab. 7.2 zeigt, welchen Einfluss verschiedene Rechtssetzungen auf die Landwirtschaft haben, welche verbindlichen Anforderungen bestehen und wie der praktische Vollzug gestaltet ist.

Betrachtet man Tab. 7.1 und 7.2 zusammen, so zeigt sich, dass sowohl der gesetzliche Mindeststandard als auch das Agrar-Beihilferecht sowohl mit einem Regelungsdefizit wie mit einem Vollzugsdefizit zu kämpfen haben. So fehlt eine entsprechende Operationalisierung der guten fachlichen Praxis fast vollständig. Die Durchsetzung der GAB beruht in erster Linie auf Cross Compliance-Prüfungen und bei Verstößen drohen prozentuale Kürzungen der Direktzahlungen. So konnte mit der Einführung von Cross Compliance, d. h. einer Kopplung der Einhaltung der gesetzlichen Mindeststandards an den Erhalt von Direktzahlungen, die Durchsetzung des gesetzlichen Mindeststandards verbessert werden.

Die Behebung der Regelungsdefizite muss an der Operationalisierung der Begrifflichkeiten ansetzen. Hierfür ist die Festlegung geeigneter Indikatoren, Messund Grenzwerte notwendig. Grenzwerte können festgelegt werden als Ober- oder Untergrenzen, gesetzliche Unterlassungspflichten (Verbote) oder gesetzliche Handlungspflichten (Möckel 2013). Dabei ist jedoch insbesondere die Möglichkeit der praktikablen Feststellung der Mess- und Grenzwerte zu berücksichtigen. Mess- und Grenzwerte oder Verhaltensregeln, die nicht oder nur unter großem Aufwand festgestellt werden können, eignen sich nicht zur Durchsetzung der entsprechenden Rechtsnormen (z. B. längere Zeiträume für die Einarbeitung organischer Dünger). Des Weiteren sollten die Grenzwerte so festgelegt werden, dass ihre Einhaltung zu einer Verbesserung der Umwelt- und Naturschutzwirkungen der Landwirtschaft beiträgt. „Das gegenwärtige Anforderungsniveau der guten fachlichen Praxis [ist jedoch] unzureichend, um durch die Landwirtschaft verursachte Umweltschäden vollkommen abzuwenden“" (Möckel et al. 2014). Auch durch die Umsetzung der 
GAB-, GLÖZ- und Greening-Auflagen ist nur ein geringer positiver Effekt auf die Ressourcen des Naturschutzes festzustellen bzw. zu erwarten (Europäische Kommission 2016).

Zur Operationalisierung der guten fachlichen Praxis werden beispielsweise die Ausweisung von Schadschwellen für den integrierten Pflanzenschutz, Grenzwerte zur Beschränkung der Bewirtschaftungsintensität (z. B. verbindliche Obergrenzen für Stickstoffüberschüsse und den Viehbesatz pro Hektar) sowie weiterführende Untersuchungs- und Dokumentationspflichten hinsichtlich Stickstoff und Humusgehalt (Möckel et al. 2014) empfohlen. Da jedoch die Art und Weise der landwirtschaftlichen Bewirtschaftung im Zusammenhang mit standörtlichen Faktoren unterschiedliche Wirkungen in Bezug auf den Natur- und Umweltschutz entfalten kann, wäre die

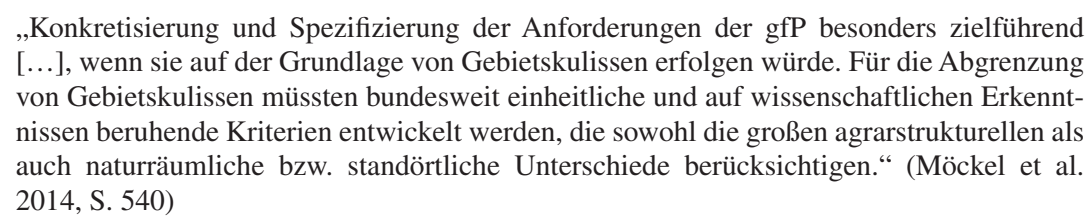

Vollzugsdefizite sind zum einen durch unbestimmte Rechtsbegriffe und einen Mangel an kontrollierbaren Indikatoren bedingt, zum anderen durch geringe Kontrollfrequenzen und Sanktionshöhen. Mit mangelnder Durchsetzung durch ungeeignete Kontroll- und Sanktionsmechanismen sinkt jedoch ceteris paribus die Bereitschaft der Landwirte, sich normgerecht zu verhalten (Rothstein und Schröder 2016). Die Durchsetzung des gesetzlichen Mindeststandards ist dabei unabhängig von der Gewährung von Direktzahlungen zu sehen. Die Kopplung der Einhaltung des gesetzlichen Mindeststandards an die Gewährung von Direktzahlungen birgt bisher den Vorteil, dass - neben der Operationalisierung von Auflagen - ein einheitliches Kontroll- und Sanktionssystem in allen Mitgliedstaaten der EU etabliert wurde. Dessen Weiterführung wäre grundsätzlich jedoch auch unabhängig von der Gewährung von Direktzahlungen möglich.

Eine Verminderung des Vollzugsdefizits könnte erreicht werden durch:

- höhere Kontrollfrequenzen und Sanktionen, wobei die Höhe der Kontrollfrequenzen und Sanktionen in einem umgekehrten Verhältnis zu einander stehen;

- Beweislastumkehr, so dass beispielsweise der Landwirt oder die Landwirtin die Einhaltung der Stickstoffbilanzgrenzwerte nachweisen muss, etwa durch Erhebung der Stickstoffgehalte im organischen Dünger oder Wiegeprotokolle der Erträge;

- Plausibilitätskontrollen, z. B. durch den zwischenbetrieblichen Vergleich von Nährstoffbilanzen in einer Region oder den Abgleich von Daten aus anderen Datenbanken;

- Einbindung externer Kontrolleinrichtungen, wie z. B. im ökologischen Landbau;

- Ziehung von Rückstellmustern, z. B. um Stickstoffgehalte in organischen Düngern zu belegen;

- Nutzung von GIS-Daten und Vernetzung digitaler Datensysteme. 
Für die Zukunft ist vorstellbar, anhand digitaler Daten und elektronischer Datenverarbeitung den bürokratischen Aufwand für landwirtschaftliche Unternehmen und Verwaltung zu reduzieren. So könnten bisher in verschiedenen Datenbanken erhobene und gespeicherte Daten zur Durchführung von Kontrollen zusammengeführt (z. B. HIT und INVEKOS) und mit Daten der Selbstkontrolle (z. B. Ackerschlagbilanzen, Daten des Precision Farming) kombiniert werden. Die gewonnen Daten könnten damit insgesamt als Kontroll-, aber auch als Monitoring- und Beratungstool für die landwirtschaftlichen Betriebe eingesetzt werden, z. B. durch Vergleich des eigenen Betriebes mit anderen Betrieben aus der Region zu Zwecken des (anonymen) Bench-Marking. Dabei sind jedoch Datenschutzerwägungen zu berücksichtigen.

Es ist auch möglich, den Erhalt von Direktzahlungen an den Nachweis der Einhaltung von Auflagen zu koppeln. Allerdings müssten die einzuhaltenden Auflagen dann über den gesetzlichen Mindeststandard hinausgehen (z. B. ökologischer Landbau), um eine Honorierung der bloßen Einhaltung der Gesetze zu vermeiden. Allerdings wird durchaus argumentiert, dass bereits die Einhaltung des gesetzlichen Mindeststandards mit einem finanziellen Ausgleich verbunden sein sollte, weil europäische Landwirtinnen und Landwirte gegenüber dem Weltmarkt höhere Natur- und Umweltschutzauflagen erfüllten, was z. B. im Ackerbau zu Kostennachteilen von ca. $50 € /$ ha führt (Wissenschaftlicher Beirat für Agrarpolitik beim BMELV 2010). Andere Quellen schätzen den Kostennachteil gegenüber der Konkurrenz außerhalb der EU eher auf ca. $20 € /$ ha (Plankl et al. 2010). Es wird jedoch auch vorgebracht, dass die Umweltleistungen der europäischen Landwirtschaft nicht notwendigerweise höher seien und Länder z. B. in Südamerika durch den Erhalt des Regenwaldes möglicherweise höhere Umweltleistungen erbringen.

$\mathrm{Zu}$ diskutieren sind des Weiteren die Wechselwirkungen, die im Zusammenhang mit der Durchsetzung eines effektiven gesetzlichen Mindeststandards entstehen könnten. Dies betrifft zum einen die oben erwähnten Wirkungen auf den Strukturwandel, die insbesondere mit der Durchsetzung von investiven Maßnahmen verbunden sein können. Hier besteht die Möglichkeit, z. B. durch Investitionsförderung gegenzusteuern (Möckel et al. 2014). Es werden jedoch auch Innovationen induziert, die dazu beitragen, die Grenzwerte möglichst effektiv und effizient einzuhalten (Rothstein und Schröder 2016; Taube 2016). Mit der Durchsetzung eines effektiven gesetzlichen Mindeststandards können jedoch auch Wirkungen auf die Verbraucherpreise verbunden sein. Durch den gesetzlichen Mindeststandard werden zumindest teilweise externe Kosten der Produktion internalisiert. Dies erhöht die Erzeugungskosten, was je nach Preiselastizität mehr oder weniger an die Abnehmer „durchgereicht“ werden kann. Sind höhere Erzeugerkosten durch EUStandards am Markt nicht durchsetzbar, könnte der Marktanteil europäischer Produkte zurückgehen. Die Größe dieses Effekts hängt u. a. von der Preiselastizität der Nachfrage ab.

In diesem Kontext können Labelling-Initiativen dazu dienen, Produkte mit höherer Umweltleistung sichtbar zu machen und den Substitutionseffekt durch Produkte, die aufgrund niedrigerer Standards preiswerter sind, zu vermindern. Eine Beschränkung des Marktzugangs von Produkten aufgrund ihrer Prozessqualität 
ist hingegen im allgemeinen nicht WTO-konform, es sei denn, dies ist zur Abwendung von Gefahren für die Gesundheit von Menschen, Tieren oder Pflanzen notwendig.

Die teilweise oder vollständige Substitution von inländischen Produkten durch Importe aus dem außereuropäischen Ausland infolge kostenintensiver Vorschriften kann mit einem Export negativer Umweltfolgen in die Erzeugerländer einhergehen. Es käme dann zu einer bloßen räumlichen Verschiebung negativer Natur- und Umweltwirkungen der Produktion (Leakage-Effekt). Angesichts der oben genannten Kosten der europäischen Standards, denen weit höhere Direktzahlungen gegenüber stehen, ist derzeit nicht davon auszugehen, dass die Mindeststandards von GAB und GLÖZ zu einer massiven Verlagerung von Produktion ins außereuropäische Ausland beitragen.

Insgesamt sind also fünf Aspekte zu beachten, um den gesetzlichen Mindeststandard effektiv und effizient durchzusetzen:

1. Praktikable Operationalisierung bisher unzureichend operationalisierter Begrifflichkeiten, wie z. B. gfP (ggf. differenziert nach Gebietskulissen);

2. Weiterführung des flächendeckenden europäischen Kontroll- und Sanktionssystems, unabhängig vom Fortbestehen einer Verknüpfung mit den Direktzahlungen (Cross Compliance);

3. Angemessene Kontrolldichte und Sanktionen mit spürbarer Anreizwirkung;

4. Adressatenorientierte Kommunikation auf Basis verhaltenswissenschaftlicher Ansätze;

5. Regelmäßige Nachjustierung der Standards nach dem Stand der Technik und neuen Erkenntnissen von Wissenschaft und Forschung.

\subsection{Baustein 2: Budget}

Das Projekt ZA-NExUS beschäftigt sich nicht vorrangig mit finanziellen Fragen der Agrarpolitik. Allerdings spielen bei der weiteren Integration des Natur- und Umweltschutzes in der Agrarpolitik die zur Verfügung stehenden finanziellen Mittel eine wesentliche Rolle. Neben dem Volumen geht es dabei auch um die Frage, welche Maßnahmen im Rahmen der Gemeinsamen Agrarpolitik vollständig von der EU finanziert werden und welche eine Ko-Finanzierung seitens der Mitgliedstaaten (aus nationalen, regionalen oder öffentlichen Haushalten oder seitens privater Geldgeber) erfordern. Die hier vorgestellten Überlegungen beschränken sich auf die Ausgabenseite des Budgets und klammern die Einnahmenseite - abgesehen von der Frage der Ko-Finanzierung - aus.

Hinsichtlich der Bedeutung des finanziellen Volumens lassen sich unter der heutigen Situation zwei Problemkreise für den Natur- und Umweltschutz unterscheiden:

- zum einen die Mittel, die für Programme und gezielte Maßnahmen des Naturund Umweltschutzes zur Verfügung stehen (inklusive der damit verbundenen Verwaltungskosten); 
- zum anderen die Mittel für flächenbezogene Direktzahlungen, deren Höhe mit darüber entscheidet, ob Betriebe in marginalen Lagen die landwirtschaftliche Produktion aufrechterhalten und ob Betriebe in hoch produktiven Lagen sich weiterhin Cross-Compliance-Auflagen unterwerfen, die über die gesetzlich verbindlichen Minimalstandards hinausgehen.

Der derzeitige Finanzrahmen für die deutsche und europäische Agrarpolitik ist erheblich. Im Jahre 2015 flossen gut 6 Mrd. € aus dem EU-Haushaltstitel 2 (Nachhaltiges Wachstum: Natürliche Ressourcen) nach Deutschland (siehe Tab. 7.3). Die Obergrenze für Direktzahlungen lag bei etwas mehr als 5,1 Mrd. €. 113 Mio. € standen für Exporterstattungen zur Verfügung. Diese beiden Posten werden zu $100 \%$ aus dem EU-Haushalt beglichen. 723 Mio. $€$ standen für Programme der ländlichen Entwicklung bereit, zu denen auch die Agrarumweltprogramme gehören. Diese Mittel konnten nur in Anspruch genommen werden, insofern es eine entsprechende Ko-Finanzierung gab. Weitere jeweils knapp 35 Mio. € flossen aus Mitteln der Gemeinsamen Fischereipolitik sowie für das Umwelt- und Klimaaktionsprogramm Life.

Der Mehrjährige Finanzrahmen 2014-2020 sieht europaweit relativ konstante Ausgaben von jährlich ca. 44,5 Mrd. € für die Direktzahlungen und marktbezogenen Ausgaben sowie ca. 13,6 Mrd. € für die ländliche Entwicklungspolitik vor (Tab. 7.4).

Tab. 7.3 EU-Ausgaben aus dem Haushaltstitel 2 (Nachhaltiges Wachstum: Natürliche Ressourcen) an deutsche Empfänger im Jahr 2015

\begin{tabular}{|c|c|c|}
\hline Titel & Bezeichnung & $\begin{array}{l}\text { Betrag in } \\
\text { Mio. } €\end{array}$ \\
\hline \multirow[t]{2}{*}{2} & SUSTAINABLE GROWTH: NATURAL RESOURCES & 6041,0 \\
\hline & Davon & \\
\hline \multirow[t]{3}{*}{2.0 .1} & $\begin{array}{l}\text { European Agricultural Guarantee Fund (EAGF) - Market related } \\
\text { expenditure and direct payments }\end{array}$ & 5247,9 \\
\hline & Direct Aid & 5135,3 \\
\hline & Export refunds & 112,7 \\
\hline 2.0 .2 & European Agricultural Fund for Rural Development (EAFRD) & 723,3 \\
\hline 2.0 .3 & $\begin{array}{l}\text { European Maritime and Fisheries Fund (EMFF), Regional Fisheries } \\
\text { Management Organisations (RFMOs) and Sustainable Fisheries } \\
\text { Agreements (SFAs) }\end{array}$ & 34,8 \\
\hline 2.0 .31 & European Maritime and Fisheries Fund (EMFF) & 34,7 \\
\hline 2.0 .32 & $\begin{array}{l}\text { Regional Fisheries Management Organisations (RFMOs) and } \\
\text { Sustainable Fisheries Agreements (SFAs) }\end{array}$ & 0,1 \\
\hline 2.0 .4 & Programme for the Environment and Climate Action (Life) & 34,5 \\
\hline 2.0.DAG & Decentralised agencies & 0,3 \\
\hline 2.0.OTH & Other actions and programmes & 0,0 \\
\hline 2.0.PPA & Pilot projects and preparatory actions & 0,1 \\
\hline 2.0.SPEC & $\begin{array}{l}\text { Actions financed under the prerogatives of the Commission and specific } \\
\text { competences conferred to the Commission }\end{array}$ & 0,0 \\
\hline
\end{tabular}

Quelle: Eigene Darstellung, nach European Commission (2016) 
Tab. 7.4 Mehrjähriger Finanzrahmen der EU 2014-2020, Haushaltstitel 2 (Nachhaltiges Wachstum: Natürliche Ressourcen)

\begin{tabular}{|c|c|c|c|c|c|c|c|c|}
\hline Titel & 2014 & 2015 & 2016 & 2017 & 2018 & 2019 & 2020 & $\begin{array}{l}2014- \\
2020\end{array}$ \\
\hline $\begin{array}{l}\text { Nachhaltiges } \\
\text { Wachstum: } \\
\text { natürliche } \\
\text { Ressourcen }\end{array}$ & 59.303 & 59.599 & 59.909 & 60.191 & 60.267 & 60.344 & 60.421 & 420.034 \\
\hline \multicolumn{9}{|l|}{ Davon } \\
\hline $\begin{array}{l}\text { Europäischer } \\
\text { Garantiefonds für } \\
\text { die Landwirt- } \\
\text { schaft (EGFL) - } \\
\text { marktbezogene } \\
\text { Ausgaben und } \\
\text { Direktzahlungen }\end{array}$ & 44.130 & 44.368 & 44.628 & 44.863 & 44.889 & 44.916 & 44.941 & 312.735 \\
\hline $\begin{array}{l}\text { Europäischer } \\
\text { Landwirtschafts- } \\
\text { fonds für die } \\
\text { Entwicklung des } \\
\text { ländlichen } \\
\text { Raums (ELER) }\end{array}$ & 13.652 & 13.652 & 13.653 & 13.653 & 13.654 & 13.654 & 13.655 & 95.577 \\
\hline $\begin{array}{l}\text { Europäischer } \\
\text { Meeres- und } \\
\text { Fischereifonds } \\
\text { (EMFF) }\end{array}$ & 1017 & 1035 & 1049 & 1058 & 1069 & 1078 & 1095 & 7404 \\
\hline $\begin{array}{l}\text { Umwelt- und } \\
\text { Klimapolitik } \\
\text { (Life) }\end{array}$ & 404 & 435 & 462 & 493 & 523 & 555 & 581 & 3456 \\
\hline Agenturen & 52 & 53 & 54 & 55 & 56 & 57 & 58 & 387 \\
\hline Spielraum & 47 & 54 & 61 & 67 & 74 & 81 & 89 & 473 \\
\hline
\end{tabular}

Mittel für Verpflichtungen in Mio. $€$ in laufenden Preisen.

Quelle: Eigene Darstellung, nach European Commission (2016)

\subsubsection{Institutioneller Rahmen}

Die Budget-Frage geht dabei weit über den Bereich der Agrarpolitik hinaus. Der Umfang des Agrarbudgets wird im Rahmen der Verhandlungen über den Mehrjährigen Finanzrahmen der EU vom Rat der EU auf Vorschlag der Kommission festgelegt. Laut Artikel 310 des Vertrags von Lissabon über die Arbeitsweise der Europäischen Union (AEUV) muss die EU einen ausgeglichenen Haushalt vorlegen. Laut Artikel 312 AEUV legt die EU einen mehrjährigen Finanzrahmen über einen Zeitraum von mindestens fünf Jahren fest. Dieser wird in einer Verordnung geregelt, deren Verabschiedung Einstimmigkeit im Rat und eine Mehrheit der Mitglieder des Europäischen Parlaments erfordert. Der Finanzrahmen legt jährliche Obergrenzen für die Haupttätigkeitsbereiche der Union fest. Daneben enthält der Finanzrahmen ,,auch alle sonstigen für den reibungslosen Ablauf des jährlichen Haushaltsverfahrens 
sachdienlichen Bestimmungen “. Im Finanzrahmen werden daher in der Regel bereits wesentliche Grundlinien der GAP mittelfristig bestimmt, deren Details dann in den agrarpolitischen Verhandlungen ausgefüllt werden, bei denen DG Agri, die Fachministerien der Mitgliedstaaten und der Agrarausschuss des Europäischen Parlaments maßgeblich sind (Matthews 2015) (siehe auch Abschn. 4.1).

Die Einflussfaktoren auf den Budgetrahmen der GAP liegen daher wesentlich jenseits der Agrarpolitik. Bei der Erstellung der strategischen Optionen haben wir daher kein bestimmtes finanzielles Szenario zugrunde gelegt. Bei den Erwartungen über das künftige finanzielle Volumen und die finanziellen Arrangements in der GAP nach 2020 sind zum einen systematische, zum anderen politische Überlegungen einzubeziehen.

\subsubsection{Systematische Aspekte}

Aus systematischer Sicht haben öffentliche Haushalte drei Funktionen: makroökonomische Stabilisierung, allokative sowie distributive Funktionen. Angesichts des Volumens von lediglich ca. $1 \%$ des BIP der Mitgliedstaaten kommt dem EU-Haushalt keine wesentliche Stabilisierungsfunktion zu. Bei den allokativen Funktionen ist der EU-Haushalt entsprechend der Lissabon-Strategie vor allem auf die Stärkung des Wachstumspotenzials in den Mitgliedstaaten und vor allem in benachteiligten Regionen ausgerichtet, etwa durch Infrastrukturausgaben. Bei den Struktur- und Kohäsionsfonds spielen verteilungspolitische Aspekte zwar eine Rolle, im Vordergrund steht aber das Ziel, Wachstumshemmnisse in benachteiligten Regionen zu vermindern sowie die grenzübergreifenden Kooperation zu fördern (Bos 2010, S. 91).

In einer Kommunikation zur Entwicklung des EU-Haushalts hat die Europäische Kommission fünf Prinzipien für den EU-Haushalt formuliert. Dieser soll der Realisierung der Schlüsselprioritäten dienen, Skaleneffekte ermöglichen, ergebnisorientiert sein, Stabilität für alle durch Solidarität mit den schwächeren Mitgliedern schaffen sowie den Prinzipien der Autonomie, Transparenz und Fairness entsprechen (European Commission 2010). Nach der Einführung der produktionsentkoppelten Direktzahlungen gab es daher Stimmen, die sich dafür aussprachen, die Politik zur Einkommensstützung zu dezentralisieren, da interpersonale Verteilungspolitik in die Kompetenz der Mitgliedstaaten fällt (Bos 2010, S. 93). Eine vorrangig einkommenspolitische Begründung der Direktzahlungen könnte daher deren Vollfinanzierung in Frage stellen. Da entkoppelte Direktzahlungen zudem weder Skaleneffekte noch Externalitäten mit sich bringen, entfallen weitere Argumente für eine Zentralisierung dieser Zahlungen (Grethe 2008).

Hinzu kommt die Überlegung, dass Maßnahmen mit Ko-Finanzierung in der Regel zu größerem Kostenbewusstsein bei den Mitgliedstaaten führen und damit zu einer stärker ergebnisorientierten und besser vorbereiteten Implementation. Beide Effekte sind geeignet, die Effektivität und Effizienz von Maßnahmen zu erhöhen. Andererseits könnte die Gefahr bestehen, dass bei knappen öffentlichen Haushalten keine hinreichenden Mittel bereitgestellt werden bzw. „Naturschutz nach Kassenlage“ betrieben wird. 
Insgesamt sind aus systematischer Sicht also sowohl die Vollfinanzierung von Maßnahmen durch die EU wie auch die zentrale Finanzierung von vorwiegend einkommenspolitischen Maßnahmen kritisch zu beurteilen.

\subsubsection{Politische Aspekte}

Im Hinblick auf die politischen Prozesse der Budgetverhandlungen ist zu berücksichtigen, dass die Mitgliedstaaten die von ihnen bereitgestellten Beiträge an die EU als ihr eigenes Geld ansehen, von dem sie einen angemessenen Rückfluss erwarten, auch wenn es sich rechtlich und technisch um Eigenmittel der EU handelt (Bos 2010, S. 89). Bei den Finanzverhandlungen spielt daher die buchhalterische Nettozahlerposition eine zentrale Rolle.

Diese Betrachtungsweise kann eine Reform der Instrumente der Agrarpolitik erschweren, wenn dadurch Unsicherheiten über die Verteilungswirkungen entstehen oder wenn einzelne Mitgliedstaaten eine Verschlechterung ihrer Nettozahlerposition hinnehmen müssten, die nicht an anderer Stelle (wenn auch nicht notwendigerweise für die gleichen Empfänger) kompensiert wird. Im Ergebnis begünstigt die Nettozahlerperspektive eine starke Status-quo-Orientierung und Pfadabhängigkeit der GAP (Ackrill 2005).

Dabei ist zu beachten, dass die GAP Umverteilungswirkungen zwischen den Mitgliedstaaten erzeugt, die zumindest in den 1990er-Jahren zwischen -20\% und +60\% des Produktionswerts des Agrarsektors streuten (Zanias 2002). Durch die teilweise Angleichung der Direktzahlungen zwischen 2014 und 2020 wurden explizit Umverteilungswirkungen im Vergleich zum Status quo zwischen den Mitgliedstaaten angestrebt, in diesem Fall im Sinne des Kohäsionsziels von den reicheren EU-15 zu den ärmeren neuen Mitgliedstaaten in Osteuropa (vgl. European Commission 2011b, S. 60). Studien mit größerer räumlicher Differenzierung finden regionale Umverteilungseffekte der GAP zugunsten ländlicher Regionen, die auch unterhalb der Ebene der Bundesländer stark variieren können (Elsholz 2009). Eine Renationalisierung der GAP könnte demnach zu einer Verminderung dieser Umverteilungseffekte führen (Elsholz 2009). Weil die Agrarzahlungen letztlich steuerfinanziert sind, ,findet eine Einkommensumverteilung von urbanen und wohlhabenden Regionen zu ländlichen und ärmeren Regionen statt" und die GAP trägt zum Kohäsionsziel der EU bei (Hansen 2009, S. 180 f.)

Aufgrund der Verteilungseffekte haben Mitgliedstaaten und Regionen, die netto von der GAP im Allgemeinen und insbesondere von den Direktzahlungen profitieren, ein Interesse an deren Fortführung zu relativ unveränderten Bedingungen. Da die Verabschiedung des Mehrjährigen Finanzrahmens Einstimmigkeit im Rat erfordert, sind die Nettoempfänger der GAP in einer relativ starken Position. Dies trägt wesentlich zur Erklärung des Entwicklungspfads der europäischen Agrarpolitik seit der MacSharry-Reform von 1992 bei: Zunächst wurde vereinbart, dass das GAP-Budget geringer steigen sollte als das BIP und damit auch als der Haushalt der EU insgesamt (Bos 2010). Für die Finanzperiode 2014-2020 bleiben die Ausgaben 
der GAP nun ungefähr konstant, was auf eine weitere Verminderung des relativen Anteils der GAP sowohl am BIP wie am Budget der EU hinausläuft und auf diese Weise gewisse Freiräume für andere Aufgaben der EU schafft.

Eine weitere Frage ist, ob in den nächsten Jahren überhaupt mit einer politischen Initiative zu rechnen ist, die auf eine grundlegende Reform der GAP abzielt. Die relativ weitgehenden GAP-Reformen von 1992 und 2003 wurden jeweils von einem Agrarkommissar mit einer konzeptionell gut unterfütterten Reform-Agenda und unter starkem äußerem Druck vorangetrieben (vgl. Abschn. 4.1). Bei unseren Hintergrundgesprächen ergab sich der Eindruck, dass derzeit eher nicht mit einer gröBeren Reforminitiative für die GAP zum Zeitpunkt 2020 gerechnet wird. Dabei spielt eine Rolle, dass die reguläre Amtszeit der derzeitigen Kommission 2019 endet und es als wenig opportun angesehen werden könnte, der Nachfolgekommission die Implementation einer radikalen Reform, die sie nicht selbst angestoßen hat, zu hinterlassen. Als wahrscheinliche Szenarien gelten daher entweder eine relativ kleine Reform für die GAP 2021-2027 oder eine Verlängerung der derzeitigen GAP um ein bis zwei Jahre mit der Gelegenheit für eine umfassendere Reform für die Zeit ab 2022.

Vor diesem Hintergrund erscheint die folgende Annahme hinsichtlich des GAP-Budgets 2021-2027 plausibel, die von einer Fortsetzung des bisherigen Politikpfads ausgeht:

- Der für die GAP zur Verfügung stehende Anteil am EU-Haushalte bleibt konstant. Unter Berücksichtigung der durch den Brexit bedingten Verminderung des Haushaltsvolumens um derzeit geschätzte $10 \mathrm{Mrd}$. €/Jahr würden die verbleibenden 27 Mitgliedstaaten ca. 4 Mrd. €/Jahr weniger als bisher für die GAP zur Verfügung stellen.

- Verschiebungen zwischen den Anteilen mit Voll- und Ko-Finanzierung sind möglich, wenn die Umverteilungseffekte relativ gering bleiben und als beherrschbar angesehen werden.

Diese Annahmen liegen der Formulierung der strategischen Optionen in Kap. 8 zugrunde.

\subsubsection{Dilemma aus Sicht der Naturschutz- und Umweltpolitik}

Aus Sicht des Naturschutz- und Umweltschutzes ergibt sich aus der finanzpolitischen Konstruktion der GAP ein Dilemma. Einerseits könnten die umweltbezogenen Maßnahmen in der Zweiten Säule bei anspruchsvoller Ausgestaltung deutlich effektiver und effizienter zur Erreichung von Umweltzielen sein als die relativ allgemeinen und wenig anspruchsvollen Instrumente in der Ersten Säule. Andererseits werden die Direktzahlungen der Ersten Säule bisher voll aus dem EU-Haushalt finanziert, während die Maßnahmen der Zweiten Säule derzeit eine nationale KoFinanzierung erfordern, die gerade in ärmeren Regionen eine Herausforderung darstellen kann. Daher besteht von Seiten der Mitgliedstaaten und Regionen, die 
Nettoempfänger der Ersten Säule sind, Widerstand gegen eine Umschichtung von Mitteln der Ersten in die Zweite Säule. Dieser Widerstand war in der letzten Reformdiskussion wirkmächtig. Nachdem der Anteil der Zweiten Säule zuvor in mehreren Reformschritten jeweils erhöht wurde, stagnierte er in der Reform von 2013 nicht nur, sondern war sogar leicht rückläufig (Anania und Pupo D'Andrea 2015). Ein mögliches Argument könnte dabei gewesen sein, dass durch die Einführung des Greenings in der Ersten Säule die Zweite Säule entlastet wurde und damit für weitergehende Maßnahmen genutzt werden sollte.

Die Teilnehmer in den Hintergrundgesprächen waren eher skeptisch, ob es zu größeren Veränderungen der Aufteilung der Mittel zwischen Vollfinanzierung und Ko-Finanzierung kommen wird. Die Erhöhung des Anteils mit erforderlicher KoFinanzierung würde - bei insgesamt gleichbleibendem GAP-Budget - erfordern, dass die Mitgliedstaaten insgesamt noch mehr Geld für die Agrarpolitik aufwenden würden, da mehr Finanzmittel zur Ko-Finanzierung aufgebracht werden müssten. Dies ist angesichts der Fülle anderer Aufgaben sowie der schrumpfenden ländlichen Bevölkerung aus polit-ökonomischer Perspektive eher unwahrscheinlich.

Mehr Erfolg verspricht daher der im Rahmen der 2013-Reform verfolgte Ansatz, den Mitgliedstaaten die Option einer freiwilligen Teilmodulation von der Ersten in die Zweite Säule bei Beibehaltung der Vollfinanzierung zu eröffnen. Die Mitgliedstaaten gewinnen dadurch mehr Spielraum für eine von finanziellen Erwägungen unabhängige Auswahl der geeignetsten Instrumente. Bis August 2017 haben die Mitgliedstaaten die Möglichkeit, die Modulation weiter auf bis zu 15 \% zu erhöhen.

Eine andere Möglichkeit wäre es, die bisherige Verknüpfung zwischen Vollfinanzierung mit Direktzahlungen/Cross Compliance einerseits und Ko-Finanzierung mit freiwilligen/regionsspezifischen Maßnahmen andererseits zu lockern oder sogar ganz aufzuheben.

\subsubsection{Handlungsalternativen}

Vor dem Hintergrund der Überlegungen ergeben sich fünf alternative Ansätze, die sich nicht gegenseitig ausschließen, sondern auch kombiniert werden können:

(1) Verlagerung von Mitteln aus der GAP in z. B. einen ,Naturschutzfonds“6: Diesem Ansatz liegt die Erfahrung zugrunde, dass nach Festlegung des Mehrjährigen Finanzrahmens 2014-2020 die Ausgestaltung der darin vorgesehenen sachlichen Rahmenrichtlinien von agrarischen Interessen dominiert wurde. Eine teilweise Verlagerung von Mitteln aus der GAP in einen „Naturschutzfonds“ würde sicherstellen, dass bei deren Vergabe die Anliegen des Natur- und Umweltschutzes Priorität erhalten. Der Nachteil dieser Strategie ist ihr redistributiver Charakter, der regelmäßig zu einem hohen Konfliktniveau führt. Dies kann einerseits Mobilisierungseffekte für den Natur- und Umweltschutz haben, andererseits wäre aber auch mit einer Mobilisierung derjenigen Kräfte zu rechnen, die befürchten, dass man ihnen ,ihr“ Budget ,wegnehmen“ will. Angesichts der 
Interessenlagen und Kräfteverhältnisse wäre hier vermutlich ein hoher politischer Krafteinsatz bei ungewissen Erfolgsaussichten erforderlich. Daneben ist zu berücksichtigen, dass auch ein bei der DG Umwelt angesiedeltes Budget für Programme des Agrarumweltschutzes den Regeln des EU-Rechts unterliegt. Zudem könnte die Koordination mit anderen Maßnahmen der Agrarpolitik schwieriger sein, und es könnten parallele Verwaltungsabläufe entstehen.

(2) Verschiebung von Mitteln von der Ersten in die Zweite Säule: Dies erschien über 20 Jahre als der evolutionäre Entwicklungspfad der GAP. Seit 2013 stagniert dieser Reformpfad jedoch. Ein erstes Hindernis dieser Strategie sind die Verteilungseffekte zuungunsten von Vetospielern, denen jedoch grundsätzlich durch Kompensations- und Paketlösungen begegnet werden kann. Ein zweites wichtiges Problem ist, dass bei Beibehaltung der (sub-)nationalen Ko-Finanzierung zu derzeitigen Sätzen insgesamt noch mehr Mittel für die Agrarpolitik aufgewendet werden müssten. Dem könnte dadurch begegnet werden, dass die nationalen Ko-Finanzierungssätze so vermindert werden, dass das finanzielle Gesamtvolumen (Aufwendungen der EU plus Mitgliedstaaten) ungefähr konstant bleibt. Bei diesem Ansatz ist weiterhin zu beachten, dass es nicht nur eine Kritik an der oberflächlichen Legitimierung der Ersten Säule durch wenig wirksame Cross-Compliance-Regelungen gibt, sondern auch eine Kritik an mangelnder Wirksamkeit der Maßnahmen der Zweiten Säule (siehe Abschn. 7.4.2).

(3) Stärkung der Agrarumweltprogramme innerhalb der ländlichen Entwicklungspolitik: Weiterhin ist zu berücksichtigen, dass innerhalb der Zweiten Säule eine Mittelkonkurrenz zwischen Agrarumweltprogrammen, ländlicher Entwicklung und betrieblichen Investitionsprogrammen besteht (Hart et al. 2016). Die Naturschutz- und Umweltkomponente könnte dadurch gestärkt werden, dass hier höhere finanzielle Mindest- und Höchstanteile innerhalb der ländlichen Entwicklungsprogramme verankert werden. Auf der nationalen und regionalen Ebene wäre dann sicherzustellen, dass die vorhandenen finanziellen Räume für Naturschutz- und Umweltmaßnahmen möglichst weitgehend ausgeschöpft werden.

(4) Dominante Direktzahlungen akzeptieren und umwelteffektiver machen: Geht man davon aus, dass die Nutznießer starker direktfinanzierter Direktzahlungen eine nicht zu überwindende Vetoposition im Rat einnehmen, dann bestehen folgende Möglichkeiten:

- stärkere Verknüpfung der Direktzahlungen mit Naturschutz- und Umweltleistungen durch Weiterentwicklung des Greenings und Neugestaltung der Instrumente (siehe Abschn. 7.3);

- fortlaufende Erhöhung des Anteils, den die Mitgliedstaaten von der Ersten in die Zweite Säule modulieren können, ggf. unter Beibehaltung der Vollfinanzierung; dadurch Erhöhung der nationalen Spielräume für zielgenauere und anspruchsvollere Maßnahmen nach Art der Zweiten Säule.

(5) Erschließen und Aktivieren neuer Finanzquellen: Eine andere Variante ist die Erschließung neuer Finanzierungsquellen für Maßnahmen des Natur- und 
Umweltschutzes. Hier könnte etwa ein Agrarumwelt-Investitionsfonds von Interesse sein, der Umweltinvestitionen ko-finanziert oder - nach dem Vorbild der Unterstützung von Energiesparmaßnahmen durch die Kreditanstalt für Wiederaufbau - mit vorteilhaften Krediten ermöglicht. Hier wäre auch darüber nachzudenken, ob aus Marktaktivitäten weitere Zahlungen aktiviert werden können, etwa durch die Einführung eines Umweltcents auf bestimmte Güter durch Einzelhändler mit Marktmacht, aus dem dann Pilotprojekte oder andere Maßnahmen gefördert oder ko-finanziert werden können.

\subsection{Baustein 3: Erste Säule der GAP - Flächenbezogene Direktzahlungen}

\subsubsection{Bewertung des derzeitigen Systems der Direktzahlungen}

Die Erste Säule der GAP beinhaltet die Gewährung von Direktzahlungen, die seit der Reform 2003 unabhängig von der Art und Höhe der Produktion (etwa Anzahl gehaltener Tiere, angebaute Kulturen) als Flächenprämie gezahlt werden. In Deutschland wurden die Direktzahlungen vollständig von der Produktion entkoppelt und spätestens ab 2019 werden in ganz Deutschland für Acker- und Grünland einheitliche Flächenprämien ausbezahlt. Seit 2015 gliedern sich die Direktzahlungen in die Basisprämie, die Greening-Prämie, die Umverteilungsprämie und die Junglandwirteprämie. Dabei sind die Basis- und die Greening-Prämie an die Einhaltung der Cross-Compliance-Verpflichtungen (GAB, GLÖZ) und der Greening-Auflagen (Anbaudiversifizierung, Erhalt von Dauergrünland, Bereitstellung ökologischer Vorrangflächen) gebunden. Mit der Umverteilungsprämie werden die ersten Hektare eines Betriebes zusätzlich gefördert, hierdurch sollen kleinere Betriebe verstärkt begünstigt werden. Ebenso werden mit der Junglandwirteprämie Berufseinsteiger stärker gefördert. Das BMEL definiert als Ziele der Gewährung der Direktzahlungen (BMEL 2015e):

- Erstens sollten damit die vielfältigen gesellschaftlichen Leistungen der Landwirtschaft honoriert und gesichert werden.

- Zweitens seien die staatlichen Förderungen ein Ausgleich dafür, dass Landwirte in Europa gerade in den Bereichen Umwelt-, Tier- und Verbraucherschutz deutlich höhere Standards einhalten müssten als viele ihrer Kollegen in anderen Teilen der Welt.

- Drittens trügen die Direktzahlungen zur Einkommenssicherung und Einkommensstabilisierung der Landwirte bei, indem sie die Auswirkungen der zum Teil extremen Preisschwankungen bei Agrarprodukten abfedern.

Die Direktzahlungen der Ersten Säule sind seit der Reform von 2003 an die Einhaltung von Natur- und Umweltschutzauflagen gebunden (Cross Compliance). Damit werden die Aspekte der Einkommenssicherung und Versorgungssicherheit als 
Ziele der GAP systematisch mit der Kontrolle der Einhaltung von Mindeststandards verknüpft. Die Zahlungen erscheinen daher als Honorierung landwirtschaftlicher Leistungen. An Grenzertragsstandorten unterstützen die Direktzahlungen zudem die Aufrechterhaltung einer flächendeckenden Bewirtschaftung, denn sie werden schon bei Offenhaltung der Flächen durch einmaliges Mähen oder Mulchen pro Jahr gewährt. Auf diese Weise wurde mit der Reform von 2003 eine argumentative Engführung von Erster und Zweiter Säule eingeleitet, denn bis dahin wurden Naturund Umweltleistungen ausschließlich in der Zweiten Säule honoriert.

Allerdings wird vielfach Kritik an diesem System geäußert. So gehen die Cross-Compliance-Auflagen nur geringfügig über den gesetzlichen Mindeststandard hinaus - nämlich in Form der GLÖZ- und seit 2015 der Greening-Auflagen. Die positiven Effekte für den Natur- und Umweltschutz sind dabei vermutlich gering (Hart et al. 2016).

Da die Landwirte nicht dazu verpflichtet sind, Cross Compliance und Greening einzuhalten (mit Ausnahme der GAB), steht ihnen die Möglichkeit offen, auf die Greening- und die Basisprämie zu verzichten, um damit die Einhaltung der GLÖZund Greening-Auflagen zu umgehen. Zwar ist die Einhaltung der GreeningAuflagen Voraussetzung für den Erhalt der Basisprämie, bei Verstößen werden jedoch max. $125 \%$ der Greening-Prämie gekürzt. In Deutschland entspricht das ca. $100 € /$ ha. Bisher erhalten die meisten Betriebe in Deutschland jedoch Direktzahlungen (siehe Tab. 7.5) und müssen damit die Cross-Compliance-Auflagen einhalten. Aussagen zur Einhaltung der Greening-Auflagen bzw. zum Umfang von Verstößen gegen die Greening-Auflagen sind noch nicht bekannt.

Wie Tab. 7.5 zeigt, nehmen konstant mehr als $90 \%$ der Betriebe in Deutschland die Direktzahlungen in Anspruch. Insgesamt wurden in Deutschland nur für ca. 49.000 ha landwirtschaftlicher Fläche keine Direktzahlungen bezogen, wobei es sich vorwiegend um Sonderkulturflächen handelte (Krämer 2017, S. 40). Diese hohe Teilnahmebereitschaft lässt sich damit erklären, dass die Höhe der Direktzahlungen die Kosten, die durch die Einhaltung der Bedingungen für die Gewährung von Direktzahlungen anfallen, typischerweise bei weitem übersteigt. Berechnungen zeigen, dass die durch die Auflagen verursachten Mehrkosten im Ackerbau gegenüber dem Weltmarkt bei nur ca. $20 € /$ ha (Plankl et al. 2010) bis $50 € /$ ha liegen (Wissenschaftlicher Beirat für Agrarpolitik beim BMELV 2010).

Auch bezüglich der Einhaltung der Greening-Auflagen ist davon auszugehen, dass die durch die Einhaltung der Auflagen verursachten Kosten durch die Greening-Prämie mehr als kompensiert werden. Im Vorfeld wurden die Kosten der Ein-

Tab. 7.5 Anteil

landwirtschaftlicher Betriebe, die keine Direktzahlungen beziehen. (Quelle: Eigene Darstellnug, nach BMELV (2013a); BMEL (2014a, 2015d))

\begin{tabular}{l|l}
\hline Wirtschaftsjahr & $\begin{array}{l}\text { Anteil der Betriebe } \\
\text { ohne } \\
\text { Direktzahlungen (\%) }\end{array}$ \\
\hline $2014 / 15$ & 6,8 \\
\hline $2013 / 14$ & 6,4 \\
\hline $2012 / 13$ & 7,2 \\
\hline $2011 / 12$ & 6,7 \\
\hline
\end{tabular}


haltung der Greening-Auflagen im EU-Durchschnitt auf ca. $35 € /$ ha geschätzt (European Commission 2011a). Seitens der Landwirtschaftsverbände stand dabei vor allem die Auflage, 5 \% ökologische Vorrangflächen bereit zu stellen, stark in der Kritik. Nimmt man nun an, dass die Direktzahlung ab 2019 in Deutschland $281 €$ / ha betragen, dann beträgt die Höhe der Greening-Prämie 84,30 €/ha (30 \% der Direktzahlungen). Nimmt man weiterhin an, dass die beiden anderen GreeningAuflagen - die Verpflichtung zum Grünlanderhalt und die Fruchtfolgegestaltung ohne Verursachung wesentlicher Kosten eingehalten werden können, dann ergibt sich so für die Bereitstellung von 1 ha ökologischer Vorrangfläche ein „Pachtpreis“ von $1686 € /$ ha. ${ }^{1}$ Selbst in aktuellen Gunstlagen ist ein Pachtpreis in dieser Höhe „,konkurrenzfähig“. Dabei ist zusätzlich zu berücksichtigen, dass die Bereitstellung ökologischer Vorrangflächen einen vollkommenen Nutzungsverzicht gar nicht vorsieht. Es können ökologische Vorrangflächen gemeldet werden, welche die Bereitstellungskosten der ökologischen Vorrangfläche weiter senken. So ist z. B. der Anbau von Eiweißpflanzen möglich. Auch wenn durch die Auflagen des Grünlanderhalts und der Einhaltung der Fruchtfolgeauflagen in einigen Betrieben Kosten entstehen können, ist davon auszugehen, dass diese durch die Greening-Prämie kompensiert werden. So wird festgestellt, dass auch unter Berücksichtigung der Kosten des Greenings, die mit 10 bis $100 € /$ ha berechnet werden, die Einhaltung der Greening-Auflagen aus betrieblicher Sicht langfristig meist sinnvoll ist (de Witte und Latacz-Lohmann 2014). Die Folgenabschätzung der Europäischen Kommission bezifferte die zu erwartenden Kosten aller Greening-Auflagen auf etwas mehr als $30 € /$ ha im EU-Durchschnitt und für Deutschland auf durchschnittlich ca. $50 € /$ ha (European Commission 2011a).

Es lässt sich somit festhalten, dass die Cross-Compliance- und GreeningAuflagen zwar nicht garantieren, dass von allen Betrieben in allen Regionen die entsprechenden Auflagen eingehalten werden, da ein „Ausstieg“ aus dem System der Direktzahlungen möglich ist. Aktuell findet ein solcher Ausstieg aber nur in sehr geringem Umfang statt, da die gewährten Prämien die entstehenden Kosten bei Weitem übersteigen. Darüber hinaus liegen die Direktzahlungen deutlich über dem Wert, der für einen Ausgleich für höhere Auflagen gegenüber dem Weltmarkt gerechtfertigt wäre.

Wenn die Direktzahlungen tatsächlich vorrangig dem Zweck dienen sollen, einen Ausgleich für die aus den Cross-Compliance- und Greening-Verpflichtungen entstehenden Mehrkosten zu gewähren, dann müssten die erheblichen Unterschiede zwischen den verschiedenen Betriebstypen deutlich stärker berücksichtigt werden (siehe Tab. 7.6). Dies betrifft z. B. tierhaltende Betriebe, die im Vergleich zu Ackerbaubetrieben mehr Auflagen einhalten müssen und dadurch zum einen höhere Kosten haben (Bürokratie, Produktion, Investitionen), aber auch ein höheres Anlastungsrisiko aufweisen (gegen die Tierkennzeichnungsverordnung wird am häufigsten

\footnotetext{
${ }^{1}$ Die Summe von $1686 € /$ ha ergibt sich, wenn man die Greening-Prämie von 84,30 €/ha mit der Anzahl der Hektare multipliziert, für welche die Greening-Prämie gezahlt wird. Diese ist 20 mal so groß wir die ökologischen Vorrangflächen, die bereitgestellt werden müssen, um die Greening-Auflagen zu erfüllen.
} 
Tab. 7.6 Steigerung der betrieblichen Kosten für die Einhaltung der EU-Auflagen im Bereich Umwelt, Tierwohl und Verbraucherschutz $(\%)$ nach Betriebstypen

\begin{tabular}{l|l|l}
\hline & Deutschland & EU \\
\hline Milchbetriebe & $1,1-1,5$ & $0,7-2,9$ \\
\hline Rindermastbetriebe & & $0,5-3,0$ \\
\hline Schafmastbetriebe & & $0,4-3,2$ \\
\hline Schweinemastbetriebe & 8,8 & $2,9-8,8$ \\
\hline Geflügelmastbetriebe & $1,4-2,2$ & $1,4-5,6$ \\
\hline $\begin{array}{l}\text { Ackerbaubetriebe } \\
\text { (Weizen) }\end{array}$ & $1,4-2,2$ & $2,1-3,4$ \\
\hline Apfelproduktion & $0,9-3,0$ & $0,9-3,0$ \\
\hline Weinbaubetriebe & & $0,1-4,1$ \\
\hline
\end{tabular}

Quelle: Eigene Darstellung, nach Menghi et al. (2014)

verstoßen). In der EU kommt es aufgrund der Auflagen im Bereich des Umwelt-, Tier- und Verbraucherschutzes zu Steigerungen der Produktionskosten bei Schweine und Geflügel haltenden Betrieben von rund 5-10\%, bei Milchvieh, Rinder und Schafe haltenden Betrieben um 2-3\% und bei viehlosen Betrieben um 1-3,5\% (Menghi et al. 2014).

Des Weiteren ist anzuführen, dass Betriebe, die z. B. in der Vergangenheit Landschaftselemente erhalten und/oder Grünland nicht umgebrochen haben, nun von den entsprechenden Auflagen und Anlastungsrisiken betroffen sind. Dies steht im Gegensatz zur Situation von Betrieben, die sich in der Vergangenheit weniger naturund umweltschutzorientiert verhalten haben. Umgekehrt erfordert die Bereitstellung ökologischer Vorrangflächen oder die Einhaltung der Fruchtfolgeauflagen von Betrieben, die dies bereits in der Vergangenheit geleistet haben, wenige Veränderungen, während diese Auflagen für andere Betriebe mit Kosten verbunden sein könnten.

Durch die Modulation bis 2014 und die Umverteilungsprämie, welche kleinere Betriebe pro Hektar besser stellen, erhalten die Direktzahlungen eine strukturpolitische Komponente. Allerdings ist diese kaum geeignet, den Strukturwandel aufzuhalten, der hin zu weniger Betrieben führt, die sich aber stärker spezialisieren. Weiterhin kommt es zu einer räumlichen Konzentration ähnlich spezialisierter Betriebe in einzelnen Regionen (z. B. die Veredelungsbetriebe im Raum Vechta-Cloppenburg). Die regionale Spezialisierung kann wiederum Umweltprobleme mit sich bringen (z. B. hoher Anfall organischer Dünger). Mit der abnehmenden Zahl an Landwirten könnte darüber hinaus Erfahrungswissen verloren gehen. In Deutschland führt die stärkere Förderung der ersten Hektare zu einer Umverteilung der Zahlungen zwischen den Bundesländern, wobei die neuen Bundesländer 85 Mio. € verlieren, während Baden-Württemberg und Bayern 48 Mio. $€$ gewinnen (Balmann und Sahrbacher 2014). Es wird erwartet, dass die Prämie geringe Effekte hinsichtlich der Entlastung kleinerer Betriebe bewirkt, aber einen hohen administrativen Aufwand verursacht (Forstner et al. 2012).

Das Hauptziel der Direktzahlungen ist die Einkommenssicherung für Landwirtinnen und Landwirte. Die Direktzahlungen machen zwar ca. die Hälfte des betrieblichen Einkommens aus, jedoch nur ca. $10 \%$ der betrieblichen Erträge (siehe Tab. 7.7). Die Abhängigkeit der Betriebe von den Direktzahlungen wird häufig mit 
Tab. 7.7 Einkommensstabilisierende Wirkung der Direktzahlungen in Deutschland

\begin{tabular}{l|l|l}
\hline & $\begin{array}{l}\text { Anteil der Direktzahlungen am } \\
\text { landwirtschaftlichen Einkommen }(\%)\end{array}$ & $\begin{array}{l}\text { Anteil der Direktzahlungen an den } \\
\text { betrieblichen Erträgen (\%) }\end{array}$ \\
\hline $2014 / 15$ & 55,8 & 11,2 \\
\hline $2013 / 14$ & 44,4 & 10,4 \\
\hline $2012 / 13$ & 45,3 & 10,8 \\
\hline $2011 / 12$ & 54,0 & 12,3 \\
\hline
\end{tabular}

Quelle: Eigene Darstellung, nach BMELV (2013a), BMEL (2014a, 2015d)

dem hohen Anteil der Direktzahlungen am landwirtschaftlichen Einkommen begründet. Die absolute Höhe der gewährten Direktzahlungen als Anteil des landwirtschaftlichen Einkommens auszuweisen und damit die Abhängigkeit der Landwirtschaft von den Direktzahlungen zu begründen, erscheint allerdings nur gerechtfertigt, wenn die Gewährung der Direktzahlungen keine Kosten sowie „Überwälzungseffekte“ beim landwirtschaftlichen Betrieb hervorruft. Dies ist jedoch nicht der Fall. Zum einen entstehen Kosten der Bürokratie und Umsetzung der Cross-Compliance- und Greening-Auflagen, zum anderen werden die Direktzahlungen zumindest zum Teil und in Abhängigkeit von der regionalen Bodennachfrage auf den Pachtpreis überwälzt (Wissenschaftlicher Beirat für Agrarpolitik beim BMELV 2010). Eine Ausweisung der Anteile der Direktzahlungen an den betrieblichen Erträgen könnte somit besser geeignet sein, die Abhängigkeit landwirtschaftlicher Betriebe von den Direktzahlungen darzustellen. Ein Anteil der Direktzahlungen an den betrieblichen Erträgen von ca. $10 \%$ scheint mit einer Übergangsfrist durchaus kompensierbar zu sein.

Des Weiteren wird häufig angemahnt, dass einkommens- und verteilungspolitische Fragestellungen nach dem Subsidiaritätsprinzip eher auf der Ebene der Mitgliedstaaten zu regeln sind (Wissenschaftlicher Beirat für Agrarpolitik beim BMELV 2010; Forstner et al. 2012). Auch ist der sektorbezogene Zuschnitt der Direktzahlungen nicht geeignet, verteilungspolitische Ziele zu verfolgen, denn ein niedriges landwirtschaftliches Einkommen kann beispielsweise einem Haushalt mit hohem Einkommen aus anderen Quellen zufließen, so dass keine verteilungspolitisch relevante Bedürftigkeit gegeben ist.

Schließlich wird argumentiert, dass die Fortführung der Direktzahlungen notwendig ist, in Grenzertragsregionen, wie etwa den Mittelgebirgen, die Aufrechterhaltung der Landwirtschaft zu ermöglichen. Tatsächlich wären zu diesem Zweck stärker räumlich fokussierte und zielgerichtete Maßnahmen effizienter, wie sie heute z. B. durch die Ausgleichszulage in der Zweiten Säule angeboten werden (Wissenschaftlicher Beirat für Agrarpolitik beim BMELV 2010).

Auch werden die Direktzahlungen zum Teil an den vor- und nachgelagerten Bereich „,durchgereicht“. Im Ergebnis ist ,,die Einkommenstransfereffizienz der meisten Unterstützungsmaßnahmen [...]<1“ (Moreddu 2011). Eine Studie aus dem Jahr 2008 zeigt, dass in Deutschland 30-60 \% der Direktzahlungen an die Landeigentümer weitergegeben werden (Swinnen et al. 2008). Bei hohen Pachtanteilen - in Deutschland im Durchschnitt ca. $60 \%$ - verbleiben damit große Teile der Direktzahlungen nicht bei den aktiven Landwirten, sondern subventionieren den Grundbesitz (Forstner et al. 
2012). Es wird davon ausgegangen, dass bei sinkenden Direktzahlungen unter ansonsten unveränderten Rahmenbedingungen auch die Pachtpreise sinken würden (Wissenschaftlicher Beirat für Agrarpolitik beim BMELV 2010).

Zusammenfassend lässt sich demnach festhalten, dass die Direktzahlungen die mit ihnen verbundenen Zielsetzungen nicht oder nur sehr ineffizient erfüllen. Durch die Cross-Compliance- und Greening-Auflagen werden nur geringe positive Effekte auf den Natur- und Umweltschutz erzielt, während eine Einhaltung der Auflagen in allen Regionen und Betrieben aufgrund der Möglichkeit zum „Ausstieg“ nicht garantiert werden kann. Die Greening-Prämie übersteigt die mit den Greening-Auflagen verbundenen Kosten für die allermeisten Betriebe bei Weitem. Auch die Basisprämie wäre als Ausgleich für die betrieblichen Kosten höherer Auflagen gegenüber dem Weltmarkt viel zu hoch angesetzt. Damit wird deutlich, dass die Direktzahlungen vor allem einkommenspolitischen Zielen dienen. Aufgrund des sektoralen Zuschnitts und der fehlenden Bindung an Bedürftigkeitskriterien stellen die Direktzahlungen aber kein effektives und effizientes Instrument der Einkommenspolitik dar. Hinzu kommt, dass - je nach den Verhältnissen auf den regionalen Bodenmärkten - ein erheblicher Teil der Direktzahlungen auf Pacht- und Landpreise überwälzt wird, so dass die Einkommenseffekte zum Teil bei Grundbesitzern anfallen, die weder landwirtschaftlich tätig noch im ländlichen Raum ansässig sind.

\subsubsection{Vorschläge zur Neustrukturierung der Ersten Säule}

Insbesondere in Hinblick auf die mangelnde Erreichung der Ziele des Natur- und Umweltschutzes werden aktuell folgende Vorschläge zur weiteren Entwicklung der Ersten Säule der GAP diskutiert (vgl. dazu das Projekt des Instituts für Agrarökologie (Oppermann et al. 2016)und Biodiversität (ifab) sowie die Vorschläge des Institute for European Environmental (Hart et al. 2016):

- Weitere Begrünung der Ersten Säule;

- Ausbau der Zweiten Säule;

- Umbau des Systems der GAP in ein integriertes System zur Honorierung öffentlicher Leistungen.

Eine Weiterentwicklung des Greenings der Ersten Säule wird in Abschn. 8.2 eingehender dargestellt, eine Stärkung der Zweiten Säule durch Umschichtung von Geldern aus der Ersten Säule in Abschn. 8.3. An dieser Stelle wird im Folgenden auf einen Umbau des Systems der GAP eingegangen. Dabei entwickeln die folgenden Überlegungen zum Umbau der Ersten Säule in ein Instrument zur Honorierung öffentlicher Leistungen der Landwirtschaft den eingeschlagenen Weg der Gewährung von Zahlungen für die Einhaltung von Umwelt- und Naturschutzauflagen weiter und orientieren sich strikt am Prinzip ,öffentliche Gelder für öffentliche Leistungen“. Als öffentliche Leistungen wird dabei im Rahmen der neuen Ersten Säule der Ausgleich von wirtschaftlichen Nachteilen und Maßnahmen verstanden, die auf Betriebsebene im Rahmen eines „Baukastensystems“ umgesetzt werden. 
Es werden verschiedene Politik-Elemente formuliert, welche die adressierten Problemlagen jeweils gezielt ansprechen. Damit sollen die Umweltwirkungen der Landwirtschaft verbessert werden, indem gezielt die Einhaltung anspruchsvollerer Auflagen honoriert wird. Die Höhe der betrieblichen Prämien würde sich dann nach den tatsächlich erbrachten öffentlichen Leistungen richten. Dies würde auch die Motivation der Landwirte erhöhen, öffentliche Leistungen zu erbringen. Da eine einheitliche Honorierung in Form einer Flächenzahlung nicht mehr gewährt würde, ist davon auszugehen, dass Prämien nur noch in geringerem Maße auf die Pacht- und Bodenpreise überwälzt würden. Eine Einkommensverbesserung der Landwirtschaft würde dadurch erreicht, dass neben der Produktion landwirtschaftlicher Erzeugnisse die Erbringung von öffentlichen Leistungen als Einkommensquelle an Bedeutung gewinnt.

Die nachfolgenden vorgestellten Elemente des Systems grenzen sich gegenüber einer neu strukturierten Zweiten Säule (siehe Abschn. 7.4) dadurch ab, dass

- sie auf EU-Ebene oder Ebene der Mitgliedstaaten programmiert und finanziert werden;

- die Maßnahmen weitgehend unabhängig von regionalen und standörtlichen Bedingungen einen positiven Mehrwert für den Natur- und Umweltschutz erwarten lassen.

Nachfolgend wird die den Elementen zugrundeliegende Idee skizziert, Ausführungen zur detaillierten Ausgestaltung der Elemente werden an dieser Stelle nicht gemacht.

\subsubsection{Element 1: Gesetzlicher Mindeststandard zur Aufrechterhaltung der natürlichen Produktivität der Standorte}

Bisher sind in Cross Compliance verschiedene Auflagen zusammengefasst. Die GAB sind dabei als Ordnungsrecht anzusehen, dessen Einhaltung prinzipiell nicht entlohnt werden sollte. Die GLÖZ- und Greening-Auflagen können aufgrund der „Ausstiegsmöglichkeit“ als freiwillige Maßnahmen angesehen werden. Dabei sind Teile der GLÖZ- und Greening-Auflagen jedoch landbautechnisch zur dauerhaften Aufrechterhaltung der Produktivität der Standorte notwendig und sollten damit einerseits im langfristigen Eigeninteresse der Bewirtschafter liegen, andererseits aber nicht der Freiwilligkeit überlassen bleiben. Daher könnte es geboten sein, weitere verpflichtende Auflagen zu definieren, die weitgehend den heutigen GLÖZ- und Greening-Auflagen entsprechen, um auch langfristig und für zukünftige Generationen die Produktivität der Standorte zu sichern. Diese Auflagen wären von allen Landwirten einzuhalten. Zu diesen Auflagen zur Aufrechterhaltung der natürlichen Produktivität könnten insbesondere zählen:

- Erhalt von Dauergrünland;

- Maßnahmen des Erosionsschutzes entsprechend dem Erosionskataster (zur Einordnung im Erosionskataster ist zusätzlich die Hanglänge zur berücksichtigen), z. B. Erosionsschutzstreifen, Winterbegrünung;

- Maßnahmen des Humuserhalts;

- Bereitstellung wertvoller ökologischer Vorrangflächen; 
- Anspruchsvollere mehrgliedrige Fruchtfolge auf der Fläche (Flächenanteil der Hauptfrucht max. $50 \%) ;^{2}$

- Erhalt von Landschaftselementen.

\subsubsection{Element 2: Prämien zur Aufrechterhaltung der Landbewirtschaftung in Gebietskulissen zum Erhalt der Landschaftsvielfalt}

Direktzahlungen können aus Sicht des Umwelt- und Naturschutzes wichtig sein, um die Landbewirtschaftung an Standorten aufrecht zu erhalten, wo dies für eine vielfältige Landschaft und die damit verbundenen Vorteile für den Erhalt der Biodiversität und der Ökosystemleistungen notwendig ist. Um diese Ziele zu erreichen, ist es jedoch effektiver und effizienter, die entsprechenden Zahlungen auf die betroffenen Standorte zu konzentrieren.

Um die landwirtschaftliche Erzeugung auch auf Grenzertragsstandorten aufrecht zu erhalten, wo dies zur Erhaltung einer Landschaftsvielfalt wünschenswert ist, könnte daher - in Weiterentwicklung der heutigen Ausgleichszulage - eine Prämie gewährt werden, deren Höhe sich daran orientiert, welche Standortnachteile ausgeglichen werden müssen, um die Bewirtschaftung attraktiv zu machen. $\mathrm{Zu}$ den möglichen Kriterien für die Bestimmung der Prämienhöhe gehören die Vegetationsdauer (ausgedrückt in Höhe über NN oder langjährige Mittel der Länge der Vegetationsperiode), die Hangneigung, die Bodenpunkte u. a. Grundsätzlich sollten Prämien für Grenzertragsstandorte so bemessen werden, dass sie die tatsächlichen Opportunitätskosten der Bewirtschaftung widerspiegeln (Hart et al. 2016). Da die Benachteiligung anhand relativ einfacher Indikatoren gut abgebildet werden kann, könnten zukünftig die Kriterien für die Höhe einer solchen Prämie auf Ebene der EU einheitlich festgelegt werden. Allerdings sollte die Zahlung einer solchen Prämie auf zielorientierte Gebietskulissen beschränkt sein. Zudem sollte die Prämie auf der Ebene von Standorten (Schlagebene) und nicht von relativ großflächigen Regionen definiert werden, um Mitnahmeeffekte zu minimieren.

Eine Finanzierung im Rahmen der Ersten Säule wäre anzuraten. Schon heute besteht die Möglichkeit für die Mitgliedstaaten, benachteiligte Standorte durch die Erste Säule zu fördern, ${ }^{3}$ die jedoch von Deutschland nicht genutzt wird (Isermeyer et al. 2014).

Ergebnisse aus der Schweiz zeigen, dass Betriebe mit einem hohen Anteil von „Erschwernisflächen" aufgrund des hohen Arbeitsaufwandes häufig in ihrem betrieblichen

\footnotetext{
${ }^{2}$ Ein minimaler Flächenanteil von $10 \%$ und ein maximaler Flächenanteil von $50 \%$ sind für jede der drei Feldfrüchte aus Sicht der Agrobiodiversität angemessen. Die Früchte müssen sich auf jeder Fläche mit den mindestens bzw. höchsten vorgegebenen Anteilen abwechseln (Wissenschaftlicher Beirat für Biodiversität und Genetische Ressourcen beim BMELV 2011).

${ }^{3}$ Deutschland macht hiervon keinen Gebrauch. Möglich wären max. $5 \%$ der nationalen Obergrenze für die Direktzahlungen. Jedoch ist die diesbezügliche Förderung über die Erste Säule bei der Bemessung der Ausgleichszulage in der Zweiten Säule zu berücksichtigen (Isermeyer et al. 2014).
} 
Wachstum beschränkt sind (Bosshard und Häusler 2012), so dass diese Prämienkomponente auch der Förderung kleinerer (Familien-)Betriebe dient. Gleiches kann auch für die folgende Prämienkomponente gelten.

\subsubsection{Element 3: Honorierung der landschaftlichen Vielfalt}

Zu einer reformierten Ersten Säule könnte auch eine Honorierung der landschaftlichen Vielfalt gehören. Da das Vorhandensein von Strukturelementen in der Landschaft sowie kleine Schlag- bzw. Gewanngrößen im Allgemeinen mit einem erhöhten Wert für die Biodiversität einher gehen, aber häufig mit einem höheren Arbeitsaufwand und Ertragsverlusten auf den angrenzenden Flächen verbunden sind, könnte eine Prämie eingeführt werden, welche landschaftliche Vielfalt belohnt. Hierbei könnten an Landschaftselemente angrenzende Flächen, die Gewanngröße unter Berücksichtigung der integrierten Schläge, lineare Landschaftselemente, ${ }^{4}$ Puffer-, Rand- und Blühstreifen (z. B. entlang von Bächen, Wassergräben und Feldwegen), Steine und Felsen (die z. B. in Steilwiesen vorkommen) in oder angrenzend an die Fläche honoriert werden, aber auch Flächen, die durch extensive, häufig traditionelle Nutzungsverfahren (z. B. Streuobstwiesen, Terrassen) gekennzeichnet sind. Neben dem Vorhandensein landschaftlicher Strukturen könnte auch die beeinflusste landwirtschaftliche Nutzfläche, z. B. Randstreifen entlang von Hecken, in die Prämienberechnung einbezogen werden. Dabei ist es unabhängig, in wessen Besitz das beeinflussende Landschaftselement ist. Im Rahmen einer solchen Prämie würde das Vorhandensein von Strukturen der landschaftlichen Vielfalt gefördert. Deren Anlage, Pflege und ggf. Bewirtschaftung würde weiterhin im Rahmen der Zweiten Säule gefördert (ähnlich dem heutigen Verfahren zum Erhalt und zur Pflege von Landschaftselementen). Da Strukturen der landschaftlichen Vielfalt als überwiegend ungenutzte Elemente unabhängig von sonstigen standörtlichen, lokalen und regionalen Bedingungen meist einen positiven Einfluss auf die Schutzgüter, insbesondere Biodiversität und Landschaftsbild, haben, aber beispielsweise im Allgemeinen auch dem Erosions- und Hochwasserschutz dienen (Hampicke 2009; Batáry et al. 2011; Kremen und Miles 2012; Scheper et al. 2013; Vogel und Inauen 2013), könnte eine Förderung im Rahmen der Ersten Säule systematisch gerechtfertigt sein.

\subsubsection{Exkurs: Ansätze zur Honorierung der landschaftlichen Vielfalt}

Landwirte pflegen und erhalten die landschaftliche Vielfalt der Kulturlandschaft. Damit erbringen sie eine gesellschaftlich gewünschte, nicht marktgängige Leistung sowohl aus Sicht des Naturschutzes als auch durch die Schaffung von Erholungsräumen

${ }^{4}$ ÖVF - lineare und/oder dauerhafte Landschaftselemente sollten anrechenbar sein (Wissenschaftlicher Beirat für Biodiversität und Genetische Ressourcen beim BMELV 2011). 
(Plankl et al. 2010). Eine gezielte Honorierung dieser Leistung ist sinnvoll und soll im Weiteren kurz skizziert werden.

\section{Der Wert landschaftlicher Vielfalt}

Der Erhalt der biologischen Vielfalt ist im Sinne des Naturschutzes wie auch des Schutzes der Stabilität von Agrarökosystemen und den mit ihnen verbundenen Ökosystemleistungen (z. B. Bestäubung, biologische Schädlingsbekämpfung) notwendig.

Landschaftliche Vielfalt fördert den Artenreichtum in der Agrarlandschaft (Duelli und Obrist 2003; Tscharntke et al. 2005). Dies trifft vor allem für generalistische (euryöke) Arten zu (Jedicke 1994).

Die hohe Diversität in komplexen Kulturlandschaften resultiert dabei in einer großen Anzahl an Arten, die Saumbiotope an den zahlreichen Grenzlinien besiedeln, und Arten die im Laufe ihrer Entwicklung zwischen verschiedenen Habitaten wechseln (Jedicke 1994). Zum Schutz spezialisierter (stenöker) Arten werden zusätzlich zu diesem Netz kleinflächiger Strukturelemente in der Agrarlandschaft großflächige hochwertige natürliche und semi-natürliche Landschaftsstrukturen benötigt (Jedicke 1994).

\section{Herausforderungen für die Landwirtschaft}

Die Bewirtschaftung von Agrarflächen in vielfältigen Landschaften mit einer hohen Anzahl an Grenzlinien (aufgrund kleiner Schlaggrößen und/oder einer hohen Anzahl angrenzender wie auch in den Schlägen enthaltener Landschaftselemente) bedeutet für die Landwirte einen erhöhten Bewirtschaftungsaufwand. Diese für den Landwirt nachteilige, aber aus gesellschaftlicher Sicht positive Mehrleistung sollte für die Landwirte honoriert werden (Abb. 7.1).

\section{Indikatoren für landwirtschaftlich erbrachte Leistungen zur Förderung landschaftlicher Vielfalt}

Folgende Parameter sind für eine Bewertung der von den Landwirten im Rahmen ihrer landwirtschaftlichen Tätigkeit erbrachten Mehrleistung sinnvoll und sollten bei einer Honorierung berücksichtigt werden:

- Schlaggröße

- Einschränkungen durch die Schlagform;

- Einschränkungen durch identische Kulturen auf benachbarten Schlägen.

Abb. 7.1 Artenreichtum von Ackerwildkräutern in Abhängigkeit von der Landschaftsstruktur. (Quelle: Eigene Darstellung nach Tscharntke et al. 2005)

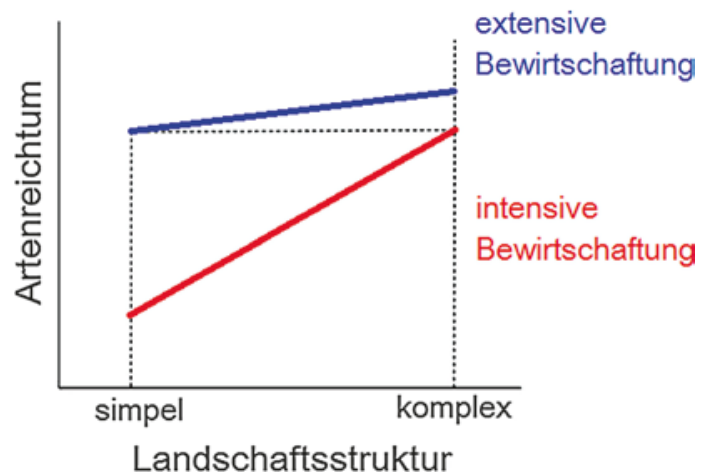


- Grenzlinien zu Landschaftselementen (innerhalb des Schlags und angrenzend an den Schlag)

- Größe und Wertigkeit der Landschaftselemente.

Schlaggröße: Ein Mosaik kleiner Schläge weist deutlich mehr Grenzlinien mit Saumbiotopen auf als wenige große Schläge. Als ökologisch sinnvoll werden von den meisten Autoren maximale Schlaggrößen im Bereich von 5 bis 12 ha, in Regionen mit großflächigen naturbetonten Zwischenflächen von 20 bis 25 ha genannt (Haber 1998; Bosch und Partner GmbH 2000; Christen et al. 2009; Ring 2013). Aus landwirtschaftlicher Sicht steigt der relative Arbeitsaufwand pro ha mit abnehmender Schlaggröße im Bereich von ca. 5 bis 1 ha besonders stark an (Engelhardt 2004).

Abb. 7.2 skizziert eine mögliche Honorierung in Abhängigkeit von der Schlaggröße.

Einschränkung durch die Schlagform: Die Schlagform in Abhängigkeit von der Schlaggröße definiert die Abstände von Saumbiotopen bzw. von Landschaftselementen (soweit diese vorhanden sind). Geringe Abstände von Saumbiotop zu Saumbiotop bzw. zu Landschaftselement sind aus ökologischer Sicht wünschenswert. Randstrukturen haben auf einer Distanz von 20 m einen deutlichen Effekt in benachbarte Agrarflächen hinein und die Angaben zu Maximalabständen zwischen zwei Saumbiotopen bzw. Landschaftselementen liegen zwischen 50 und $250 \mathrm{~m}$ (Kaule 1991; Bosch und Partner GmbH 2000; Nentwig 2000). Diese Forderung beeinflusst die Honorierungswürdigkeit vor allem von größeren Schlägen. Ein 20 ha großer Schlag hat in Form eines Quadrates mit einem Rand-zu-Rand-Abstand von $447 \mathrm{~m}$ und trägt damit über seine Schlagform nicht positiv zum ökologischen Wert der Landschaft bei. Geht man von einem wünschenswerten Mindestabstand von z. B. $100 \mathrm{~m}$ zwischen 2 gegenüberliegenden Schlaggrenzen aus, so kann für die verschiedenen Schlaggrößen (unter der vereinfachenden Annahme, dass jeder Schlag

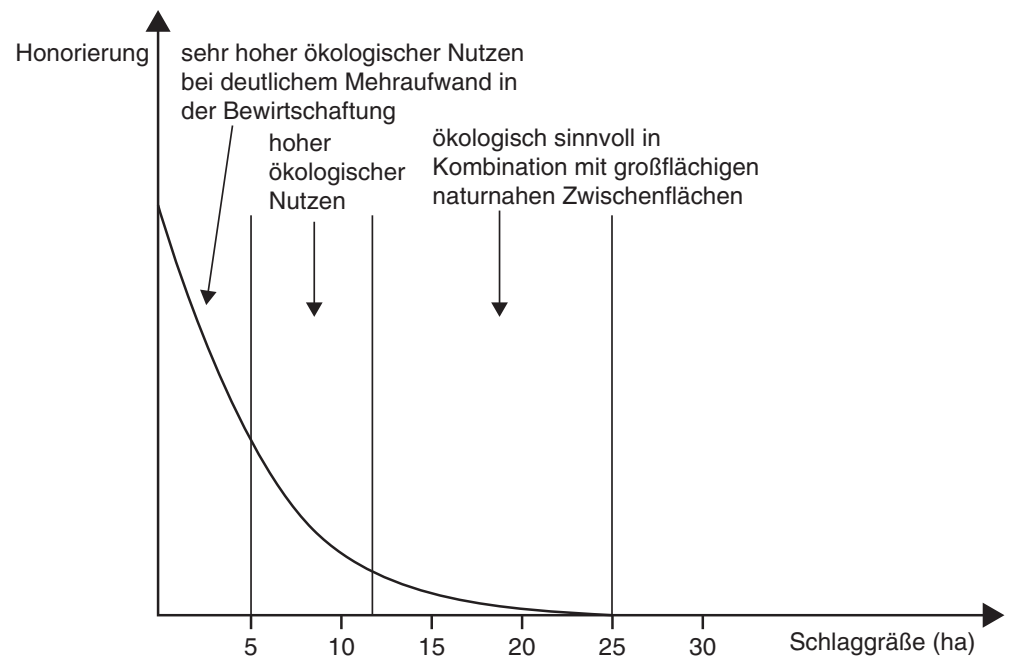

Abb. 7.2 Honorierung von Landschaftsvielfalt in Abhängigkeit von der Schlaggröße. (Quelle: Eigene Darstellung nach Engelhardt 2004) 
als Rechteck betrachtet wird) der minimale Umfang berechnet werden, bei dem der wünschenswerte Mindestabstand zwischen 2 gegenüberliegenden Schlaggrenzen noch eingehalten wird. Nur Schläge mit diesem oder einem höheren Schlagumfang sind demnach für ihre geringe Schlaggröße honorierungswürdig (Abb. 7.3). Bei Schlägen unter 1 ha ist diese Bedingung für alle Schlagformen erfüllt. Schläge mit einer Dreiecksform oder andere Vielecke werden bei dieser Methode geringfügig benachteiligt, da bei diesen Schlagformen in Teilen der Schläge die Bedingungen des Mindestabstandes erfüllt sind, ohne dass dafür automatisch eine Honorierung erfolgt.

Einschränkung durch gleiche Kulturen auf angrenzenden Schlägen: Bei angrenzenden Schlägen mit gleicher Kultur kann eine geringe Schlaggröße keine positive Wertung erhalten, da keine Grenzlinie mit Saumbiotopen zwischen den beiden Schlägen zu erwarten ist. In einem kooperativen Ansatz können Landwirte mit ihren Bewirtschaftungsnachbarn Absprachen in der Anbauplanung treffen. Dies ist eine wichtige Voraussetzung, um langfristig eine vielfältige Fruchtfolge in der Agrarlandschaft zu sichern. Sind keine Absprachen möglich, bietet sich hier die Möglichkeit zur gezielten Anlage von Randstreifen. Unabhängig von der Schlaggröße sind daher nur Schläge honorierungswürdig, die keine (nur in geringem Umfang) angrenzenden Schläge mit identischer Ackerkultur aufweisen.

Grenzlinien zu Landschaftselementen: Landschaftselemente spielen als potenziell hochwertige Habitatinseln bzw. als Trittsteinhabitate eine entscheidende Rolle beim Artenschutz in der Agrarlandschaft (Jedicke 1994; Haber 1998). Die Bewirtschaftung entlang der Grenzlinien zu Landschaftselementen sind aus landwirtschaftlicher Sicht teilweise mit einem deutlichen Mehraufwand verbunden (u. a. kein Befahren möglich, schlechte Wendemöglichkeiten). Neben den an die Schläge angrenzenden Landschaftselementen fallen dabei auch die in den Schlägen

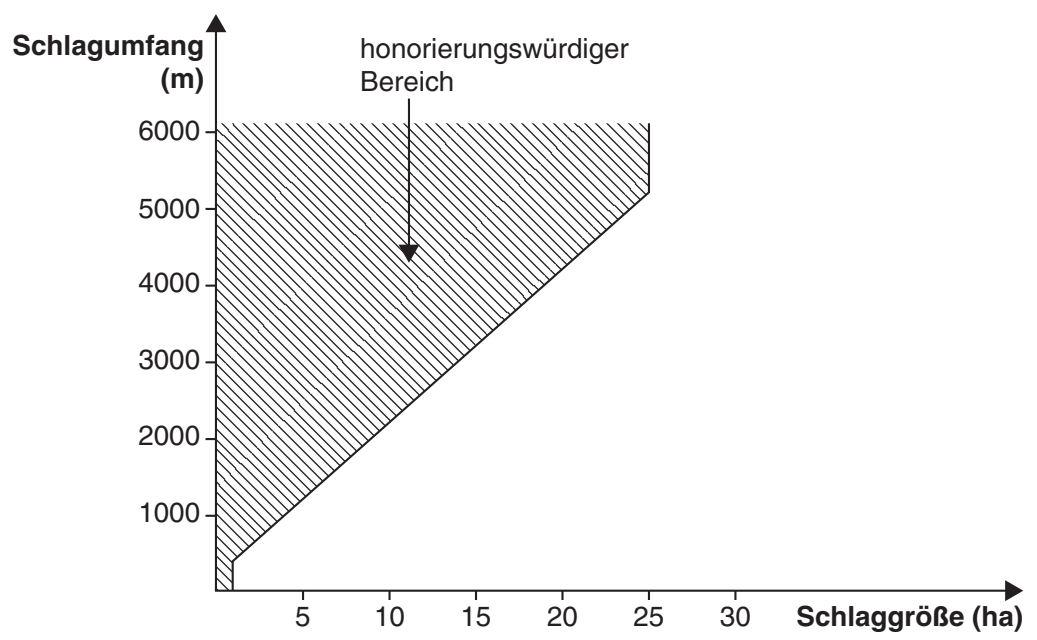

Abb. 7.3 Beispiel für honorierungswürdige Schlagformen, dargestellt am Schlagumfang in Abhängigkeit von der Schlaggröße. (Quelle: Eigene Darstellung) 
enthaltenen Landschaftselemente ins Gewicht, denen eine besondere Bedeutung als Trittsteinbiotope, besonders in größeren Schlägen zukommt (Bosch und Partner GmbH 2000). Abb. 7.4 skizziert eine mögliche Honorierung der Bewirtschaftung entlang von Grenzlinien zu Landschaftselementen.

Größe und Wertigkeit der Landschaftselemente: Je nach Größe und Wertigkeit der Landschaftselemente steigt auch ihr ökologischer Nutzen. Der Anreiz zum Erhalt besonders hochwertiger Landschaftselemente sollte daher auch höher angesetzt sein als bei weniger wertigen Landschaftselementen. Der High-Nature-Value (HNV) Indikator zur Bewertung der Umweltsituation in der Agrarlandschaft bietet ein System, Landschaftselemente in drei Wertigkeitsstufen einzuordnen (Bundesamt für Naturschutz 2016a). Diese Wertigkeit kann in die Honorierung der Bewirtschaftung entlang von Grenzlinien zu Landschaftselementen über die Einführung eines Faktors $\mathrm{X}$ berücksichtigt werden, z. B.:

- Honorierung $=$ Grenzlinienbezogene Honorierung $* \mathrm{X}$

\subsubsection{Exkurs: Praktikabilität einer GIS-gestïtzten Honorierung von Landschaftsvielfalt}

Die Vielgestaltigkeit der Landschaft und damit die entsprechende Prämie könnten anhand von GIS-Daten berechnet werden. Eine solche Berechnung wurde im Rahmen eines Werkvertrags von Herrn Dr. Machl, Weihenstephan, beispielhaft für drei bayerische Regionen durchgeführt. Die Regionen sind folgendermaßen charakterisiert:

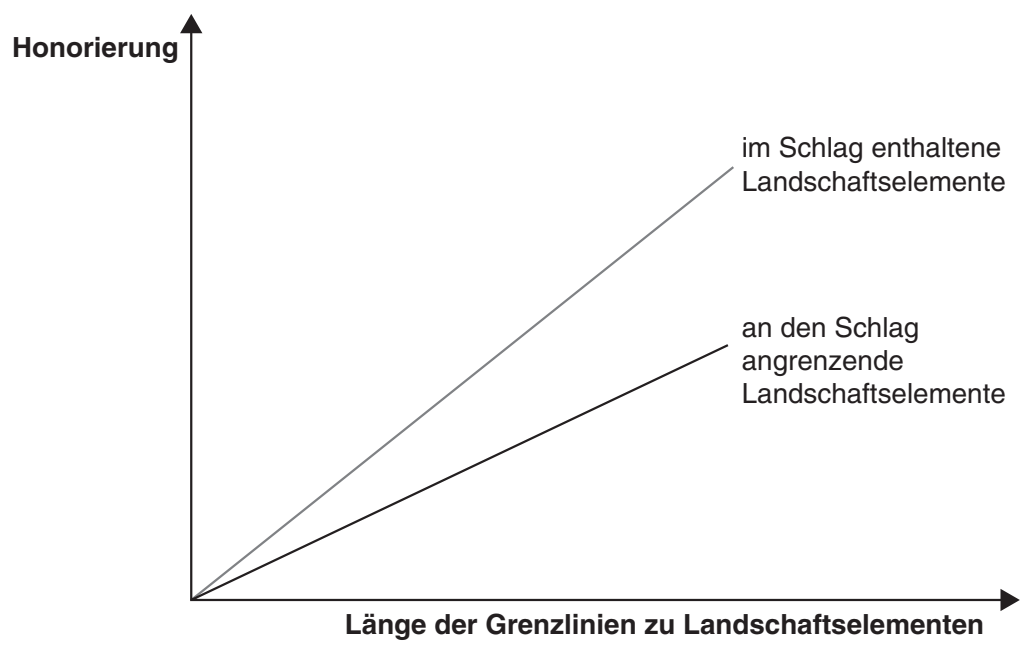

Abb. 7.4 Honorierung der Landschaftsvielfalt in Abhängigkeit von der Länge der Grenzlinien eines Schlages zu Landschaftselementen. (Quelle: Eigene Darstellung) 
- Testregion 1: Kleinstrukturierte Region mit zahlreichen Landschaftselementen und umgebenden Wäldern;

- Testregion 2: Region mit großen landwirtschaftlichen Parzellen und wenigen Landschaftselementen und Wäldern;

- Testregion 3: Strukturreiche Grünlandregion mit eher unförmigen Parzellen.

Für die Analyse wurde der Datensatz „Tatsächliche Nutzung“verwendet, der detaillierte Angaben zu verschiedenen Nutzungen der Erdoberfläche (Hecken, Gewässer, Wälder, Landwirtschaft etc.) enthält. Für die Berechnung der Kennzahlen wurde folgendermaßen vorgegangen: Zunächst wurden den Flächen der Klasse „Landwirtschaft" die angrenzenden Nachbarn zugeordnet. Als angrenzend galten dabei sowohl die unmittelbar benachbarten Flächen als auch Flächen in einer Distanz von bis zu $3 \mathrm{~m}$. Ausgehend von der Grenzlinie des betreffenden Polygons wurde dann ein $20 \mathrm{~m}$ Puffer nach innen erzeugt und die dadurch entstandenen Polygone nach Typ der angrenzenden Fläche aggregiert. Als mögliche Säume für Saumflächen kamen dabei folgende Typen in Frage: „Stehendes Gewässer“, „Fließgewässer“, „Wald“, „Gehölz“, „Moor“ und „Unland bzw. vegetationslose Fläche“. „Unland bzw. vegetationslose Fläche“" gilt dabei erst ab einer Mindestbreite von $3 \mathrm{~m}$ als „wirklicher“ Nachbar bzw. als „Kandidat“ für ein Saumbiotop. Für jede einzelne Parzelle wurde die Summe der potenziellen Saumbiotopfläche sowohl in absoluter wie auch in relativer Fläche (bezogen auf die Gesamtfläche) angegeben. Die Summe über die verschiedenen Kategorien konnte dabei die Gesamtfläche einer Parzelle übersteigen. Das konnte z. B. dann der Fall sein, wenn eine sehr kleine landwirtschaftliche Parzelle von einem Entwässerungsgraben umgeben ist und sich zwischen der Parzelle und dem Graben ein Gehölzstreifen befindet. In diesem Fall ist die betreffende Parzelle einerseits sowohl vollständig ein Saumbiotop zu Gewässer als auch ein Saumbiotop zu Gehölz. Die folgenden Abbildungen zeigen den Anteil der Saumbiotope in den Testregionen (Abb. 7.5, 7.6 und 7.7).

Die drei Abbildungen zeigen jeweils einen gleich großen Ausschnitt der Agrarlandschaft. Die strukturellen Unterschiede lassen sich in den Abbildungen deutlich erkennen.

Der genutzte Datensatz „Tatsächliche Nutzung“ erlaubt jedoch nicht (immer), einzelne Feldstücke oder Schläge zu identifizieren, da angrenzende Flächen gleicher Nutzung zu einem Polygon zusammengefasst werden. Es liegen allerdings bereits seitens der Mitgliedstaaten der EU bzw. auf Ebene der Bundesländer schärfere Flächeninformationen vor. Auch sind im genutzten Datensatz die Strukturelemente nicht vollständig erfasst. Dies ist besonders deutlich in der Abb. 8.1 zu Testgebiet 3 ersichtlich. Auch hier liegen den Behörden jedoch wahrscheinlich deutlich bessere Daten bereits vor. Nicht berücksichtigt wurden in der beispielhaften Berechnung der Daten für die drei Testgebiete jene Landschaftselemente, die innerhalb der bewirtschafteten Flächen liegen.

Anhand der dargestellten Beispiele der Testregionen zeigt sich, dass bereits Daten vorliegen, mit denen der Strukturreichtum von Regionen und die Zuordnung zu einzelnen landwirtschaftlichen Parzellen erfolgen kann. Mit einer zu entwickelnden Formel könnten die genannten Strukturen und beeinflussten landwirtschaftlich 


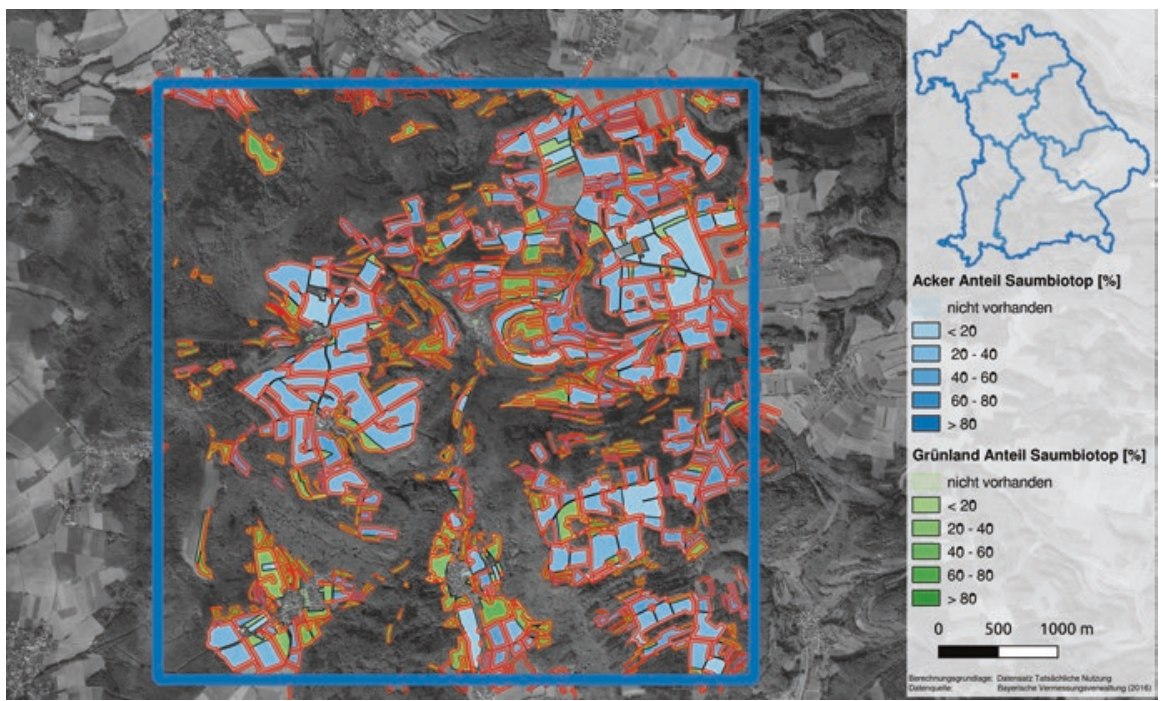

Abb. 7.5 Anteil Saumbiotope, Testregion 1. (Quelle: Orthophoto: geoservices.bayern.de; Lizenz: creativecommons.org/licenses/by/3.0/deed.de), (Analyse und Visualisierung: Thomas Machl (vgl. Machl 2016))

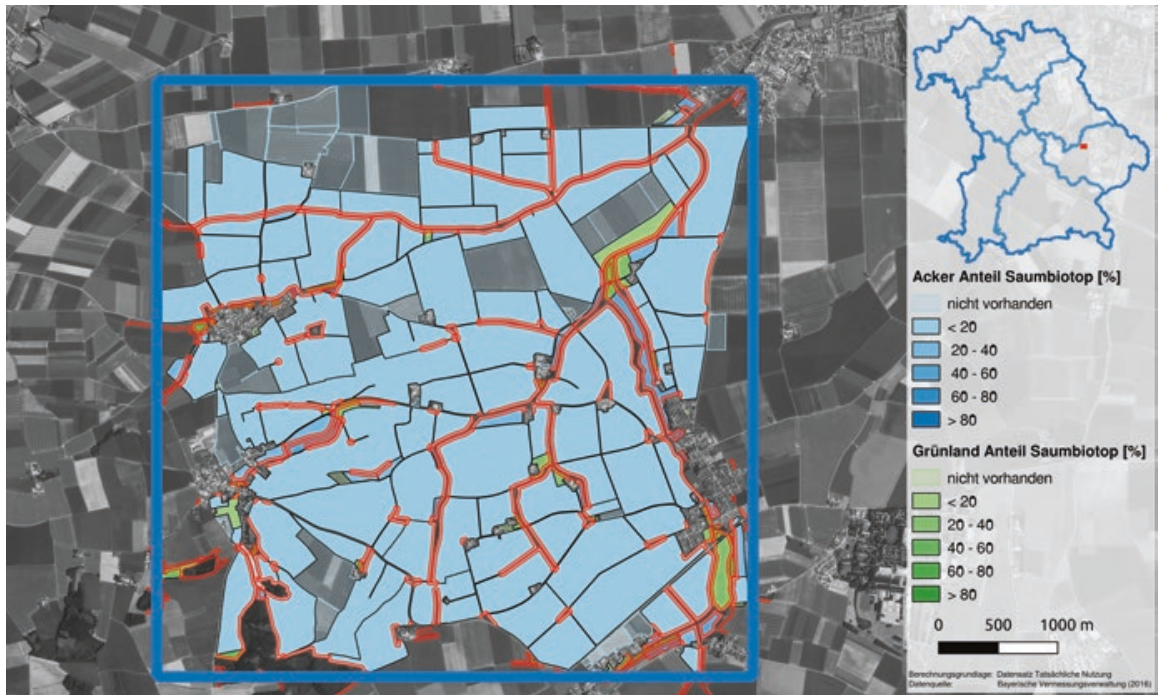

Abb. 7.6 Anteil Saumbiotope, Testregion 2. (Quelle: Orthophoto: geoservices.bayern.de; Lizenz: creativecommons.org/licenses/by/3.0/deed.de), (Analyse und Visualisierung: Thomas Machl (vgl. Machl 2016)) 


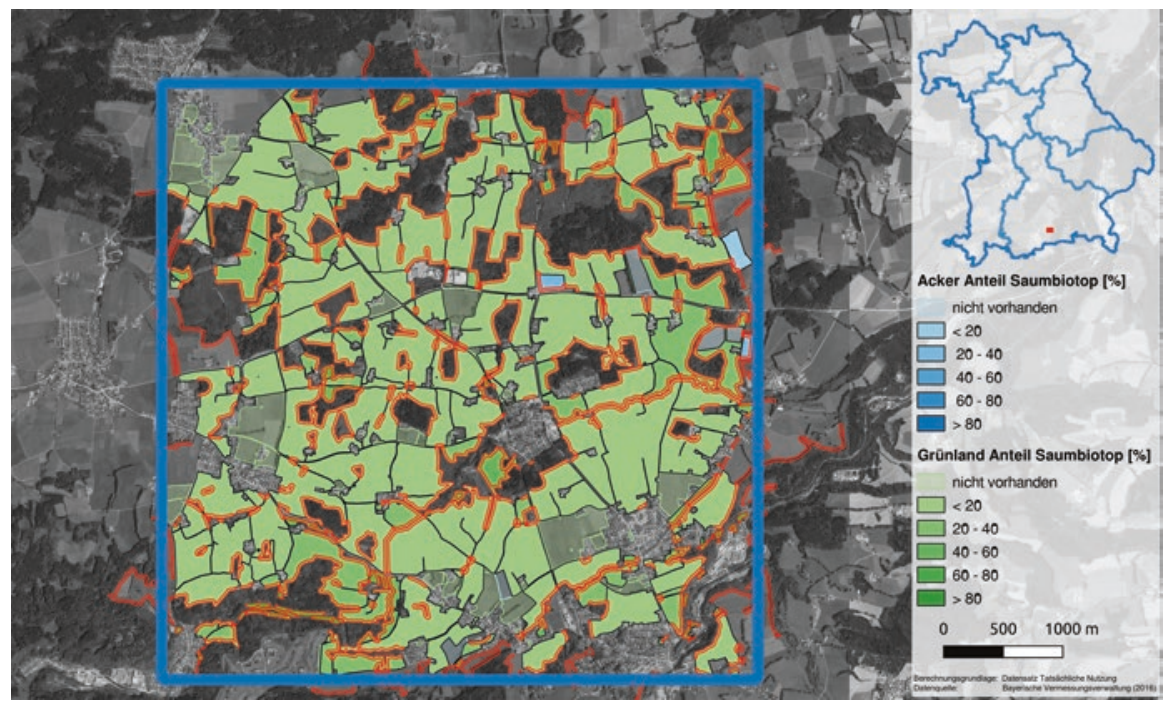

Abb. 7.7 Anteil Saumbiotope, Testregion 3. (Quelle: Orthophoto: geoservices.bayern.de; Lizenz: creativecommons.org/licenses/by/3.0/deed.de), (Analyse und Visualisierung: Thomas Machl (vgl. Machl 2016))

genutzten Flächen berücksichtigt werden und eine individuelle flächenbezogene Berechnung der Prämienhöhe erfolgen. Die Zuweisung der Prämien erfolgt automatisch mit Antragsstellung für die entsprechenden Flächen. Für Landschaftselemente in der Agrarlandschaft besteht ein Beseitigungsverbot (siehe Element 1). Mit zunehmend präziseren Datensätzen werden zukünftig weitere Aspekte sowie auch die ökologische Wertigkeit der Landschaftsstrukturen honoriert werden können. Mit präziseren Datensätzen könnten zukünftig weitere Aspekte sowie auch die ökologische Wertigkeit von Landschaftsstrukturen bei der Berechnung der Prämienhöhe berücksichtigt werden. ${ }^{5}$

\subsubsection{Element 4: Honorierung besonderer Leistungen im landwirtschaftlichen Natur- und Umweltmanagement}

Als viertes Element einer neuen Prämienstruktur könnte ein Punkte- bzw. „Baukastensystem" zur ökologischen Leistungserbringung auf Ebene der landwirtschaftlichen Betriebe (oder Kooperationen) eingeführt werden. Dort könnten Maßnahmen

\footnotetext{
${ }^{5}$ „Nachvollziehbare und mit quantitativen Daten hinterlegte Erfassung von Grünlandlebensräumen als Grundlage für effektives Monitoring und angepasstes Management“, nicht nur zur Kontrolle, sondern auch für die Beratung und ergebnisorientierte Anpassung bisheriger Managementpraktiken (NABU 2012).
} 
honoriert werden, die in allen Regionen, auf jedem Standort und in jedem Betrieb positive Umwelt- und Naturschutzeffekte erwarten lassen. Die in Tab. 7.8 aufgeführten Maßnahmen lassen positive Effekte auf die Bereitstellung von Ökosystemleistungen und die Umweltressourcen unabhängig von der räumlichen Allokation erwarten und könnten daher flächendeckend gefördert werden. Ziele der aufgelisteten Maßnahmen sind dabei die Verminderung negativer Einträge aus der Landwirtschaft, eine erhöhte Diversität der Feldfrüchte, die Gewährleistung einer natürlichen Nährstoffversorgung, der Schutz natürlicher Prozesse des Bodens sowie die Förderung und Extensivierung der Grünlandnutzung. Ansätze in dieser Richtung wurden auch vom DVL (Neumann 2016) und der Land Use Policy Group (Hart et al. 2016) vorgeschlagen.

Die Liste in Tab. 7.8 stellt eine Auswahl an möglichen Maßnahmen dar, erhebt jedoch keinen Anspruch auf Vollständigkeit. Ebenso können an dieser Stelle nicht die Zielwerte für die einzelnen Maßnahmen diskutiert werden. Innerhalb des Ansatzes besteht die Möglichkeit, verschiedene Untergruppen an Maßnahmen zu bilden, z. B. entsprechend der verschiedenen Schutzgüter.

Basierend auf einer solchen Liste könnten die Landwirtinnen und Landwirte selbst aus dem „Baukasten“ auswählen, welche Maßnahmen sie erbringen wollen. Es werden demnach nicht alle Maßnahmen von allen Landwirten in allen Regionen erwartet, sondern eine sinnvolle Auswahl. Die Leistungen (Maßnahmen auf Betriebsebene) werden in eine Punktzahl umgerechnet, die Honorierung ergibt sich aus der Formel Punkte*Punktwert (€)*ha. Ähnliche Ansätze werden beispielsweise bereits in der Schweiz (Birrer et al. 2014, 2015) und in Niederösterreich (Ökopunktemodell: Umsetzung der Zweiten Säule in Niederösterreich) umgesetzt und innerhalb von Pilotprojekten in Nord- und Ost-Deutschland erprobt (Neumann und Dierking 2014; Gottwald und Stein-Bachinger 2015). Während im Ökopunktemodell Niederösterreichs eine Mindestpunktzahl zu erreichen ist, sind im Schweizer Ansatz Maßnahmen aus verschiedenen Untergruppen zu wählen, so dass ein Nutzen für verschiedene Naturgüter erbracht wird. Um eine Entlastung beim Verwaltungsaufwand zu erreichen, könnte das System anstelle einer jährlichen eine mehrjährige Antragstellung vorsehen. Des Weiteren sollten die Maßnahmen in der Liste eine relativ einfache Dokumentation und Kontrolle ermöglichen. Das bedeutet, dass sie im Allgemeinen anhand von GIS-gestützten Fernerkundungsdaten, der Nutzung der InVeKoS- und HIT-Datenbank sowie amtlichen Dokumente und Zertifikaten nachgewiesen werden können.

\subsubsection{Diskussion}

Die folgende Tab. 7.9 gibt einen Überblick über das hier skizzierte mögliche neue Prämiensystem.

Systematik und Verhältnis zur Zwei-Säulen-Struktur: Das hier dargestellte System folgt dem Grundsatz „Öffentliches Geld für öffentliche Güter“. Alle Zahlungen 
Tab. 7.8 „Baukasten“ zur Honorierung von Basisleistungen im landwirtschaftlichen Natur- und Umweltmanagement

\section{Maßnahmen auf Schlagebene:}

- Zwischenfruchtanbau;

- Gemenge/Polykulturen/Mischkulturen;

- Verzicht auf chemisch-synthetischen Dünger, Pflanzenschutzmittel bzw. Wachstumsregulatoren;

- Verzicht oder Einschränkung von Managementmaßnahmen (Striegeln, Pflügen, Walzen, Schleppen etc.);

- Anbau alter Nutzpflanzenarten;

- Brache (auf Acker mit Selbstbegrünung).

Maßnahmen auf Betriebsebene:

- Fruchtfolge ab 4 Fruchtfolgeglieder;

- Bereitstellung wertvoller ökologischer Vorrangfläche;

- GV-Besatz (<2,0 GV/ha) (Kooperationen auf Regionsebene evtl. ermöglichen)a , bei einem Mindestviehbesatz von $0,3 \mathrm{GV} / \mathrm{ha}$;

- Einsatz von Festmist, Kompost und Gründüngung Dauergrünland/Ackergras/Kleegras pro Raufutter-GV (Ziel: hoher Grundfutteranteil) ${ }^{\mathrm{b}}$;

- Umsetzung von Tierschutzmaßnahmen (z. B. Tierbesatz/Stallfläche);

- Erhaltung der genetischen Vielfalt (z. B. seltene Nutztierrassen);

- Amtl. Nachweise der Teilnahme an hochwertigen Fortbildungsmaßnahmen (z. B. Tierschutz, Biodiversitätsschutz);

- Amtl. Nachweis erhöhter Stickstoffnutzungseffizienz (Ertrag/Düngung);

- Amtl. Nachweis eines geringen Arzneimitteleinsatz;

- Amtl. Nachweis reduzierter Ammoniak-Emissionen (z. B. entsprechende Stall- und Ausbringtechnik);

- Amtl. Nachweis entsprechender Betreuungs-Indices pro Tier (und Fläche);

- Whole-Farm-Ansätze (z. B. ökologischer Landbau), Nachweis von Zertifikaten (z. B. nachhaltige Landwirtschaft (Bereich Ökologie) der DLG usw.).

${ }^{a}$ Die Flächenintensität der Tierhaltung sollte bereits innerhalb des Greenings berücksichtigt werden (Wissenschaftlicher Beirat für Biodiversität und Genetische Ressourcen beim BMELV 2011) ${ }^{\mathrm{b}}$ Graslandbasierte Milch- und Fleischproduktion ist in der Schweiz als Maßnahme definiert

sind nachweisbar an die Erbringung von öffentlichen Leistungen geknüpft. Ein solches System kombiniert Elemente aus dem Ordnungsrecht (Element 1a), der Ersten Säule (Element 1b) sowie Instrumente, die dem ähneln, was derzeit in der Zweiten Säule angeboten wird (Elemente 2, 3 und 4). Der Ansatz löst sich daher von der derzeitigen Zwei-Säulen-Struktur. Die Verwirklichung eines solches Ansatzes wäre wahrscheinlich auch im Rahmen der Zwei-Säulen-Struktur möglich, würde dann aber vermutlich eine bessere Ausstattung der Zweiten Säule erfordern (siehe dazu auch Abschn. 7.2 und 7.4).

Programmierung: Bei der Frage einer EU-weiten oder nationalen Programmierung wäre eine durchgehende EU-weite Programmierung aller vier Elemente vorstellbar. Dies ist jedoch nicht zwingend und unterscheidet sich zwischen den Elementen:

- Element 1 betrifft den Rechtsrahmen des Binnenmarkts sowie eine Basiskompensation. Die Ausgestaltung sollte daher EU-einheitlich geregelt sein.

- Bei Element 2 ist es sinnvoll, die Bestimmung der Gebietskulissen, der prämienberechtigten Schläge und der notwendigen Prämienhöhe den Mitgliedstaaten 


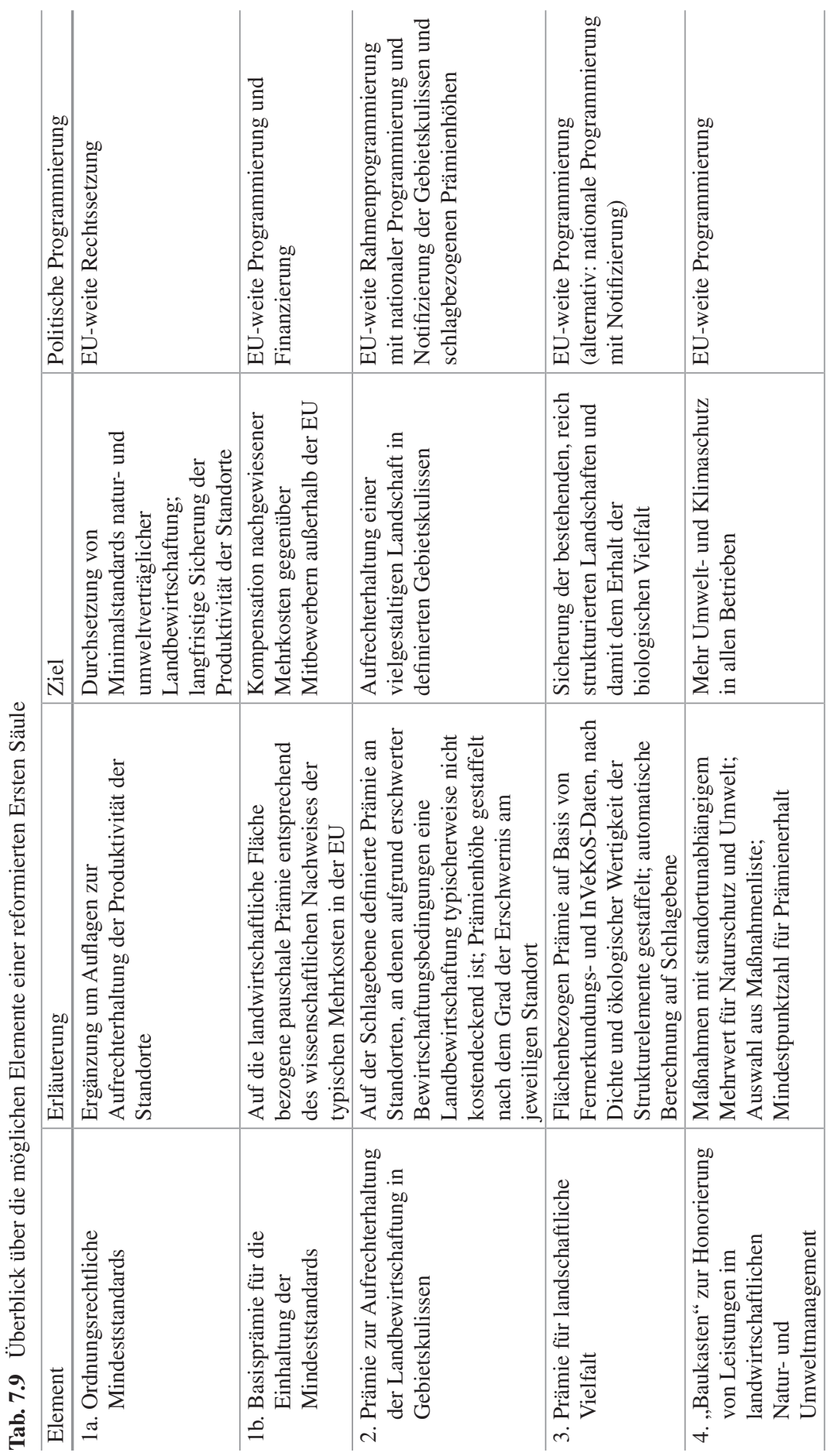


(bzw. in Deutschland den Bundesländern) im Rahmen klarer Rahmenvorgaben zu überlassen. Die Programmierung sollte dann bei der EU-Kommission notifiziert und von dieser genehmigt werden.

- Bei Element 3 könnte die Programmierung sowohl auf der EU- wie der nationalen Ebene erfolgen. Die wesentlichen Variablen sind dabei die Bestimmung des Bewertungsalgorithmus und des monetären Multiplikators. Letzterer könnte variabel gestaltet werden, so dass ein vorgegebenes Budget eingehalten wird. Bei Programmierung auf nationaler Ebene wäre wiederum ein Notifizierungsverfahren bei der EU-Kommission vorzusehen. Eine nationale Programmierung wäre möglicherweise weniger komplex, würde aber nicht die Notwendigkeit einer wissenschaftlich basierten Bestimmung der EU-weiten Rahmenregelung aufheben.

- Bei Element 4 sieht das Modell eine EU-weite Programmierung vor. Es handelt sich hier in gewisser Weise um ein weiterentwickeltes Greening.

Finanzierung: Die Finanzierung der Elemente 1 und 4 wäre im Anschluss an die bisherige Finanzierungssystematik in der GAP zu $100 \%$ bei der EU anzusiedeln (Kompensation für EU-weite gehobene Standards und weiterentwickeltes Greening). Bei den Elementen 2 und 3 wäre zu argumentieren, in welchem Verhältnis hier der europäische und der nationale Nutzen stehen. In der verteilungspolitischen Diskussion zwischen den Mitgliedstaaten würde sicherlich eine Rolle spielen, dass der Anteil der Flächen, die unter die Anforderungen des Elements 2 (Prämie zur Aufrechterhaltung der Landbewirtschaftung in Gebietskulissen) fallen, zwischen den Mitgliedstaaten stark variieren dürfte. In ähnlicher Weise werden sich die Anteile der landschaftlichen Flächen, die eher hohe oder eher niedrige Zahlungen aus einer Prämie für landschaftliche Vielfalt (Element 3) erwarten könnten, zwischen den Mitgliedstaaten unterscheiden. Ob die mit den Elementen 2 und 3 gewollte Umverteilung hin zu Flächen mit relativ hohem Wert für die landschaftliche Vielfalt eher auf europäischer oder nationaler Ebene organisiert werden sollte, würde einer weiteren Diskussion bedürfen. Generell hätte eine Vollfinanzierung aus EU-Mitteln den Vorteil, dass Natur- und Umweltschutz nicht „,nach Kassenlage“ der einzelnen Mitgliedstaaten und Regionen erfolgen würde.

Mögliche Ergänzungen: Das in diesem Abschnitt vorgestellte System würde eine betriebsgrößenabhängige Förderungskomponente zunächst nicht vorsehen. Eine höhere Förderung kleiner Betriebe könnte jedoch aufgrund der geringeren Möglichkeit, Skaleneffekte zu realisieren, gerechtfertigt sein. So wird in ,der EU-VO 1307/2013 [...] die größenabhängige Ausgestaltung der Direktzahlungen mit Effektivitäts- und Verteilungsaspekten vor dem Hintergrund des Ziels der Einkommensstützung begründet" (Isermeyer et al. 2014). In dem hier vorgeschlagenen System könnte eine strukturpolitische Komponente - ähnlich wie in der derzeitigen Basisprämie - mit dem Element 1 verknüpft werden. Allerdings ist dabei zu bedenken, dass ein kleiner Betrieb nicht notwendig mit einer einkommenspolitischen Bedürftigkeit der Betriebsinhaber einhergeht. Auf die begrenzte Eignung sektorspezifischer Instrumente, wie den Direktzahlungen als einkommenspolitisches Instrument, ist an anderer Stelle hingewiesen worden (Wissenschaftlicher 
Beirat für Agrarpolitik beim BMELV 2010) mit der Schlussfolgerung, dass, um abrupte Übergänge zu vermeiden, Maßnahmen zur Einkommenssicherung ,nur noch in Form zeitlich begrenzter, sozial begründeter Maßnahmen Bestandteil einer zukünftigen Agrarpolitik sein“"sollten (Bosshard et al. 2010). Alternative Ansätze zur Verfolgung einkommenspolitischer Ziele im Agrarbereich werden diskutiert. Anders als die Direktzahlungen setzen etwa Überlegungen zu einem „Sicherheitsnetz“ am Problem der Preisschwankungen an. Dieses Konzept findet in naturschutz- und umweltpolitischen Konzeptionen durchaus Widerhall (Hart et al. 2016). Ähnliche Überlegungen zu Preis-Ausgleichszahlungen wurden vom Kasseler Institut für ländliche Entwicklung e.V. vorgelegt (Thomas et al. 2016). Eine offene Frage ist dabei, ob nicht im Endeffekt wieder ein Mindestpreis für Erzeuger eingeführt würde, der produktionsstimulierend wirken und damit auch negative Auswirkungen auf die Ziele des Natur- und Umweltschutzes haben könnte.

Das in diesem Abschnitt vorgestellte System dient dem Zweck, ein EU-weites System von Mindeststandards und Mindestleistungen für den Natur-, Umwelt- und Verbraucherschutz sowie das Tierwohl zu etablieren und den landwirtschaftlichen Betrieben die daraus entstehenden Mehrkosten zu kompensieren. Die Verwirklichung eines solchen Ansatzes würde dem Prinzip einer ergebnisorientierten Politik entsprechen. De facto würden durch die Einführung eines solchen Systems die Gemeinwohlleistungen der Landwirtschaft zu einer neuen Einkommensquelle neben der Produktion führen. Die Höhe der entsprechenden Zahlungen sollte dabei auf transparenten Berechnungen beruhen und einen effizienten Mitteleinsatz unter Vermeidung von systematischen Überkompensationen und Mitnahmeeffekten ermöglichen.

Ein solches EU-weites System würde weiterhin der Flankierung durch regionale und standörtliche Programme zum Agrarumwelt- und Klimaschutz bedürfen. Dieses diskutieren wir im nächsten Abschnitt.

\subsection{Baustein 4: Regional und standörtlich ausgerichtete AUKM}

\subsubsection{Ziele von Agrarumwelt- und Klimaschutzmaßnahmen}

Dieser Abschnitt befasst sich mit den leistungsbezogenen Zahlungen der GAP im Agrarumwelt- und Klimaschutz, die derzeit im Bereich der Zweiten Säule angesiedelt sind. Gemäß dem Leitsatz ,öffentliches Geld für öffentliche Güter“ sind solche Zahlungen spätestens seit 1992 Teil der GAP und richten sich vor allem an einzelne Landwirte, die auf vertraglicher Basis und gegen Entgelt ökologische Leistungen auf ihren bewirtschafteten Flächen erbringen.

Die Agrarumwelt- und Klimaschutzmaßnahmen (AUKM) der GAP sind derzeit in die Programme zur Entwicklung des ländlichen Raums integriert, in denen mindestens 
$30 \%$ der Finanzmittel für umwelt- und klimabezogene Maßnahmen ${ }^{6}$ angesetzt werden müssen. Derzeit sehen die auf der Ebene der Mitgliedstaaten oder auf regionaler Ebene (in Deutschland: Bundesland) aufgestellten Maßnahmenkataloge sehr divers aus, sodass eine große Anzahl verschiedener Ziele verfolgt wird:?

- Erhaltung oder Verbesserung der Umweltsituation;

- Klimaschutz durch Reduzierung der Treibhausgas-Emissionen;

- Erhalt und Steigerung der biologischen Vielfalt;

- Pflege und Erhalt der Kulturlandschaft;

- Schutz der natürlichen Ressourcen, der Gewässer und des Bodens;

- Erhalt und Steigerung der genetischen Diversität.

\subsubsection{Bewertung der gegenwärtigen Ausgestaltung der Agrarumwelt- und Klimaschutzmaßnahmen}

Empirische Studien zur Wirksamkeit der AUKM in der EU können trotz des relativ hohen Finanzeinsatzes für diesen Politikbereich kein eindeutiges Bild liefern. Bezüglich der ökologischen Effektivität wurde eine Debatte im Jahre 2001 mit einem Artikel in Nature ausgelöste (Kleijn et al. 2001). Dieser bescheinigte durch eine quasi-experimentelle Analyse, dass die untersuchten AUKM nicht in der Lage waren, die Biodiversität in der beabsichtigten Art und Weise zu schützen. Seither hat sich eine Vielzahl weiterer Studien mit diesem Sachverhalt beschäftigt und kommt zu gemischten Ergebnissen: Einige Studien können einen positiven Effekt feststellen (Kleijn und Sutherland 2003; Knop et al. 2006; Batáry et al. 2011, 2015), andere nicht unmittelbar (Berendse et al. 2004; Kleijn et al. 2006; Wilson et al. 2007). Uthes und Matzdorf (2013) listen mehrere Beispiele von Programmen auf, die entgegengesetzte Effekte produziert haben. Es zeichnet sich ab, dass die Ergebnisse stark variieren, je nachdem welche und wie viele Arten über welchen Zeitraum und in welcher geografischen Ausdehnung bzw. in welchem Landschaftskontext untersucht werden (Whittingham 2007; Armsworth et al. 2012). Auch die Frage, ob AUKM in intensiven oder extensiven Regionen einen größeren Erfolg versprechen, konnte noch nicht abschließend geklärt werden (Duelli und Obrist 2003; Tscharntke et al. 2005; Batáry et al. 2011). Eine Evaluierung der ökonomischen Effizienz gestaltet sich noch schwieriger, da die tatsächlichen Kosten der Landwirtschaft für den Staat

\footnotetext{
${ }^{6}$ Umwelt- und klimabezogene Maßnahmen umfassen die folgenden Artikel der ELER-Verordnung: Art. 17 Umwelt- und klimaschutzbezogene Investitionen; Art. 21 Aufforstung und Agroforstsysteme; Art. 28 Agrarumwelt- und Klimamaßnahmen; Art. 29 Ökologischer Landbau; Art. 30 Zahlungen für Natura 2000 und WRRL; Art. 31/32 Zahlungen für benachteiligte Gebiete; Art. 34 Waldumwelt- und -klimamaßnahmen.

${ }^{7}$ Verordnung (EU) Nr. 1305/2013 des Europäischen Parlaments und des Rates vom 17. Dezember 2013 über die Förderung der ländlichen Entwicklung durch den Europäischen Landwirtschaftsfonds für die Entwicklung des ländlichen Raums (ELER) und zur Aufhebung der Verordnung (EG) Nr. 1698/2005, AB1. L 347 vom 20.12.2013, S. 487-548.
} 
nicht direkt messbar sind. Umfassende empirische Studien lassen sich daher nicht finden. Marggraf (2003) attestiert den deutschen Agrarumweltprogrammen in einer Expertenanalyse große Unterschiede in ihrer Kosteneffizienz im Vergleich zwischen den Ländern. Andere, vor allem modellgestützte Evaluationen finden hohe Mitnahmeeffekte und eine geringe Kosteneffizienz (Drechsler et al. 2007; Chabé-Ferret und Subervie 2010).

Als Ursache werden in der Literatur vier Problemkomplexe ausgemacht, die im Folgenden kurz skizziert werden:

Problemkomplex 1: Vielen Maßnahmen fehlt ein Bezug zu den eigentlichen Umweltzielen, so dass die angestrebten Ziele nicht oder nur unzureichend erreicht werden. Es können hier verschiedene Ursachen ausgemacht werden:

- Maßnahmenportfolios werden nicht evidenzbasiert programmiert und es bestehen kaum Möglichkeiten zur institutionalisierten Evaluierung der Programme (Primdahl et al. 2003; Whitfield 2006);

- Mangelnde Berücksichtigung der regionalen Charakteristika und von Effekten der Intensivierung und Extensivierung der Landnutzung;

- Wenig gezielte Wahl und Allokation von Einzelmaßnahmen zur Nutzung von Synergieeffekten (z. B. Schaffung von Nahrungs- und Nisthabitaten mit gleichzeitiger Vernetzungs- und Erosionsschutzfunktion);

- Mangel an räumlicher und zeitlicher Passgenauigkeit;

- Vage Zielsetzungen der maßnahmenorientierten AUKM (Uthes und Matzdorf 2013) und wenig Anreiz, landwirtschaftliche Praktiken langfristig zu ändern (Matzdorf und Lorenz 2010).

- Die angebotenen Maßnahmen sind starr und offerieren den Landwirten eine zu geringe Flexibilität (Mettepenningen et al. 2009). Es wird kein Anreiz zur Entfaltung von Innovationspotenzial gegeben (Hodge 2001).

Problemkomplex 2: Nahezu allen AUKM-Programmen fehlt ein Bezug zu unterschiedlichen räumlichen Skalen (sieht auch Abschn. 4.3). Es wird überwiegend die Feldebene angesprochen, selten die Betriebsebene und niemals die Landschaftsebene (Concepción et al. 2008).

Problemkomplex 3: Das angewandte Zahlungsschema wird weder der Heterogenität der Landnutzer noch den Eigenarten der jeweiligen Landschaften gerecht (Hanley et al. 2012). Der Kostenersatz beruht auf regionalen Durchschnittswerten und führt zu Unter- und Überkompensation sowie Mitnahmeeffekten (Armsworth et al. 2012). Dies hat zur Folge, dass Intensivregionen nicht hinreichend erreicht werden (Pretty et al. 2001; Uthes und Matzdorf 2013). Ferner werden Transaktionskosten bei der Berechnung der Zahlungshöhe nur unzureichend mit einbezogen (Mettepenningen et al. 2009). Auch werden Verträge teilweise nach dem Prinzip ,wer zuerst kommt, mahlt zuerst“" vergeben (Smits et al. 2008). Bei knappen Budgets führt dies zu Einbußen bei der Kosteneffizienz, da die Verträge nicht auf Basis einer Kosten-Nutzen-Berechnung vergeben werden (Armsworth et al. 2012).

Problemkomplex 4: Maßnahmenorientierte Honorierung und geringe MonitoringHäufigkeiten kreieren einen Anreiz zur Nicht-Befolgung von Managementvorgaben (Hodge 2001; Hanley et al. 2012). Häufig werden nur sehr geringe Strafen bei Missachtung der Vorgaben angesetzt. 


\subsubsection{Ziele und Struktur zukünftiger regionaler und standörtlicher AUKM}

Der im vorigen Abschnitt vorgestellte Vorschlag eines EU-weiten Systems von Zahlungen für erhöhte Mindeststandards, vielfältige Landschaften und einem „Baukasten“ von Basismaßnahmen für den Umweltschutz würde EU-weit eine Grundlage für die Sicherung der von der Landwirtschaft betroffenen Natur- und Umweltgüter etablieren. Darauf aufbauend werden Programme für gezielte Maßnahmen des regionsund standortspezifischen Natur- und Umweltschutzes benötigt. Um die Effektivität der Maßnahmen bezüglich ihrer Wirkungen auf die Umweltressourcen zu steigern, wird in der Literatur ein Management auf unterschiedlichen räumlichen und zeitlichen Skalen gefordert (van Dijk et al. 2015; Tscharntke et al. 2012; Prager 2015). Entscheidend dabei ist die Unterscheidung von Maßnahmen, welche die Bereitstellung von Ökosystemleistungen fördern und meist auf lokaler Ebene anzusetzen sind, und Maßnahmen des Arten- und Biotopschutzes, die oft eher auf Landschaftsebene ansetzen sollten (Scheper et al. 2013; Ekroos et al. 2014). Darüber hinaus sollte gezielt versucht werden, die überbetriebliche Ebene und die Landschaftsebene zu adressieren. Zu diesem Zweck werden im Folgenden drei Elemente vorgestellt.

\subsubsection{Element 1: Betriebsübergreifende, langfristige Ansätze auf der Landschaftsebene zur Steigerung der Landschaftsvielfalt und zum Schutz der natürlichen Ressourcen}

Das erste Element dient dem Schutz und der Förderung der landschaftlichen Vielfalt und dem Schutz der natürlichen Ressourcen. Im Mittelpunkt steht die gezielte Ausdehnung und Zustandsverbesserung von Strukturen in der Landschaft mit hohem Naturwert und der damit verbundenen Reduktion der negativen Auswirkungen der Landwirtschaft auf die Umwelt. In Abgrenzung von der im Abschn. 7.3.5 vorgestellten Prämie für Landschaftsvielfalt geht es hier weniger um die Erhaltung und Belohnung als vielmehr um eine Erhöhung der strukturellen Landschafts- und Habitatvielfalt.

Im Fokus stehen dabei Flächen, die halbnatürliche Vegetation tragen oder extensiv genutzt werden und auf Landschaftsebene ein zusammenhängendes Mosaik von halbnatürlichen oder angepassten Flächen bzw. Kleinstrukturen bilden. Solche Strukturen dienen Tier- und Pflanzenarten als Lebensraum und Trittsteinbiotop und lassen einen positiven Einfluss auf die Schutzgüter erwarten (Batáry et al. 2011; Kremen und Miles 2012; Scheper et al. 2013). Zur gezielten Steigerung von Landschaftsheterogenität, -komplexität und -konnektivität unter Berücksichtigung der regionalen Besonderheiten und entsprechender Maßnahmenimplementierung ist ein betriebsübergreifendes Management auf der Landschaftsebene notwendig. Mögliche Maßnahmen sind hierbei die Förderung der Anlage von linearen Landschaftselementen in und angrenzend an landwirtschaftliche Flächen (Blüh-, Randund Pufferstreifen, z. B. entlang von Bächen, Hecken und Baumreihen). 
In Kopplung mit einer Prämie für Landschaftsvielfalt, wie sie im Abschn. 7.3.5 vorgeschlagen wurde, könnte die Sicherung von Strukturelementen in der Landwirtschaft durch eine langfristige Honorierung unterstützt werden. Darüber hinaus würde ein solcher Ansatz auch zur Erreichung des im Bundesnaturschutzgesetz festgeschriebenen Ziels eines Biotopverbundes von $10 \%$ der Fläche beitragen.

Die angebotenen Maßnahmen könnten von relativ einfachen, „hellgrünen“ Maßnahmen bis hin zu komplexeren und wesentlich gezielter programmierten „dunkelgrünen“ Maßnahmen reichen. Dabei wäre abzuwägen, ob eine regionale Zahlungsdifferenzierung angebracht ist, so dass auch Landwirte in Intensivgebieten einen Anreiz erhalten, in eine vielfältige Landschaftsstruktur zu investieren. Unter dem Gesichtspunkt der Anreizwirkung könnten sowohl maßnahmen- als auch ergebnisorientierte Honorierungsansätze geeignet sein. Zusätzlich könnte ein Agglomerationsbonus eingesetzt werden, um bei Abwesenheit lokaler Koordinationsstrukturen (siehe dazu Element 3 in diesem Abschnitt) einen Anreiz zur Koordination zu geben.

\subsubsection{Element 2: Zielgerichtete Maßnahmen des Arten- und Biotopschutzes}

Eine zweite Komponente könnte dazu dienen, zielgerichtete Maßnahmen des Artenund Biotopschutzes zu honorieren, die insbesondere der Umsetzung der europäischen und nationalen Ziele der Biodiversitätserhaltung dienen. Es handelt sich hier also hauptsächlich um ,dunkelgrüne“ AUKM (Maßnahmen zur gezielten Erhaltung und Förderung der biologischen Vielfalt), die lokal oder regional programmiert werden, da ihre Effektivität je nach Landschaftskontext räumlich und zeitlich sehr stark variieren kann. Mögliche Maßnahmen können sowohl auf der Feldebene als auch auf Landschaftsebene angesiedelt sein:

- Feldebene: Förderung von Nist-, Ruhe- und Nahrungshabitaten (z. B. Blühstreifen), gezielte Erhaltungsmaßnahmen wertvoller Flächen (z. B. extensiver Ackerbau, artenreiches Grünland, Streuobst);

- Landschaftsebene: Maßnahmen zur Förderung des Biotopverbunds für Zielarten auf Landschaftsebene entsprechend Biotopvernetzungsplan (z. B. angepasste Nutzung für Wiesenbrüter, Feldhamster etc.).

Dieses Element beinhaltet ein explizites Nutzen-Targeting, da die Maßnahmen nur dort angeboten werden, wo ein positiver Nutzen sehr wahrscheinlich ist. Da ,dunkelgrüne“ Maßnahmen häufig sehr arbeitsintensiv sind und die damit verbundenen Kosten je nach Standort stark variieren können, kann eine Zahlungsdifferenzierung angezeigt sein, um eine effektive Allokation der finanziellen Mittel zu gewährleisten. Dazu können entweder regional angepasste Zahlungshöhen oder Auktionen dienen. Weiterhin kann bei Vorhandensein geeigneter und praktikabler Indikatoren eine erfolgsorientierte Honorierung die ökologische Effektivität der Programme steigern. Um Risiken auf der Seite der Landwirte zu minimieren, kann 
eine maßnahmenbasierte Grundprämie mit einer mittelfristigen Erfolgshonorierung kombiniert werden. Wie auch beim vorherigen Element könnte auch hier eine regionale Kooperation durch einen Agglomerationsbonus stimuliert oder durch kooperative Ansätze organisiert werden.

\subsubsection{Element 3: Förderung von lokalen oder regionalen Organisationsstrukturen zur gezielten Programmierung und Koordination von AUKM}

Im Zuge der verstärkten Aufmerksamkeit für Ökosystemleistungen, für die Bedeutung der Landschaftsstrukturen für die biologische Vielfalt und für die im NexusAnsatz beschriebenen Wechselwirkungen zwischen den Sektoren Land- und Forstwirtschaft, Energie und Wasser kommt einem integrierten Ressourcen- und Landschaftsmanagement zunehmende Bedeutung zu. Daher sind Mittel erforderlich, um Kooperationen zwischen der Landwirtschaft einerseits und den Akteuren des Natur- und Umweltschutzes andererseits zu stimulieren.

Kooperative Ansätze für ein integriertes regionales Ressourcen- und Landschaftsmanagement könnten nicht nur beratend die Programmierung von AUKM unterstützen, sondern auch eine verbesserte Koordination von Maßnahmen zum Gewässerschutz, Biotopverbund, ,grüne“ und „,blaue“ Infrastruktur (also ein Netzwerk natürlicher und naturnaher Flächen) usw. auf der Landschaftsebene ermöglichen. In solche Kooperationen wären landwirtschaftliche und naturschutzfachliche Sichtweisen und Interessen gleichermaßen einzubinden.

Lokale oder regionale Kooperationen könnten einen integrierten Plan zur Verbesserung beim Landschafts- und Ressourcenmanagement entwickeln und implementieren, indem sie die Expertise (z. B. lokale Artenkenntnis) und das soziale Kapital (z. B. Netzwerk der Landwirte) unterschiedlicher Akteursgruppen (z. B. Landwirtinnen und Landwirte, Agrar- und Umweltämter, Landschaftspflegeverbände, Umweltverbände, Forstwirtschaft, Jagdverbände, Wasserverbände) bündeln. Neben der Vernetzung könnten auch die Bereitstellung und Fortschreibung der notwendigen ökologischen Daten gefördert werden.

Ein wichtiges Ziel solcher lokalen oder regionalen Kooperationen sollte es sein, eine übergreifende und längerfristige Wirkungsabschätzung der Maßnahmen für die Ressourcen Boden, Wasser, Klima, Biodiversität und Landschaftsbild zu möglichen, so dass auch Trade-Offs und Synergien frühzeitig identifiziert werden.

In Zusammenarbeit mit solchen lokalen oder regionalen Kooperationen könnten unter direktem Bezug zu lokalen Umweltzielen auch Maßnahmenprioritäten in den AUKM entwickelt und lokale Zielregionen und Standorte (z. B. durch die Erstellung eines Biotopvernetzungsplans) priorisiert werden.

Ein weiterer Schritt wäre es, lokale oder regionale Kooperationen mit der Implementierung der vorgeschlagenen Maßnahmen in den jeweiligen Regionen zu betrauen. Ein solches Vorgehen könnte sich an den Erfahrungen mit den Agrarumweltkooperativen in den Niederlanden orientieren (Renting und Ploeg 2001; van Dijk et al. 2015). Die lokalen oder regionalen Kooperationen müssten dazu mit einem 
geeigneten Organisationsstatus und einem Budget ausgestattet werden. Die Mittelvergabe an die Kooperationen könnte in einem Wettbewerbsverfahren erfolgen.

Zur Umsetzung der von ihnen erarbeiteten Pläne könnten die Kooperationen dann sowohl mit Einzellandwirten als auch mit Gruppen von Landwirten oder mit anderen Akteuren Maßnahmenverträge schließen, die entweder ein maßnahmenoder ein ergebnisorientiertes Entgelt vorsehen könnten. Vertragsdetails, wie etwa die Laufzeit oder der Zahlungsmodus, können direkt innerhalb der lokalen Organisationsstruktur abgestimmt werden. Auch ist es möglich, die Gruppen von Landwirten im Rahmen eines Budgets und einer Zielvorgabe selbst über die Verteilung der Pflichten und Prämien entscheiden zu lassen, was zu einem effizienteren Einsatz der Ressourcen beitragen könnte. Allerdings sind die Traditionen der Zusammenarbeit in Gruppen unter Landwirten in Deutschland weniger ausgeprägt als in den Niederlanden, so dass möglicherweise erst Zeit und Moderationskapazität in die Etablierung einer kooperativen Kultur investiert werden müsste.

Ein solcher kooperativer Ansatz könnte eine Reihe von positiven Effekten ermöglichen (siehe auch Abschn. 4.3). Neben den naturschutzfachlichen Vorteilen einer stärker integrierten, systemischen Planung könnten die Interaktionsformen mit den Landwirten verbessert werden, indem diese nicht einer Bürokratie, sondern einem interaktiven Planungsprozess begegnen. Ein partizipatorischer Prozess der Maßnahmenprogrammierung und Implementierung schafft Gelegenheit für Lernprozesse, Vernetzung und Vertrauensbildung. Eine etablierte regionale Organisationsstruktur könnte eine Schlüsselrolle in der vertrauensvolleren Zusammenarbeit zwischen Landwirtschaft und Bevölkerung einnehmen (z. B. gegenseitige Wissensvermittlung, Abbau von Stigmatisierung, regionales Bewusstsein, Vermarktungsplattform).

\subsubsection{Diskussion}

Abschließend soll noch dargestellt werden, wie die drei hier vorgestellten Elemente die in Abschn. 7.4.2 identifizierten Problemkomplexe adressieren.

Für Problemkomplex 1, den fehlenden Bezug zu den eigentlichen Umweltzielen, wurde eine größere Anzahl an Ursachen ausgemacht. Generell gilt, dass die hier vorgestellten Handlungsansätze ein starkes Nutzen-Targeting aufweisen. Die Maßnahmen würden kleinräumig programmiert und nach Möglichkeit in kooperativer Weise geplant und ausgeführt werden. Dadurch könnten lokale und regionale Charakteristika besser adressiert und eine höhere räumliche und zeitliche Passgenauigkeit erreicht werden. Durch die kooperativen Ansätze könnte gezielt fachliche Expertise aus dem Umweltbereich einbezogen werden, so dass eine evidenzbasierte Programmierung und die gezielte Nutzung von Synergien ermöglicht werden.

Ein multiskalares Landschaftsmanagement (Problemkomplex 2) wird explizit durch alle drei beschriebenen Elemente angestrebt. Die Elemente 1 und 2 stellen Maßnahmen bereit, die über die Feldebene hinausgehen, während Element 3 versucht, eine entsprechende Kooperationsstruktur zu etablieren. Ein Agglomerationsbonus kann bei den Elementen 1 und 2 weitere Anreize für betriebsübergreifende Kooperationen setzen. 
Probleme mit Über- und Unterkompensation sowie den Transaktionskosten (Problemkomplex 3) werden zunächst einmal durch eine regionale Zahlungsdifferenzierung adressiert. Bei einigen der Maßnahmen können auch Auktionen geeignet sein, die finanziellen Mittel effizienter zu verteilen. Die Transaktionskosten verringern sich beispielsweise, wenn Landwirte in der Gruppe Verträge abschließen, die über einen längeren Zeitraum laufen.

Das Problem der bislang oft unzureichenden Anreize zur Erfüllung der Managementvorgaben (Problemkomplex 4) würde auf drei Wegen angegangen: durch eine verstärkte Nutzung von ergebnisorientierter Honorierung; durch die partizipative Einbindung der Landwirtinnen und Landwirte in die Erarbeitung von lokalen und regionalen Maßnahmenplänen, welche Selbstbindung und einen „,sense of ownership“ generieren; sowie bei Honorierung auf Gruppenebene durch Prozesse der sozialen Kontrolle, weil Verfehlungen einzelner dann auch die anderen betreffen. Fragen von Monitoring und Sanktionierung werden vertieft in Abschn. 7.6 diskutiert.

Kooperative Ansätze wurden in der deutschen Agrarpolitik bisher wenig verfolgt. Ein Problem kann daher die Etablierung der entsprechenden Organisationsstrukturen darstellen (Prager 2015). Vertrauensbildung zwischen den Landwirtinnen und Landwirten sowie anderen gesellschaftlichen Gruppen ist dabei wichtig. Der Aufwand zur Etablierung kooperativer Strukturen (Sitzungen, Anfahrt, Abstimmungen, Meinungsverschiedenheiten etc.) erfordert Kompensation der Transaktionskosten und Unterstützung durch professionelle Moderation. Dabei handelt es sich jedoch um Investitionen in die Zukunft des ländlichen Raums, da die sektorübergreifende Vernetzung und Vertrauensbildung positive Wirkungen weit über die unmittelbaren Fragen des Landschafts- und Ressourcenmanagements hinaus erwarten lässt.

\subsection{Baustein 5: Nicht-staatliche Standards und Ko-Regulierung}

Regulierung bezeichnet staatliche Interventionen zur Beeinflussung des Verhaltens von Individuen und Organisationen (Levi-Faur 2009). Eigenregulierung bezeichnet demgegenüber ein Governance-Arrangement, bei dem diejenigen, von denen die Befolgung bestimmter Regeln, Normen und Verfahren erwartet wird, diese auch selbst formulieren und vereinbaren (Führ 2003; Porter und Ronit 2006). In der internationalen Diskussion sind dafür auch die Begriffe „private Regulierung“ (Vogel 2010) und ,private governance“ (Busch 2011) gebräuchlich. Private Regulierung fungiert dabei oft komplementär zu staatlicher Regulierung und ihre Durchsetzung vollzieht sich vor dem Hintergrund des staatlich konstituierten regulatorischen Rahmens, insbesondere Ordnungs-, Privat- und Haftungsrechts (Ménard und Valceschini 2005; Porter und Ronit 2006). Mitunter beziehen sich private auch auf staatliche Regelungen. Daher ist der Begriff der Ko-Governance (Tosun et al. 2016) bzw. der Ko-Regulierung geeignet, das Zusammenspiel von staatlicher und nichtstaatlicher Regulierung zu bezeichnen. 
Die Diskussion um Eigenregulierung setzt sich im Kern auseinander mit nicht-staatlichen und in diesem Sinne privaten Regeln in Bezug auf:

1. Standards für die Charakteristika und Inhaltsstoffe von Produkten (Produktstandards);

2. Standards für die Verfahren zur Erzeugung oder Verarbeitung von Produkten (Prozessstandards);

3. die Nachvollziehbarkeit der Herkunft von Produkten bzw. von deren Bestandteilen;

4. die Kennzeichnung von Produkten aufgrund von einem oder mehreren der Aspekte 1-3.

In der wissenschaftlichen Literatur diskutierte Beispiele sind etwa das Label Filière Qualité Carrefour der französischen Supermarktkette für Qualitätsfleisch (Ménard und Valceschini 2005) oder das britische Kennzeichen Red Tractor. Im internationalen Raum haben sich neben den zwischenstaatlichen Regeln der WTO transnationale Handelsstandard wie GlobalG.A.P. (Botterill und Daugbjerg 2015) oder auch ethisch ausgerichtete Lebensmittelstandards - z. B. Fairtrade, Marine Stewardship Council, ECOFAM - etabliert (Daugbjerg und Botterill 2012). Im Sinne des Ansatzes der Corporate Social Responsibility versuchen nicht zuletzt Handelsketten zunehmend, sich von ethisch problematischen Praktiken zu distanzieren. Dies kann entweder dazu führen, dass als problematisch empfundene Produkte ausgelistet werden, wie zum Beispiel Eier aus Käfighaltung. Zunehmend versuchen Handelsketten aber auch, aktiv eigene Nachhaltigkeitsstandards für ihre Lieferanten zu setzen. Ein Beispiel ist die Sieben-Siegel-Kampagne von ALDI, in welcher der Discounter die Bekanntheit ausgewählter Nachhaltigkeitslabel zu erhöhen und sich kommunikativ mit diesen zu assoziieren sucht (ALDI SÜD 2016).

Bei privater oder Eigenregulierung stellt sich grundsätzlich die Frage der Verbindlichkeit und Durchsetzbarkeit. Hinsichtlich der Verbindlichkeit reicht das Spektrum von freiwilliger Teilnahme bis zu staatlich unterstützter privater Regulierung.

Die Durchsetzbarkeit privater Standards ist von der Frage der Marktmacht nicht zu trennen. In diesem Zusammenhang ist der Unterschied zwischen privater Regulierung von Marktnischen einerseits und flächendeckender privater Regulierung wie GlobalGAP oder dem QS-System zu unterscheiden.

- Standards oberhalb der gesetzlich vorgesehenen Mindeststandards können dabei helfen, Marktnischen im Premiumsektor zu schaffen. Beispiele sind Öko-Labels oder die Kennzeichnung regionaler Herkunft. Dabei liegt insofern viel Marktmacht beim Handel, als dieser über die Listung entscheidet und erfolgreiche Konzepte oft durch Eigen-Labels kopiert, etwa biologische Eigenmarken wie das ,biobio“-Label von Plus.

- Die Durchsetzung privater Standards auf breiter Ebene geht in der Regel vom Handel aus, also der Stufe mit der höchsten Marktkonzentration. Große Supermarktketten sind damit de facto zu privaten Regulatoren geworden, die einen starken Einfluss auf die Erzeugung, Verarbeitung und Distribution von Nahrungsmitteln nehmen (Burch et al. 2013). 
Der Markterfolg von privaten Standards hängt wesentlich vom Vertrauen der potenziellen Käufer ab. Handel und Erzeuger kooperieren daher oft mit Nichtregierungsorganisationen, um die Glaubwürdigkeit ihrer Standards und Labels zu erhöhen (Busch 2011; Fuchs et al. 2011; Ponte und Cheyns 2013; Botterill und Daugbjerg 2015). Aus Sicht der Verbraucherinnen und Verbraucher besteht oft eine verwirrende Label-Vielfalt, welche die Mehrpreisbereitschaft für Produkte mit besonderen ethischen Merkmalen unterlaufen kann (Zander und Hamm 2010; Janssen und Hamm 2012). Bei vielen Nachhaltigkeits-Labels ist der tatsächliche Mehrwert unter Nachhaltigkeitsgesichtspunkten oft fraglich, weshalb „Standards für Standards“ gefordert werden und der Transparenz der Informationen hinter einem Label große Bedeutung zukommt (Adger und Jordan 2009).

In vielen Bereichen bestehen zunehmend staatliche und private Standards nebeneinander. Im Bereich biologischer Lebensmittel gibt es beispielsweise einerseits die zwischenstaatlichen Richtlinien des Codex Alimentarius und andererseits die privaten Richtlinien der International Federation of Organic Agriculture Movements (FOAM). Oft erteilen auch private Organisationen Zertifikate auf der Basis von staatlichen Standards. In der WTO wird daher diskutiert, ob eine staatliche Verantwortung für die Qualität solcher Labels besteht und diese ggf. als technisches Handelshemmnis gegen WTO-Recht verstoßen (Daugbjerg 2012).

Staatliche Regulierungsstrategien sind wesentlich für die Entwicklung privater Standards. Zum einen definieren die staatlichen Mindeststandards den Raum, der zur Profilierung mit höherwertigen Standards zur Verfügung steht (Vogel 2010). Zum anderen dient Eigenregulierung oft dazu, drohender staatlicher Regulierung zuvorzukommen, wie etwa bei Selbstverpflichtungen zu zucker- und fetthaltigen Lebensmitteln (Jensen und Ronit 2015).

Während eine optimistische Perspektive erwarten lässt, dass der Profilierungswettbewerb am Markt ein „race to the top“ auslöst, entsteht aus einer pessimistischen Perspektive Skepsis gegenüber dem Anspruchsniveau privater Standards sowie den Problemen bei der privaten Durchsetzung und Kontrolle (Vogel 2010; Jensen und Ronit 2015).

Eine wesentliche Diskussion betrifft auch die Frage, ob Eigenregulierung den Landwirten und Umweltorganisationen mehr Einfluss verschaffen kann oder ob private Standards zur Individualisierung und Privatisierung der Verantwortung für öffentliche Aufgaben und öffentliche Güter führen (Ménard und Valceschini 2005; Fuchs et al. 2011; Botterill und Daugbjerg 2015).

Auf globalisierten Märkten müssen Standards zudem in globalen Normsetzungsgremien abgestimmt werden. Der europäische Einfluss gilt hier als begrenzt (Young 2014).

Insgesamt ist davon auszugehen, dass auf internationalisierten Märkten transnationale private Standards wie GlobalGAP erheblich an Bedeutung gewinnen, um die Qualität von Produkten zu harmonisieren und den Akteuren entlang der Wertschöpfungskette einklagbare Qualitätserwartungen über gehandelte Ware zu ermöglichen. Dabei spielen auch Umwelt- und Nachhaltigkeitsstandards eine zunehmende Rolle (Havinga et al. 2015). Ob sich daraus eine Triebkraft für eine multifunktionale, natur- und umweltgerecht Landwirtschaft ergibt, ist offen. Allerdings haben 
transnationale Standards den Vorteil, dass sie auch die Importkonkurrenz betreffen und damit das Problem umgehen, dass staatliche Erzeugerstandards immer nur für diejenigen Produzenten verbindlich sind, die im territorialen Geltungsbereich der betreffenden Regeln operieren.

Fazit: Die Entwicklung von Vorschlägen für spezifische Labels würde über den Rahmen dieses Projekts hinausgehen. Im Zuge der Entwicklung von strategischen Handlungsoptionen ist jedoch festzuhalten, dass Kennzeichnungen ein wichtiger Baustein für die bessere Verankerung von Natur- und Umweltschutz in den landwirtschaftlichen Wertschöpfungsketten sind. Denn sie ermöglichen es nicht nur, die Naturschutz- und Umweltleistungen besser in Wertschöpfung am Markt umzusetzen, sondern sie unterstützen auch die Herausbildung sozialer Normen und erstrecken sich potenziell auf importierte Erzeugnisse.

\subsection{Baustein 6: Monitoring- und Sanktionssysteme}

\subsubsection{Aufgaben, Zielkonflikte und Problemlagen von Monitoring- und Sanktionssystemen}

Mehrere Elemente des agrarpolitischen Rahmens erfordern ein flächendeckendes Monitoring-System, um sicherzustellen, dass gesetzliche Regelungen befolgt und ggf. Sanktionen verhängt werden können:

- die Durchsetzung der ordnungsrechtlichen Mindestanforderungen an die landwirtschaftliche Betriebsführung;

- die Einhaltung der Auflagen, an welche die betrieblichen Direktzahlungen geknüpft sind (derzeit in der Ersten Säule der GAP);

- die tatsächliche Durchführung vereinbarter freiwilliger Maßnahmen (derzeit in der Zweiten Säule der GAP).

Bei der Einrichtung von Monitoring- und Sanktionssystemen besteht grundsätzlich ein Zielkonflikt zwischen

- dem Interesse an einer flächendeckenden und zuverlässigen Erfassung derjenigen Tatbestände, die für die angestrebte Verhaltensbeeinflussung (politische Steuerung) im weiteren Sinne sowie die Implementation der Rechtsnormen im engeren Sinne relevant sind;

- den direkten und indirekten Kosten von Monitoring- und Sanktionssystemen, die im Allgemeinen mit dem Detaillierungsgrad, der Neuheit des Systems sowie der Qualität der Daten (Validität der Indikatoren, Reliabilität der Datenerhebung) steigen. Dies beinhaltet zum einen die Kosten der Systemadministration, die bei den Kontrollinstanzen anfallen, andererseits die Transaktions- und ComplianceKosten für die Normadressaten und ggf. andere Akteure.

Monitoring- und Sanktionssysteme sind zudem nicht neutral, sondern haben eine „Performanz“, wie Politik-Instrumente generell (Lascoumes und Le Gales 2007; 
Turnhout et al. 2010). Die verschiedenen Akteure interagieren mit diesen Systemen, z. B. als Antragsteller oder als Administrator, und erleben sich dabei nicht nur in den durch das Recht zugewiesenen Rollen, sondern auch in den Rollen, die ihnen durch die Interaktionsformen zugewiesen werden. So berichten Landwirte, dass sie sich etwa als Bittsteller oder als permanent latent Verdächtiger erleben. Diese PerformanzFunktion der Monitoring- und Sanktionssysteme kann die Wirksamkeit anderer Politik-Instrumente unterstützen oder behindern. Beispielsweise können Monitoring- und Sanktionssysteme einerseits die Durchsetzung ordnungsrechtlicher Normen unterstützen. Andererseits können sie der Herausbildung von Normen der Eigenverantwortung oder dem Leitbild des kreativen Unternehmers widersprechen, indem sie den Normadressaten Formen der Interaktion aufzwingen, in denen sie sich als passiv und unterworfen erleben. Wünschenswert wäre, dass bei der Setzung von Standards und dem flankierenden Monitoring- und Sanktionssystem soziale Normen der Einhaltung der Standards entstehen und so Verstöße gegen die Standards von der Gesellschaft nicht akzeptiert würden (im Gegensatz zum heutigen Umgang etwa mit Steuerhinterziehung).

Monitoring-Systeme können auch mit Formen der Selbst- oder Ko-Regulierung verbunden sein, wie beispielsweise die Kontrollen im Rahmen privater Standardund Zertifizierungssysteme (z. B. QS oder GlobalGAP). Sind solche Systeme hinreichend weit verbreitet, können sie für die Zwecke staatlicher Kontrolle anerkannt werden.

Im Zusammenhang mit Monitoring- und Sanktionssystemen ergeben sich folgende relevante Problemlagen:

- in Teilbereichen fehlende Datengrundlage (siehe Kap. 3);

- ungenaue Indikatoren (zum Beispiel der Vogelindikator als Leitindikator für Biodiversität);

- Zuverlässigkeit der Datenerhebung, insbesondere bei Angewiesenheit auf Aktivitäten Dritter;

- mangelnde Durchsetzung der Auflagen - Vollzugsdefizit;

- hohe Kosten der Datenerfassung;

- hierarchische Interaktionsformen (Instrumentenperformanz).

Im Folgenden diskutieren wir Ansatzpunkte für eine Verbesserung des Monitoringund Sanktionssystems für natur- und umweltbezogene Problemlagen im Bereich der Agrarpolitik.

\subsubsection{Baustein 6.1: Investition in das Indikatorensystem}

Abschn. 6.5 enthält eine umfassende Liste möglicher Indikatoren für die Verwirklichung des Leitbilds einer natur- und umweltverträglichen Landwirtschaft. Die Auflistung zeigt, dass für wichtige Aspekte einer solchen Politik keine oder keine hinreichend operationalisierten Indikatoren zur Verfügung stehen. 
Wie in Kap. 3 und 4 dargestellt, sind auch viele gesetzliche Vorgaben des Naturund Umweltschutzes nicht hinreichend operationalisiert, um ihre Durchsetzung zu ermöglichen.

Vor diesem Hintergrund erscheint es geboten, ein Review der Indikatorensysteme durchzuführen und Mängel bei der Operationalisierung, vor allem bei rechtlich kodifizierten Zielen, abzustellen. Dazu sollte in einen entsprechenden, wissenschaftlich basierten Konsultationsprozess, bei Bedarf unterstützt durch Forschungs- und Entscheidungsvorhaben, investiert werden.

\subsubsection{Baustein 6.2: Digitale Informationssysteme und Fernerkundung zur automatischen Erhebung}

Für das Monitoring der Flächennutzung werden heute in erster Linie InVeKoSDaten genutzt. Zukünftig werden daneben andere GIS-Daten verwendet, um die angrenzende Flächennutzung zu dokumentieren, zu beobachten und zu überwachen. So kann beispielsweise mit Hilfe von GIS-Daten die landschaftliche Vielfalt erfasst werden. Auch können Informationen zur Flächennutzung - z. B. Fruchtfolgegestaltung - aus den InVeKoS-Daten oder anhand von anderen GIS-Daten überprüft werden.

Die Zunahme der Rechenleistung und das Vorhandensein mehrjähriger Daten ermöglichen ein automatisiertes Monitoring der Flächennutzung. Auf dieser Basis könnten in Zukunft die Einhaltung von Auflagen etwa für Fruchtfolgen (und nicht nur Diversität der Anbaufrüchte), aber auch Kennzahlen für die Vielfalt der Landschaftsnutzung berechnet werden, die als Grundlage für entsprechende Prämien dienen könnten.

In dem Maße, wie GIS-gestützte digitale Informationssysteme zur automatisierten Erfassung von Landnutzung und Landschaftsstrukturen beitragen, können sie geeignet sein, den bürokratischen Aufwand bei der Ausgestaltung von flächenbezogenen Monitoring- und Informationssystemen und der Berechnung von landschaftsbezogen Prämien zu verringern. Fachgespräche mit Experten der Fernerkundung haben Aufschluss über derzeitige Entwicklungen bei der Nutzung von digitalen Technologien gegeben. Neue Erdbeobachtungssatelliten stellen räumlich und zeitlich hoch aufgelöste Datensätze zur Verfügung und ermöglichen so die flächendeckende Aufnahme von Landnutzungsstrukturen.

Das europäische Erdbeobachtungsprogramm Copernicus (Programm der Europäischen Kommission und der Europäischen Weltraumorganisation) stellt eine leistungsfähige Infrastruktur für Erdbeobachtung und Dienstleistungen der Geoinformation zur Verfügung. Die Copernicus-Satelliten Sentinel-2A und -2B überfliegen die globale Landoberfläche alle 5 Tage, was zur Verfügbarkeit einer zeitlich hoch aufgelösten Zeitreihe von Daten führt. Sie liefern mit einer räumlichen Auflösung von 10 m seit Kurzem Fernerkundungsdaten, die aufgrund ihrer hohen Qualität (räumliche und zeitliche Auflösung) grundsätzlich für das Monitoring von 
landwirtschaftlichen Flächen geeignet sind. Die Daten des europäischen Copernicus-Erdbeobachtungsprogramms stehen offen zur Verfügung und sind gezielt für die Entscheidungsfindung bei Politikprozessen und für das Monitoring und Management von Umweltbelangen eingeführt worden.

Fernerkundungstechniken werden auf nationaler Ebene bereits zur Unterstützung des Integrated Administrative Control System (IACS) der EU eingesetzt. Hierbei werden u. a. Flächengrößen, Nutzungsarten und Landschaftselemente identifiziert sowie Angaben von Landwirten überprüft. Zum Einsatz kommt hier beispielsweise die GIS-Umgebung des Land Parcel Identification Systems (LPIS) innerhalb des Integrierten Verwaltungs- und Kontrollsystems (InVeKoS). Die genutzten Analysesysteme beruhen aktuell allerdings noch nicht in vollem Maße auf den neuen Sentinel-Satelliten und sind nicht voll automatisiert. Genutzt werden in der Regel etablierte Sensoren wie Landsat, RapidEye und WorldView, welche nicht die Vorzüge der sowohl räumlich wie zeitlich hohen Auflösung bei flächendeckender und kostenfreier Verfügbarkeit bieten.

Für die voll automatisierte Extraktion der genannten Informationen besteht aktuell jedoch noch Forschungsbedarf. Projekte zur Entwicklung entsprechender Copernicus-Services für die Landwirtschaft, an denen auch das Deutsche Zentrum für Luft- und Raumfahrt (DLR) beteiligt ist, werden u. a. von der EU gefördert. Hierbei spielt jedoch der Aspekt von Landschafts- und Strukturelementen bisher noch keine große Rolle. Diese Daten könnten eine deutlich verbesserte Grundlage zur Erfassung von Schlaggrößen, Fruchtfolgen, Länge der Vegetationsperiode und Strukturelementen, die bei einer Pixelgröße von $10 \mathrm{~m}$ x $10 \mathrm{~m}$ erkannt werden, darstellen. Landschaftselemente könnten zukünftig über Fernerkundung automatisch erfasst werden. Forschungsbedarf besteht bei der automatischen Erfassung von kleinen Strukturen, wie z. B. Einzelbäumen, die bei einer Pixelgröße von $10 \mathrm{~m}$ x $10 \mathrm{~m}$ nicht ohne Weiteres erfasst werden.

Derzeit laufen mehrere Forschungsprojekte, die sich mit der Klassifizierung von Agrarräumen mit Hilfe von Fernerkundungsdaten beschäftigen, u. a. an den Universitäten in Würzburg, Halle und Hannover. Feldfrüchte können z. B. über die spektrale und phänologische Signatur mittlerweile recht eindeutig bestimmt werden. Für eine europäische automatisierte Erfassung der Landnutzungsstrukturen erscheint derzeit jedoch die Erstellung der Trainingsdaten über Beobachtung oder Kalibrierung noch als relativ aufwendig. Hier könnte die partielle Verschneidung mit aktuellen Vektordatensätzen (InVeKoS, Amtliches Liegenschaftskatasterinformationssystem ALKIS) Abhilfe schaffen. Ein vielversprechender Datensatz zur Erfassung der Hangneigung ist das neue Höhenmodell TandDEM-X DEM. Je nach Nutzungszweck und gewünschter Flächengröße ist der Zugang zu den Daten unter verschiedenen Voraussetzungen möglich.

Die Überwachung einer auf die Landschaftsstruktur bezogenen Prämie mittels GIS-gestützter Systeme mit Hilfe von Fernerkundungsdaten erscheint daher mittelfristig als eine realistische Option. Voraussetzung dafür wäre es, dass die Fehlerhaftigkeit unter den von EU-Kontrollsystemen geforderten Wert von 2 \% fällt. Dies erfordert weitere Investitionen in ein solches System. Im Ergebnis könnte dadurch jedoch ein Kontrollsystem ermöglicht werden, das die laufenden Administrations- 
kosten und die bürokratische Last für Landbewirtschafter vermutlich deutlich verringern könnte. Voraussetzung für die Zahlung einer auf Daten zur Landschaftsstruktur basierenden Prämie wäre eine Einigung auf einen fachlich belastbaren Satz von nachvollziehbaren, gewichteten Faktoren für die Zuteilung der Prämienansprüche und die Berechnung der Prämienhöhe.

\subsubsection{Baustein 6.3: Monitoring stofflicher Einträge - Plausibilitätsprüfungen}

Stoffliche Einträge sind auf absehbare Zeit kaum durch Fernerkundung zu erfassen, so dass in diesem Bereich weiterhin Dokumentation und Bilanzerstellung auf betrieblicher Ebene notwendig sein werden. Um sicherzustellen, dass die ausgewiesenen Bilanzwerte den tatsächlichen stofflichen Einträgen entsprechen, sind jedoch zum einen die Vorschriften der Bilanzierung in einigen Bereichen zu überarbeiten (z. B. anrechenbare Verluste in der Düngeverordnung), zum anderen sind auf Seiten der Überwachung entsprechende Plausibilitätsprüfungen einzuführen. Am Beispiel der Düngeverordnung hieße dies, dass z. B. die angegebene Ertragsmenge bzw. Bilanzwerte mit regions- und betriebsformtypischen Werten auf Plausibilität verglichen werden sollten. Entsprechende Prüfmechanismen können ebenfalls automatisiert in den Systemen der Datenverarbeitung hinterlegt werden. Werden Werte angeben, die von den definierten Grenzwerten - z. B. für den Stickstoffgehalt im organischen Dünger - abweichen, kann hierfür die Vorlage entsprechender amtlicher Belege oder Rückstellmuster gefordert werden. Für den Einsatz zugekaufter Düngeund Pflanzenschutzmittel ${ }^{8}$ sind des Weiteren die Belege auf Verlangen der Kontrollbehörden vorzulegen.

\subsubsection{Weitere Bausteine}

\section{Baustein 6.4: Amtliche Belege bei komplexen Problemlagen}

Des Weiteren kann für Aspekte, wie etwa die Erstellung von Humusbilanzen oder den Einsatz von Tierarzneimitteln, die Vorlage amtlicher Belege eingeführt werden. Diese Praxis wird heute schon teils angewendet, sollte zukünftig aber ausgebaut werden, so dass eine Einbindung externer (Kontroll-) Einrichtungen, wie z. B. im ökologischen Landbau, erfolgt. Dieses Vorgehen bietet sich vor allem für Maßnahmen an, deren Messwerte nur mit hohem betrieblichen und/oder verwaltungstechnischen Aufwand zu erheben sind und/oder deren Messung spezifisches Fachwissen und entsprechende technische Ausrüstung erfordert.

\footnotetext{
${ }^{8}$ Da z. B. auch bei hohem Anfall organischer Dünger zusätzlich hohe Mengen an mineralischem Dünger eingesetzt werden (Taube 2016).
} 


\section{Baustein 6.5: Mehrjährige Antragstellung und Gruppenanträge}

Eine bürokratische Entlastung kann des Weiteren durch mehrjährige Antragsstellung auch in der Ersten Säule erreicht werden. Weiterhin würde eine Reduzierung der Ausnahmetatbestände den Verwaltungsaufwand vermindern (Hart et al. 2016). Daneben könnte die Verlagerung der Antragstellung auf die Ebene von lokalen oder regionalen Kooperativen wie in den Niederlanden zu einer Reduzierung des bürokratischen Aufwandes führen, da nicht nur Verantwortlichkeiten weitergegeben werden, sondern auch Mechanismen sozialer Kontrolle verstärkt greifen. Der anfangs eventuell erhöhte Zeitaufwand für Planung, Ausführung und Erfassung der Auflageneinhaltung würde im Zeitverlauf durch Routinebildung typischerweise abnehmen.

\section{Baustein 6.6: Abstimmung von Kontrollfrequenzen und Sanktionshöhe}

Die Durchsetzung der gesetzlichen Mindestanforderungen und weiteren Auflagen hat häufig mit einem Vollzugsdefizit zu kämpfen. Die Durchsetzung der GAB beruht bspw. in erster Linie auf Cross Compliance-Prüfungen mit prozentualen Kürzungen der Direktzahlungen bei Verstößen. Mit der Einführung von Cross Compliance konnte ein flächendeckendes Kontrollsystem mit der Verteilung der Direktzahlungen verknüpft werden, was die systematische Durchsetzung der gesetzlichen Mindeststandards erleichtert. Um die Durchsetzung des gesetzlichen Mindeststandards und der genannten Auflagen zu sichern, könnte die Anhebung der Kontrollquote und -frequenz in Kombination mit der Sanktionshöhe angebracht sein. Dabei sollte die Höhe der Kontrollquoten und -frequenzen unter Berücksichtigung der möglichen Schäden bei Verstoß in einem umgekehrten Verhältnis zur Sanktionshöhe stehen. Die Einführung eines effektiven Kontroll- und Sanktionsmechanismus bestärkt auch die Einsicht der Landwirte in die Bedeutung der Maßnahmen und den Wunsch der Gesellschaft, dass diese eingehalten werden. Zugleich sollte der Kontrollaufwand in einem angemessenen Verhältnis zur erwarteten Häufigkeit und Schwere der Verstöße stehen. Hier kann ein risiko-basierter Ansatz zu einer an den Prinzipien der Effektivität, Effizienz und Angemessenheit orientierten Kontrollpraxis beitragen.

\section{Baustein 6.7: Beweislastumkehr}

Eine Umkehr der Beweislast kann ebenso wie ein starker Kontroll- und Sanktionsmechanismus dazu beitragen, die Bedeutung der Grenzwerte und Maßnahmen und deren Einhaltung zu bestärken. Bei Anlastung der Beweislast müssten die Landwirtinnen und Landwirte aber auch in die Lage versetzt werden, die Einhaltung der Auflagen selbst nachweisen zu können. So könnten bspw. die landwirtschaftlichen Betriebe durch Erhebung der Stickstoffgehalte im organischen Dünger und Wiegeprotokolle der Erträge die Einhaltung der Stickstoffbilanzgrenzwerte nachweisen, falls hieran Zweifel bestehen.

\subsubsection{Fazit}

Zusammenfassend ist festzuhalten, dass es für die Zukunft vorstellbar ist, anhand digitaler Daten und elektronischer Datenverarbeitung den bürokratischen Aufwand für die landwirtschaftliche Betriebe und die Verwaltung zu reduzieren. So können bisher in verschiedenen Datenbanken erhobene und gespeicherte Daten 
zur Durchführung von Kontrollen zusammengeführt werden (z. B. HIT und InVE$\mathrm{KoS}$ ) und mit Daten der Selbstkontrolle (z. B. Ackerschlagbilanzen, Daten des Precision Farming) kombiniert werden. Die gewonnenen Daten können damit insgesamt als Kontroll- aber auch als Monitoring- und Beratungstool für die landwirtschaftlichen Betriebe eingesetzt werden, z. B. durch Vergleiche des eigenen Betriebes mit anderen Betrieben aus der Region (Tab. 7.10).

\subsection{Baustein 7: Unterstützende Elemente}

Die Verwirklichung des Leitbilds einer multifunktionalen, natur- und umweltverträglichen Landwirtschaft erfordert von den Beteiligten viel neues Wissen und zum Teil auch eine Umorientierung. Dazu könnten unterstützende Maßnahmen angeboten werden. Dies betrifft zum einen Ausbildung und Beratung für die in der Landwirtschaft tätigen Personen, zum anderen verbraucherorientierte Maßnahmen.

\subsubsection{Ausbildung und Beratung}

Die Entwicklung einer multifunktionalen, natur- und umweltverträglichen Landwirtschaft erfordert von den Landwirten erhebliches Wissen. Die Verwirklichung des Leitbildes könnte dadurch unterstützt werden, dass Workshops, Kurse oder Informationsbroschüren neuere Ansätze vermitteln und dadurch sowohl das Wissen wie die Akzeptanz erhöhen (Frondel et al. 2012). Weitere sinnvolle Ansätze sind Demonstrationsprojekte (Schleyer und Plieninger 2011), Beratung durch Fachleute (Meyer et al. 2015a) oder gegenseitige Hilfe der Landwirte untereinander (Prager 2015). Für die Einführung neuer, zum Teil komplizierter Verfahren, wie etwa Auktionen, ist eine intensive Begleitung, vor allem in den Anfangsstadien, unerlässlich (Freese et al. 2011; Ulber et al. 2011). Ebenso benötigen viele ergebnisorientierte Maßnahmen eine fachliche Begleitung (Schroeder et al. 2013). Auch kann fachliche Expertise helfen, Transaktionskosten zu senken, die als wesentliche Teilnahmehürde vieler AUKM angesehen werden (Meyer et al. 2015a).

Einführung eines Curriculums an den landwirtschaftlichen Fachschulen: $\mathrm{Zu}$ nächst ist es wichtig, die neuesten wissenschaftlichen Erkenntnisse zu den Umweltleistungen der Landwirtschaft überall im Curriculum zu verankern.

Angeboten und gefördert werden könnten laufende Seminarangebote für Landwirte zu Themen wie:

- Auswirkungen landwirtschaftlicher Aktivitäten auf die Bodenqualität;

- nachhaltige Landnutzungssysteme;

- Wasserhaushalt, Artenvielfalt;

- ökologischer Pflanzenbau;

- EU-/Landes-Verordnung;

- Verwaltungsverfahren. 


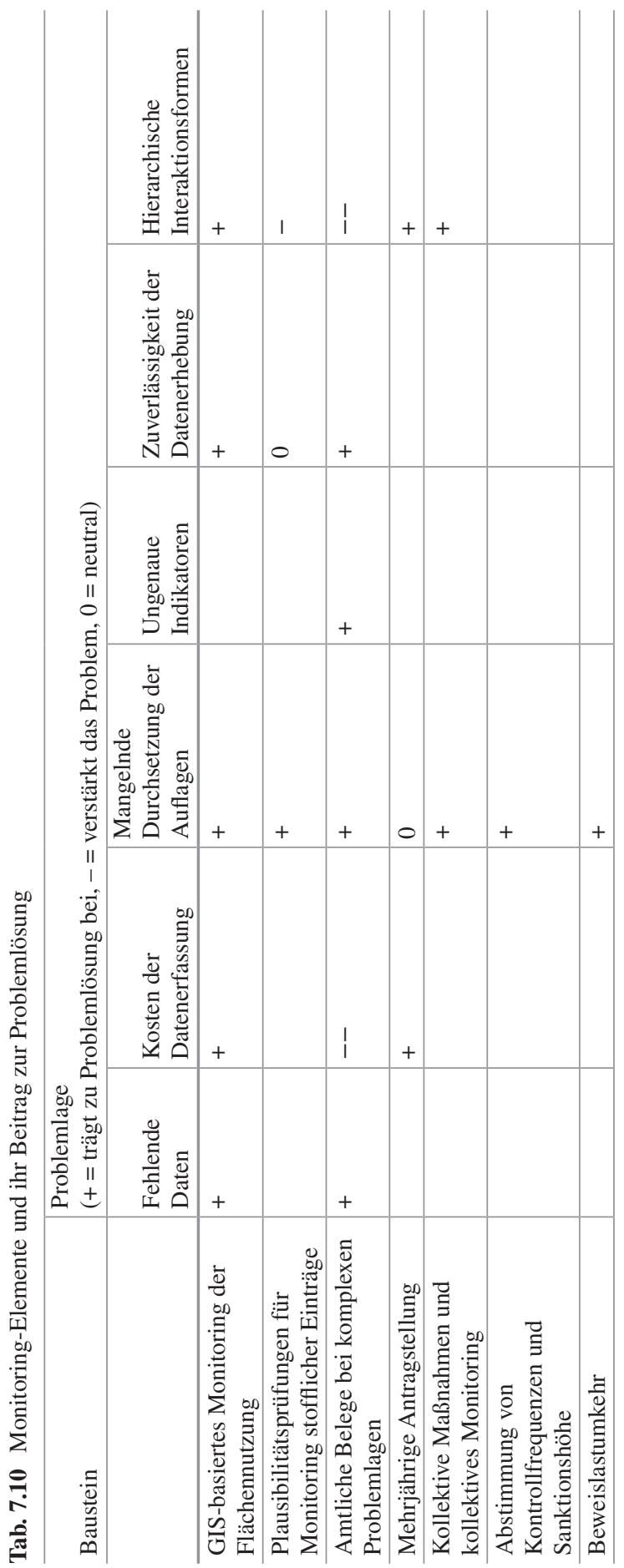


Weiterhin könnte durch Leistungsvereinbarungen zwischen Landesregierungen und Hochschulen/Universitäten ein Curriculum zum Thema ,Nachhaltige Landwirtschaft" etabliert werden mit Inhalten wie:

- systemisches Denken;

- Flächennutzungskonzepte;

- Wasserkreislauf;

- umweltorientiertes Marketing und regionale Märkte;

- Energiefragen;

- Artenvielfalt;

- Konsequenzen landwirtschaftlicher Aktivitäten auf lokalem, regionalem und globalem Niveau;

- Tierschutz, Agrarpolitik;

- Plurale Ökonomik ${ }^{9}$

- EU-/Landes-Verordnung und Verwaltungsverfahren.

Beratungsdienste können mit Hilfe von Training und Vorführungen im Feld (Demonstrationsprojekte), in Zusammenarbeit mit Hochschulen, gerade bei fehlenden Kapazitäten viel erreichen (Klair et al. 1998).

Weiterhin könnte ein anerkannter, fachlich hochwertiger Sachkundenachweis für nachhaltige Landtechnik, Tierhaltung, und Pflanzenbau eingeführt werden. Eine Auffrischung dieser Kenntnisse alle drei bis fünf Jahre wäre wünschenswert, um auf dem neuesten Stand zu bleiben. Damit würden Kapazitäten der Landwirte aufgebaut und gefestigt.

Die Erstellung oder Unterstützung der Entwicklung von umweltorientierten Betriebsentwicklungsplänen für Pflanzen- und Tierproduktionsbetriebe könnte durch Beratungsstellen gefördert und angeboten werden. ${ }^{10}$

\subsubsection{Verbraucherorientierte Maßnahmen}

Das Engagement von Individuen, Haushalten, Schulen und anderen Einrichtungen, in denen Lebensmittel zubereitet und serviert werden, kann auch einen Multiplikatoreffekt haben. Hier spielen Regeln, Konsumentensteuerung, Produktkennzeichnung, Direktmarketing, Bewusstseinsbildung und Bildung von Konsumenten wichtige Rollen.

\footnotetext{
${ }^{9}$ Plurale Ökonomik, auch als Real World Economics oder Post-autistische Ökonomie bekannt, fordert die neoklassischen Standardannahmen heraus und integriert Ideen aus der Soziologie und Psychologie in die wirtschaftliche Analyse (Fullbrook 2007).

${ }^{10} \mathrm{Vgl}$. dazu die Einrichtung eines „,Kompetenzzentrums für ländliche Entwicklung“ bei der Bundesanstalt für Landwirtschaft und Ernährung (BLE) mit Informationsplattform zur Intensivierung der landwirtschaftlichen Beratung und Innovationsförderung in gezielten Bundesprogrammen (BMEL 2015a, S. 29).
} 


\subsubsection{Steuern und Regulation}

Konsumenten spielen eine zentrale Rolle für die Chancen einer nachhaltigen (oder nicht nachhaltigen) Landwirtschaft. Fördernde Maßnahmen, darunter regulierende, steuerliche und freiwillige Maßnahmen, Produktlabels, direktes/lokales Marketing, Bewusstseinsbildung über Nahrungsmittelentscheidungen und Ernährung, sowie individuelles Engagement als auch Engagement von Haushalten, Schulen und sonstigen Organisationen in denen Nahrung vorbereitet und konsumiert wird, können effektiv sein.

Grundsätzlich kann das Konsumentenverhalten durch die erhöhte Besteuerung von Produkten beeinflusst werden, welche nicht nachhaltig produziert wurden oder als gesundheitsschädigend (bspw. Tabak oder Alkohol) oder umweltschädigend (bspw. Dünger, Plastikverpackungen, ölbasierte Kraftstoffe) eingestuft werden. Der Vorschlag, den reduzierten Mehrwertsteuersatz für tierische Erzeugnisse in Frage zu stellen, hat jedoch zu einer kontroversen öffentlichen Diskussion geführt. Andere Ansätze wären die Besteuerung von Inputs in die Produktion, wie Mineraldünger oder Pestizide (Pedersen et al. 2012). Die ökonomische Begründung für eine solche Steuer wäre immer die Beeinflussung der relativen Faktorpreise. Der Umfang, in dem eine Besteuerung zur Reduzierung des Einsatzes der besteuerten Faktoren führt, hängt von den Faktorpreiselastizitäten ab. Beim Pestizideinsatz ist weiterhin zu berücksichtigen, dass die Umweltverträglichkeit durch die Genehmigungsverfahren und die Auflagen beim Gebrauch sichergestellt werden sollen. Eine gesonderte Produktsteuer bedürfte daher in diesem Fall einer besonderen Begründung.

Regulative Ansätze können beispielsweise die Werbung und Produktinformation betreffen. Während dies eine übliche Methode ist, den Alkohol- und Tabakkonsum zu regulieren, gibt es nur unzureichende Analysen der Wirksamkeit regulativer Ansätze im Nahrungsmittelbereich (OECD 2016).

\subsubsection{Produktkennzeichnung}

Ein effektives Marketing von nachhaltig produzierten landwirtschaftlichen Produkten von Landwirten und Nahrungsmittelindustrie braucht gut informierte Verbraucherinnen und Verbraucher. Insbesondere müssen Unterschiede zwischen konventionellen und nachhaltig hergestellten Produkten verstanden werden. Zudem sollten die Gründe für die höheren Preise klar kommuniziert werden (Klair et al. 1998; von Meyer-Höfer und Spiller 2014). Auch wenn Verbraucherinnen und Verbraucher eine positive Einstellung gegenüber nachhaltig erzeugten Lebensmitteln besitzen, gibt es immer noch Hindernisse, welche die Beachtung und Auswahl dieser Produkte hemmen, wie etwa Wahrnehmung, Wissen über die Produkte, Konflikte mit anderen Prioritäten (z. B. Geschmack, Preis), mangelndes Bewusstsein oder mangelnde Motivation (Kuhnert et al. 2005; Grunert 2011).

Um die Nachhaltigkeit von Produkten zu kommunizieren, wurde ein , übergreifendes Nachhaltigkeitslabel“" als effektivste regulierende Maßnahme empfohlen 
(von Meyer-Höfer und Spiller 2014). Als allgemeine Anforderungen an ein solches Label gelten (Grunert 2011):

- Es muss die Aufmerksamkeit des Käufers auf sich ziehen;

- den Käufer an seine ,guten Absichten“ erinnern;

- einfach zu verstehen und zu lesen sein und

- glaubwürdig und vertrauenswürdig sein.

Die Einführung eines allgemein anerkannten Nachhaltigkeitslabels ist jedoch bisher nicht gelungen, u. a. weil dadurch der Spielraum für einzelne Anbieter, sich durch Eigen-Labels zu profilieren, vermindert würde.

Eine direkt mit dem Naturschutz verbundene Kennzeichnung ist das ,landscape label", welches die Produktzertifikation mit der Entrichtung von Zahlungen für Ökosystemdienstleistungen kombiniert (Ghazoul et al. 2009). Zu den vielen Herausforderungen bei der Einführung eines solchen Labels gehören der Aufbau von „fairen und transparenten community-basierten Organisationen“ und die Gefahren vor „Trittbrettfahrern“ (Ghazoul et al. 2009). Verbraucherbefragungen haben gezeigt, dass die beiden genannten Punkte wichtig für die Glaubwürdigkeit und das Vertrauen für Label sind (McEachern et al. 2005; Eden et al. 2008; Golan et al. 2001). Obwohl dies für die meisten Nahrungsmittel der Fall ist, ist der Marktanteil von Bio-Produkten in Deutschland mit 7 \% (2011) sehr gering und stieg in den letzten Jahren nur minimal an (BMUB und Umweltbundesamt 2013). Höhere Verkaufspreise, Zweifel an Umweltnutzen und korrekter Deklaration sowie die verwirrende Label-Vielfalt ${ }^{11}$ vermindern das Vertrauen und damit die Wirksamkeit von Umwelt- und Nachhaltigkeitslabels (van der Zee 2016). Die Einführung eines staatlich garantierten Labels, welches auf transparente und nachvollziehbare Weise die mit einem Produkt verbundenen Leistungen im Natur- und Umweltschutz zertifiziert, wäre daher ein wichtiger Schritt zur Aktivierung der Verbrauchernachfrage nach nachhaltigen Produkten.

\subsubsection{Bewusstseinsbildung und Verbindung zwischen Konsumenten und Erzeugern}

Eine Vielzahl von freiwilligen „Bottom-up“-Initiativen zielt darauf ab, das Bewusstsein bei Verbrauchern für Ernährungsfragen und für den Einfluss ihrer eigenen Kaufentscheidungen zu stärken sowie stärkere Verbindungen zwischen Konsumenten und Erzeugern herzustellen (siehe dazu auch Abschn. 4.3.6). Beispiele reichen von einfachen Maßnahmen, wie fleischfreien Tagen in Kantinen, bis hin zur Förderung von nachhaltigem Nahrungsmittelkonsum im öffentlichen Sektor, wie zum Beispiel Gerichte aus saisonaler, regionaler und biologischer Produktion. Durch

\footnotetext{
${ }^{11}$ So gab es laut der Verbraucherinitiative Label-online.de allein aus Deutschland 34 Labels, welche „Essen und Trinken“ als „Bio“ deklarieren. Zugleich wurden 21 Nachhaltigkeits-Labels aufgeführt (www.label-online.de. Zugegriffen am 28.06.2016).
} 
systematische Planung, niedrige Darlehenszinsen und auch durch Wissensaustausch können solche freiwilligen Initiativen unterstützt werden.

Direktvermarktung ist nicht nur eine Möglichkeit für Landwirtinnen und Landwirte, ihr Einkommen zu steigern, indem sie kommerzielle Weiterverarbeitung und Zwischenhändler in der Lebensmittelkette umgehen. Es stellt auch sozial eine direkte Verbindung zwischen Verbrauchern und Erzeugern her. Die sichtbarste und aktuell vorherrschende Form von Direktvermarktung in Deutschland sind regionale Wochenmärkte. Wochenmärkte stellen nicht nur eine Quelle lokaler und regionaler Produkte dar, sondern stärken die Verbindung sowohl zwischen Landwirten und Endverbrauchern als auch zwischen ländlichen und städtischen Regionen. Sie tragen zur Bewusstseinsbildung bei und können Konsumenten dazu motivieren, mehr über das Essen, welches sie kaufen, und die dafür benötigten Ressourcen für landwirtschaftliche Betriebe, zu lernen. Andere Formen des Direktmarketings von Landwirten an Konsumenten sind der Hofverkauf via Hofläden und Hofautomaten. Allerdings sind diese Initiativen nicht immer eindeutig mit besonderen Leistungen im Natur- und Umweltschutz verknüpft.

Auch könnte die Arbeit von Ernährungsräten wie den 2016 gegründeten Initiativen in Berlin und Köln dabei unterstützt werden, eine Verbindung zwischen städtischen Verbraucherinnen und Verbrauchern und besonders natur- und umweltfreundlichen Formen der Landwirtschaft herzustellen.

\subsubsection{Investitionshilfen}

Betriebliche und ländliche Infrastrukturinvestitionen werden im Rahmen der Zweiten Säule der GAP gefördert. Oft dienen diese Maßnahmen bereits jetzt der Verbesserung des Umweltschutzes. Zur Verwirklichung des Leitbilds einer multifunktionalen, natur- und umweltverträglichen Landwirtschaft könnten die Investitionshilfen konsequent an dem neuen Leitbild ausgerichtet werden. Im Bereich der Tierhaltung sollen im Prinzip bereits jetzt ,geförderte Investitionen besondere Anforderungen an den Umwelt-, Klima- und Ressourcenschutz erfüllen, die über die geltenden Standards hinausgehen" (BMEL 2015i).

Eine neuere Untersuchung aus dem Thünen-Institut (2016) zu den Agrarinvestitionsförderungsprogrammen findet dabei zwar positive Effekte, aber wenig Belege dafür, dass die Förderung tatsächlich zu zusätzlichen Leistungen im Natur-, Umwelt- und Tierschutz (Additivität) führt. Auch wird die Frage aufgeworfen, welche Funktion angesichts niedriger Zinsen und hoher Kreditvergabewilligkeit der Banken eine zusätzliche staatliche Investitionsförderung haben kann.

Neben staatlichen wäre dabei auch an private Kreditprogramme zu denken. Oft werden dabei die Aspekte der Kostensenkung und der Ökologisierung verknüpft, um ,die Anpassung der Betriebe an z. B. neue oder wechselnde Rahmenbedingungen [zu ermöglichen]. Die Produktionskosten sollen gesenkt, die Ökologisierung gefördert und damit die Wettbewerbsfähigkeit einer nachhaltig produzierenden Landwirtschaft gestärkt werden“ (Weber 2005, S. 400). Beispielsweise finanziert 
die GLS-Bank spezifisch die Umstellung auf Ökolandbau, ökologische Betriebserweiterungen und Modernisierungen bis hin zu Hofgemeinschaften, die neben der Landwirtschaft auch einen Hofladen, Kulturprogramme oder Übernachtungen anbieten. Das Förderprogramm „Nachhaltigkeit“ der Landwirtschaftlichen Rentenbank dient der Verbesserung der Lebens-, Produktions- und Arbeitsbedingungen unter Berücksichtigung der Verbraucherinteressen und dem Erhalt der biologischen Vielfalt, aber auch Investitionen zur Erfüllung besonderer Anforderungen im Bereich Tierschutz.

\subsection{Fazit}

In diesem Kapitel wurden die verschiedenen Instrumente der Agrarpolitik im Hinblick auf ihren Beitrag zur Realisierung des Leitbilds einer multifunktionalen, natur- und umweltverträglichen Landwirtschaft diskutiert. Die Übersicht in Tab. 7.11 zeigt, dass eine Kombination der Bausteine notwendig ist, um die verschiedenen prioritären Problemkomplexe (vgl. Abschn. 6.6) zu adressieren. Daher ist ein koordinierter Gesamtansatz, eine Policy-Architektur, notwendig, die ein abgestimmtes Design der verschiedenen Politik-Instrumente ermöglicht. Dafür werden im folgenden Kapitel mehrere strategische Entwicklungsoptionen aufgezeigt. Natürlich folgt auch die derzeitige Agrarpolitik einem Gesamtansatz. Dieser ist aber historisch entstanden und reformbedürftig.

Zugleich zeigt die Diskussion in diesem Kapitel, dass in jedem der Elemente der Agrarpolitik verschiedene Instrumenten-Varianten bestehen, die mehr oder weniger geeignet sind, zur Verwirklichung des in Kap. 6 entwickelten Leitbilds beizutragen. Bei der Verwirklichung des Leitbilds kommt es also sowohl auf eine überzeugende Gesamtkonzeption wie auch auf die Ausgestaltung der verschiedenen Instrumente im Detail an.

Die Übersicht in Tab. 7.11 bestätigt den Befund aus der SWOT-Analyse, dass die Instrumentenvielfalt eine Stärke der gegenwärtigen Agrarpolitik darstellt, die genutzt werden sollte, um die vielfältigen Probleme des Natur- und Umweltschutzes im Zusammenhang mit der Landwirtschaft zu adressieren. Zugleich hat die Diskussion in diesem Kapitel gezeigt, dass eine effizientere und effektivere Ausgestaltung der meisten Elemente der Agrarpolitik möglich wäre. Dies wird zum Teil zusätzliche Ressourcen erfordern. Da die Diskussion in Abschn. 7.2 zu dem Ergebnis geführt hat, dass bestenfalls mit einer Aufrechterhaltung des Anteils der GAP am EU-Budget zu rechnen ist, aber nicht mit einer Steigerung des Agrarbudgets, müssten die Mittel innerhalb der bisherigen Agrarpolitik anders eingesetzt werden. Die Diskussion des Instruments der Direktzahlungen hat dabei ergeben, dass diese in ihrer derzeitigen Form insgesamt wenig effektiv und effizient sind. Ein stärker am Prinzip der Ergebnisorientierung ausgerichteter Einsatz der erheblichen Mittel, die derzeit für Direktzahlungen verwendet werden, erscheint daher geboten. Dafür bestehen grundsätzliche drei Optionen: (1) eine stärkere Verknüpfung der Direktzahlungen mit der Erbringung von öffentlichen Leistungen, etwa 
Tab. 7.11 Zuordnung der Instrumenten-Bausteine zu den prioritären Problembereichen

\begin{tabular}{|c|c|}
\hline Zielgröße/Problembereich & $\begin{array}{l}\text { Baustein/Variante, welche das Ziel bzw. den } \\
\text { Problembereich prioritär adressiert }\end{array}$ \\
\hline \multicolumn{2}{|c|}{ Komplex 1: Stoffeinträge in Boden, Wasser und Luft } \\
\hline $\begin{array}{l}\text { Verlust von Biodiversität und } \\
\text { Habitatqualität durch Stoffeinträge } \\
\text { Nitratproblematik, } \\
\text { Arzneimitteleinträge, } \\
\text { Pestizideinträge (Auswirkungen } \\
\text { u. a. auf Wasserqualität) } \\
\text { - Antibiotikaresistenz } \\
\text { - Klimaschutz: Treibhausgas- } \\
\text { Emissionen }\end{array}$ & $\begin{array}{l}\text { Ordnungsrecht und Mindeststandards, ggf. } \\
\text { Ausgleich erhöhter regulationsbedingter Kosten } \\
\text { im Vergleich zu Nicht-EU-Erzeugern auf } \\
\text { wissenschaftlicher Basis } \\
\text { - Investitionshilfen bei Anhebung der Standards im } \\
\text { Ordnungsrecht }\end{array}$ \\
\hline
\end{tabular}

Komplex 2: Flächennutzung

- Biodiversitäts- und Habitatverlust

- Bodenschutz: Erosion, Schadverdichtung

- Treibhausgas-Emissionen durch Landnutzungsänderungen

- Anpassung an den Klimawandel

- GLÖZ, Greening-Auflagen (ggf. teilweise Überführung ins Ordnungsrecht)

- Mindeststandards zur Aufrechterhaltung der natürlichen Produktivität der Standorte

- Prämien zur Aufrechterhaltung der Bewirtschaftung in Gebietskulissen mit erschwerten Bewirtschaftungsbedingungen

- Prämien zur Honorierung der landschaftlichen Vielfalt

- Flächendeckendes Minimum von Natur- und Umweltschutzmaßnahmen gegen Honorierung

- Honorierung besonderer Leistungen im landwirtschaftlichen Natur- und Umweltmanagement

- Regional und standörtlich ausgerichtete AUKM

- Koordinationsansätze zum integrierten Landschafts- und Ressourcenmanagement

Komplex 3: Implementations-, Partizipations- und Innovationsdefizite

- Implementationsdefizite

- Unzureichende Kontroll- und Sanktionsmechanismen

- Ko-Regulierung und nicht-staatliche Standards

- Verbesserte Monitoring- und Sanktionssysteme inkl. GIS-gestützter Fernerkundungssysteme

- Monitoring stofflicher Einträge Plausibilitätsprüfungen

- Fehlende operationalisierte Ziele und unklare Rechtsbegriffe

- Priorisierung und Operationalisierung der naturschutz- und umweltpolitischen Zielgrößen

- Schließung von Operationalisierungsdefiziten bei Ordnungsrecht und Mindeststandards

- Zu wenige Lernprozesse und zu wenig sektorübergreifende Kooperation
- Ausbildung und Beratung

- Verbraucherorientierte Ansätze

- Partizipative und kooperative Instrumente bei der Planung und Implementation regionaler und standörtlicher Programme und Maßnahmen

- Integriertes Ressourcen- und Landschaftsmanagement 
durch eine anspruchsvollere Ausgestaltung der Cross-Compliance- und Greening-Anforderungen; (2) eine Umschichtung von Mitteln von den Direktzahlungen in der Ersten Säule hin zu den stärker ziel- und ergebnisorientierten Maßnahmen der Zweiten Säule; und/oder (3) der Übergang zu einem integrierten System aufeinander aufbauender Prämien und Programme, welche zusammen mit einem verbesserten Ordnungsrecht systematisch die verschiedenen Problemlagen des Naturund Umweltschutzes im Agrarsektor adressieren.

Im folgenden Kapitel werden diese drei strategischen Optionen weiter ausformuliert und diskutiert.

Open Access Dieses Kapitel wird unter der Creative Commons Namensnennung 4.0 International Lizenz (http://creativecommons.org/licenses/by/4.0/deed.de) veröffentlicht, welche die Nutzung, Vervielfältigung, Bearbeitung, Verbreitung und Wiedergabe in jeglichem Medium und Format erlaubt, sofern Sie den/die ursprünglichen Autor(en) und die Quelle ordnungsgemäß nennen, einen Link zur Creative Commons Lizenz beifügen und angeben, ob Änderungen vorgenommen wurden.

Die in diesem Kapitel enthaltenen Bilder und sonstiges Drittmaterial unterliegen ebenfalls der genannten Creative Commons Lizenz, sofern sich aus der Abbildungslegende nichts anderes ergibt. Sofern das betreffende Material nicht unter der genannten Creative Commons Lizenz steht und die betreffende Handlung nicht nach gesetzlichen Vorschriften erlaubt ist, ist für die oben aufgeführten Weiterverwendungen des Materials die Einwilligung des jeweiligen Rechteinhabers einzuholen. 